UNIVERSIDADE DE SÃO PAULO

ESCOLA DE EDUCAÇÃO FÍSICA E ESPORTE

\title{
ANÁLISE BIOMECÂNICA DO ANDAR DE ADULTOS E IDOSOS NOS AMBIENTES AQUÁTICO E TERRESTRE
}

Ana Maria Forti Barela

SÃO PAULO

2005 


\section{ANÁLISE BIOMECÂNICA DO ANDAR DE ADULTOS E IDOSOS NOS AMBIENTES AQUÁTICO E TERRESTRE}

ANA MARIA FORTI BARELA

Tese apresentada à Escola de

Educação Física e Esporte da

Universidade de São Paulo, como requisito parcial para obtenção do grau de Doutor em Educação Física. 


\section{AGRADECIMENTOS}

São tantas as pessoas que se envolveram, ou pelo menos tiveram que se envolver, (in)diretamente no processo do meu doutorado, que fica difícil lembrar de todas elas. Portanto, se eu esquecer de mencionar alguém (o que pode ser muito provável), peço desculpas antecipadamente. Nesse sentido, expresso profunda gratidão:

Ao Dr. Marcos Duarte, pela confiança que depositou em mim, pela orientação e pelos ensinamentos durante todas as etapas.

Aos membros da banca examinadora, Dra. Isabel de Camargo Neves Sacco, Dr. Ulisses Fernandes Ervilha, Dra. Sueli Santos e Dra. Emico Okuno, pelos comentários e sugestões.

Ao Sandro F. Stolf pelo auxílio durante todo o processo de coleta de dados, e principalmente pela amizade, que prezo muito.

Ao Welber Marinovic, que ajudou muito durante os testes piloto e estava sempre disposto a ajudar de alguma forma, independentemente se era às quartas-feiras às 7 da manhã ou às sextas-feiras a partir das 5 da tarde (os únicos horários disponíveis para usar a piscina durante os testes piloto).

Ao Paulo Marchetti e Rozilei, que também ajudaram durante alguns testes piloto.

A todos os voluntários que participaram do estudo e que não mediram qualquer esforço em momento algum.

À FAPESP pelo apoio financeiro durante três anos.

Aos membros do Laboratório de Biofísica atuais e que já não estão mais aqui, Wilson, Silvana, Sandro, Sandra, Rozi, Rogério, Reginaldo, Paulo, Luiz, Janina, Daniel, Brenda, Bel e Alexandre.

Aos funcionários da Secretaria de Pós-Graduação, em especial à Maria de Lourdes. 
Aos funcionários da Biblioteca da Escola de Educação Física e Esporte, em especial à Selma e à Lúcia.

Aos funcionários responsáveis pela piscina, em especial ao Sr. Manoel e Ricardo.

Ao Umberto, pela amizade, incentivo e ajuda nos momentos "difíceis" dessa etapa.

Ao Marcos Bedinelli, um grande amigo que após muitos anos nos reencontramos "virtualmente" e, que mesmo morando no Canadá, não mediu qualquer esforço para ler este trabalho e fazer algumas sugestões/considerações.

À Dra. Ana Maria Pellegrini, que me orientou durante a iniciação científica por dois anos, me proporcionando grandes oportunidades e desafios para eu prosseguir no meio acadêmico.

Aos membros do Laboratório para Estudo do Movimento (UNESP-Rio Claro), em especial, à Paula, Dani, Carol, Thátia, Paulão, Priscila, Maria Solange, Ana Paula, etc.

Ao Barela, um grande companheiro, amigo e um dos amores da minha vida, pelo incentivo, pelos ensinamentos e pela compreensão e conselhos. Você é um grande exemplo em (quase) tudo!

Aos meus pais, que além de me apoiarem e incentivarem em todas minhas decisões, nunca mediram qualquer esforço para me ajudar, e auxiliam sobremaneira nos cuidados de meu filho Guilherme.

Às minhas irmãs Bia e Marô, tias do Gui, que estão sempre mudando suas rotinas em função do sobrinho e da mãe do sobrinho, e sempre ajudando muito, principalmente nas "horas de emergência".

Ao meu querido filho Guilherme, que traz muita alegria e descontração. Agradeço muito por você ter nascido, mesmo que tenha sido no meio de uma fase profissional tão "conturbada", mas tem sido tão gratificante...

$\mathrm{E}$ a todos que mesmo sem terem sido mencionados, estão no meu coração. 


\section{SUMÁRIO}

Página

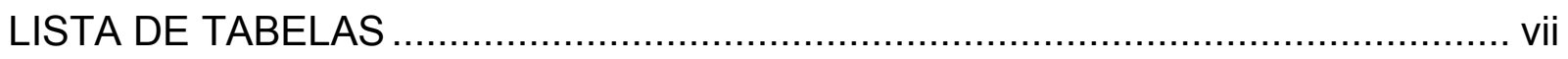

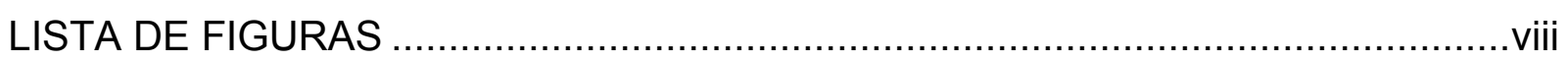

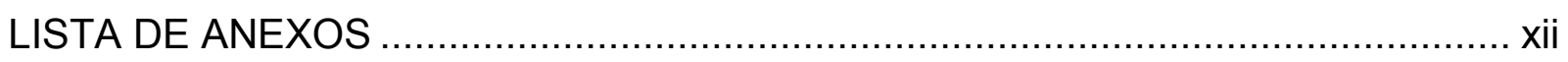

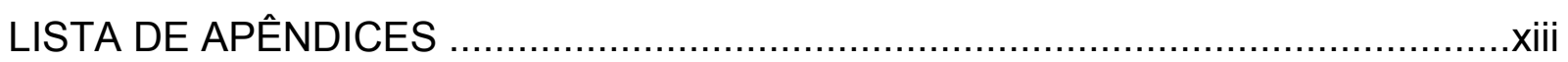

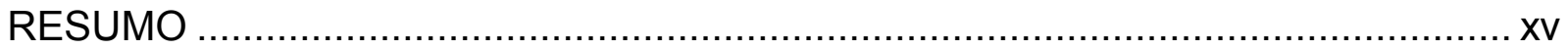

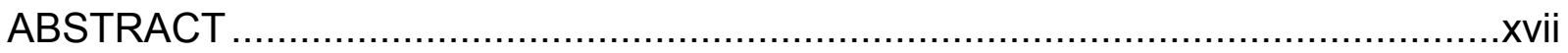

1 INTRODUÇÃO

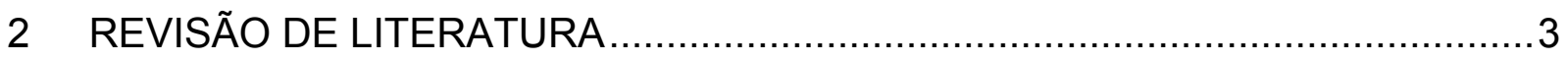

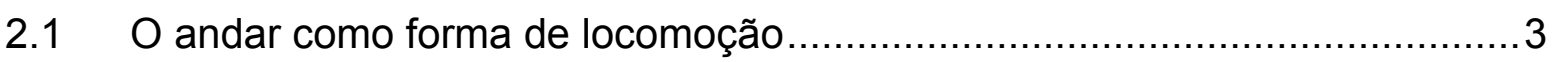

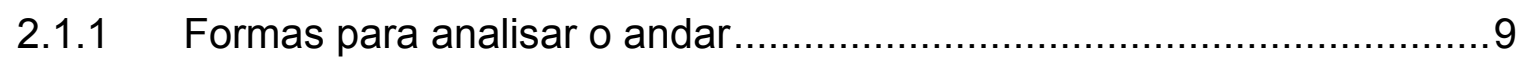

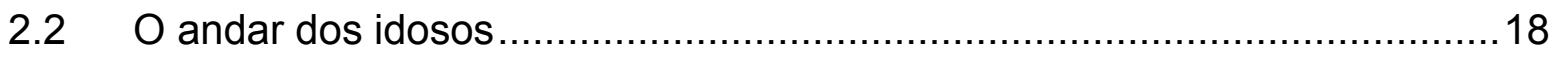

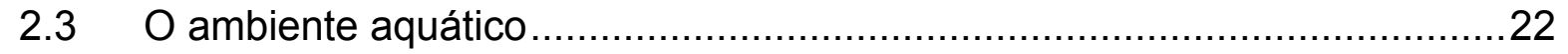

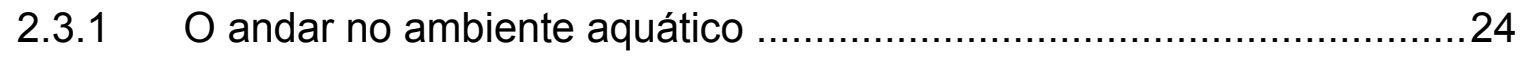

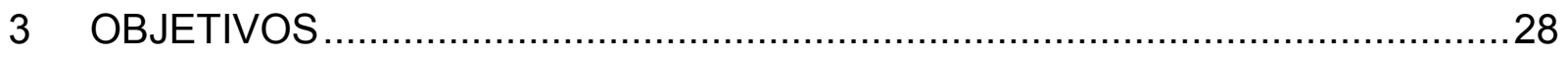

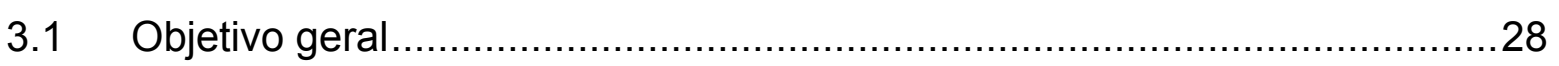

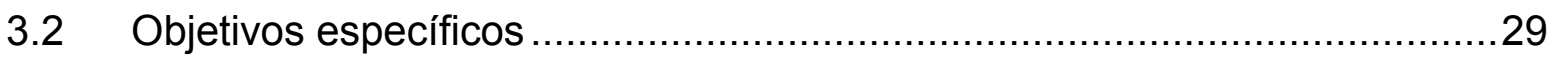

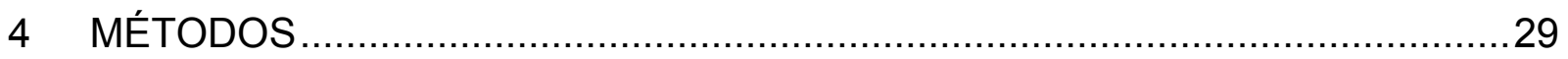

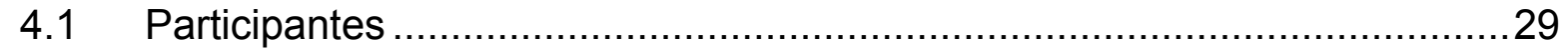

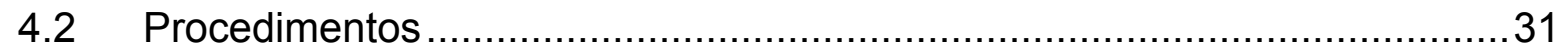

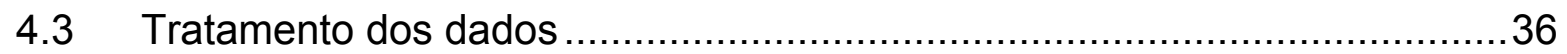

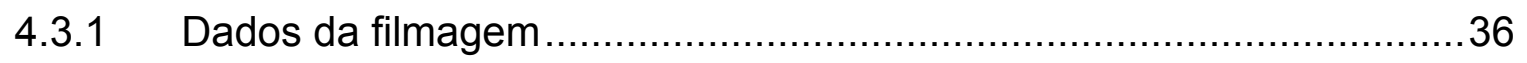

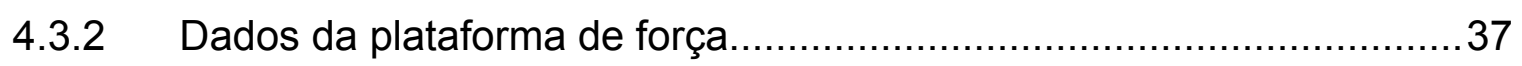

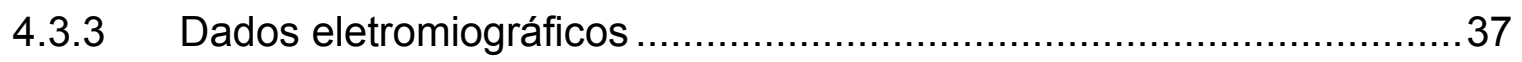

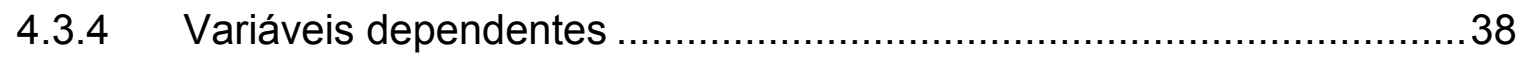

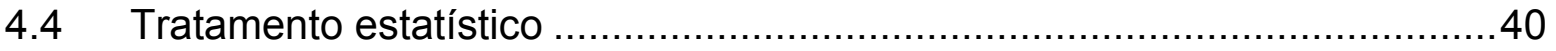

5 RESULTADOS 


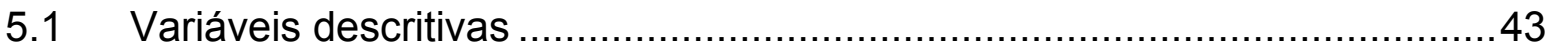

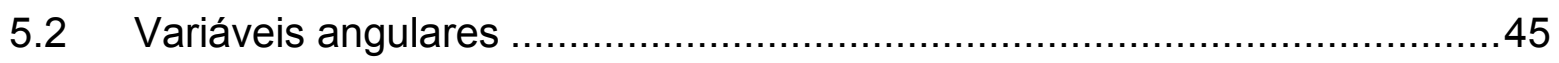

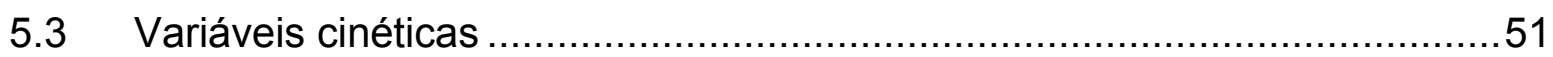

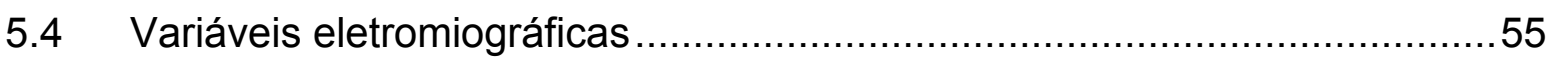

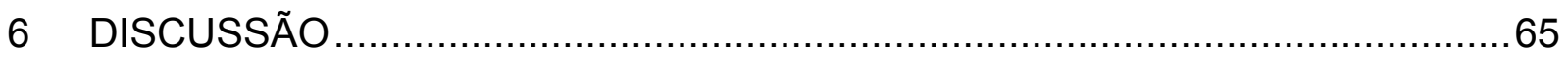

6.1 O andar dos adultos nos ambientes terrestre e aquático........................66

6.2 O andar dos idosos nos ambientes terrestre e aquático...........................69

6.3 O andar dos idosos e adultos no ambiente terrestre ..............................71

6.4 O andar dos idosos e adultos no ambiente aquático ............................73

6.5 Implicações para andar no ambiente aquático .................................. 75

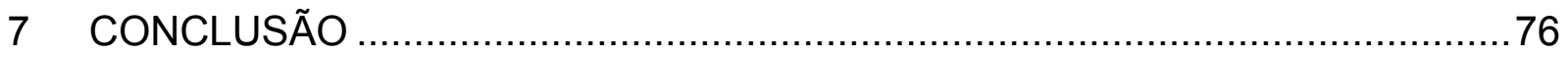

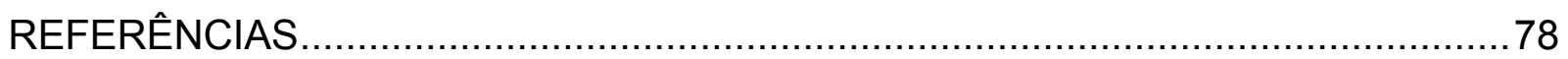




\section{LISTA DE TABELAS}

Página

TABELA 1 - Informações sobre tipo de atividade física e freqüência de prática (número de vezes por semana) dos participantes idosos. Nota: Educação física se refere às aulas do programa de Educação Física para Idosos oferecidas na EEFE-USP (mais detalhes sobre essas aulas no ANEXO II).

TABELA 2 - Porcentagem média do coeficiente de variação dos ângulos articulares do tornozelo, joelho e quadril durante o ciclo do andar dos adultos e idosos nos ambientes terrestre (AT) e aquático (AA).

TABELA 3 - Porcentagem média do coeficiente de variação das componentes da força de reação do solo (FRS) vertical $\left(F_{z}\right)$ e horizontal ântero-posterior $\left(F_{y} A-P\right)$ durante o ciclo do andar dos adultos e idosos nos ambientes terrestre (AT) e aquático (AA).

TABELA 4 - Número de adultos e idosos nos ambientes terrestre (AT) e aquático (AA) em que foi possível adquirir dados da atividade eletromiográfica dos músculos gastrocnêmio medial (GM), tibial anterior (TA), cabeça curta do bíceps femoral (BFCC), vasto lateral (VL), cabeça longa do bíceps femoral (BFCL), tensor da fáscia látea $(T F L)$, eretor espinhal $(E E)$ e reto do abdome (RA). 56

TABELA 5 - Porcentagem média do coeficiente de variação dos músculos gastrocnêmio medial (GM), tibial anterior (TA), cabeça curta do bíceps femoral (BFCC), vasto lateral (VL), cabeça longa do bíceps femoral (BFCL) e eretor espinhal (EE) durante o ciclo do andar dos adultos e idosos nos ambientes terrestre (AT) e aquático (AA). 


\section{LISTA DE FIGURAS}

Página

FIGURA 1 - Ilustração referente ao passo (contato de um pé seguido de contato do pé contralateral na superfície) e da passada (dois contatos sucessivos do mesmo pé na superfície).

FIGURA 2 - Representação dos períodos (apoio e balanço), dos três intervalos do período de apoio (apoio duplo inicial, apoio simples e apoio duplo final) e das fases (contato inicial, resposta à carga, apoio médio, apoio final, pré-balanço, balanço inicial, balanço médio, e balanço final) do andar.6

FIGURA 3 - Definições dos ângulos articulares (quadril, joelho e tornozelo) e segmentares (tronco, coxa, perna e pé) dos membros inferiores. Ângulos articulares são os ângulos entre os segmentos corporais adjacentes e ângulos segmentares são os ângulos relativos à horizontal. 11

FIGURA 4 - Valores médios ( \pm desvio padrão) dos ângulos articulares (em graus) do quadril, joelho e tornozelo no plano sagital durante um ciclo do andar de indivíduo adulto em velocidade confortável auto-selecionada. Nota: valores positivos e negativos indicam movimentos de flexão e extensão, respectivamente (Adaptado de PERRY, 1992)...

FIGURA 5 - Componentes da força de reação do solo (FRS) normalizadas pelo peso corporal (PC) durante um ciclo do andar. Linha contínua representa a componente vertical, linha pontilhada representa a componente ânteroposterior, e linha tracejada representa a componente médio-lateral da FRS. Dados referentes a adultos normais andando em velocidade confortável auto-selecionada. 
FIGURA 6 - Envoltórios lineares da atividade elétrica (EMG) dos músculos gastrocnêmio medial (GM), tibial anterior (TA), bíceps femoral $(B F)$, vasto lateral $(V L)$, semitendinoso $(S T)$, tensor da fáscia látea ( $T F L)$, eretor espinhal $(\mathrm{EE})$ e reto do abdome (RA) durante um ciclo do andar. Nota: linhas contínuas: valores médios; linhas pontilhadas: desvio padrão. (Adaptado de WINTER, 1991). 18

FIGURA 7 - Representação esquemática do arranjo experimental para a aquisição de dados no ambiente terrestre, indicando início e fim do percurso, o posicionamento da plataforma de força (PF), das câmeras (I e II), e do trecho considerado para análise da passada (A e B).

FIGURA 8 - Ilustração parcial do arranjo experimental para a aquisição de dados no ambiente aquático, com a plataforma de força embutida na região central da passarela redutora de profundidade. 32

FIGURA 9 - Valores médios (D.P.) das variáveis descritivas: comprimento (A), duração (B), velocidade (C) e cadência (D) da passada, e duração do período de apoio (PA) (E) durante o ciclo completo do andar dos adultos e idosos nos ambientes terrestre (AT) e aquático (AA).

FIGURA 10 - Média ( \pm D.P) dos ângulos articulares do tornozelo, joelho e quadril durante um ciclo do andar dos adultos (coluna à esquerda) e dos idosos (coluna à direita) nos ambientes terrestre (AT, sombreado) e aquático (AA, preto). Nota: valores positivos indicam flexão do tornozelo e flexão do joelho e quadril.

FIGURA 11 - Valores médios (D.P) da amplitude de movimento articular (ADM) do tornozelo $(A, B, C)$, joelho $(D, E, F)$ e quadril $(G, H, I)$, durante $o$ período de apoio (coluna à esquerda), período de balanço (coluna central) e ciclo completo (coluna à direita) do andar dos adultos e idosos nos ambientes terrestre (AT) e aquático (AA). Nota: a escala do eixo vertical varia conforme a articulação em consideração. 
FIGURA 12 - Valores médios (D.P) dos ângulos articulares do tornozelo (A, B), joelho $(C, D)$ e quadril $(E, F)$ durante as fases de contato inicial (coluna à esquerda) e de balanço inicial (coluna à direita) do andar dos adultos e idosos nos ambientes terrestre (AT) e aquático (AA). Nota: a escala do eixo vertical varia conforme a articulação em consideração; valores positivos indicam flexão do tornozelo e flexão do joelho e quadril. ....50

FIGURA 13 - Média ( \pm D.P) das componentes vertical e horizontal antero-posterior da FRS durante o ciclo do andar dos adultos (coluna à esquerda) e dos idosos (coluna à direita) nos ambientes terrestre (AT, sombreado) e aquático (AA, preto). Os eixos verticais à esquerda indicam as forças normalizadas pelo peso corporal (PC) no AT e pelo PC aparente no $\mathrm{AA}$, e os eixos à direita indicam as forças normalizadas pelo $\mathrm{PC}$......53

FIGURA 14 - Valores médios (D.P) do primeiro pico $(A)$ e do segundo pico (B) da componente vertical da FRS, da força de impacto (C) e do impulso horizontal (D) durante o período de apoio do andar de adultos e idosos nos ambientes terrestre (AT) e aquático (AA). Nota: os valores foram normalizados pelo peso corporal (PC) dos participantes no AT e pelo PC aparente no AA. 55

FIGURA 15 - Média ( \pm D.P.) da atividade eletromiográfica (EMG) normalizada pelo valor médio dos músculos gastrocnêmio medial (GM), tibial anterior (TA), cabeça curta do bíceps femoral (BFCC), vasto lateral (VL), cabeça longa do bíceps femoral (BFCL), eretor espinhal (EE) e reto do abdome (RA) durante o ciclo do andar dos adultos (coluna à esquerda) e idosos (coluna à direita) nos ambientes terrestre (AT, área sombreada) e aquático ( $\mathrm{AA}$, linha preta). 
FIGURA 16 - Valores médios (D.P) da magnitude da atividade eletromiográfica (EMG) normalizados pela contração voluntária máxima isométrica (CVMI) dos músculos gastrocnêmio medial (GM) e tibial anterior (TA) durante os períodos de apoio (coluna à esquerda) e de balanço (coluna à direita) do andar dos adultos e idosos nos ambientes terrestre $(A T)$ e aquático $(A A)$.

FIGURA 17 - Valores médios (D.P.) da magnitude da atividade eletromiográfica (EMG) normalizados pela CVMI dos músculos cabeça curta do bíceps femoral (BFCC) e vasto lateral (VL) durante os períodos de apoio (coluna à esquerda) e de balanço (coluna à direita) do andar dos adultos e idosos nos ambientes terrestre (AT) e aquático (AA). 62

FIGURA 18 - Valores médios (D.P) da magnitude da atividade eletromiográfica (EMG) normalizados pela CVMI dos músculos bíceps femoral-cabeça longa (BFCL) e tensor da fáscia látea (TFL) durante os períodos de apoio (coluna à esquerda) e de balanço (coluna à direita) do andar dos adultos e idosos nos ambientes terrestre (AT) e aquático (AA).

FIGURA 19 - Valores médios (D.P) da magnitude da atividade eletromiográfica (EMG) normalizados pela CVMI do músculo eretor espinhal (EE) durante os períodos de apoio (coluna à esquerda) e de balanço (coluna à direita) do andar dos adultos e idosos nos ambientes terrestre $(A T)$ e aquático $(A A)$. 65 


\section{LISTA DE ANEXOS}

Página

ANEXO I - Anamnese.

ANEXO II - Informações sobre o programa de educação física para idosos da Escola de Educação Física e Esporte, Universidade de São Paulo. 92

ANEXO III - Carta do Comitê de Ética. 93

ANEXO IV - Termo de consentimento. 94

ANEXO V - Resultados dos testes post hoc de Tukey da interação entre grupos (adultos e idosos) e ambientes (ambiente terrestre (AT) e ambiente aquático $(\mathrm{A} A)$ ) de acordo com as variáveis analisadas. 


\section{LISTA DE APÊNDICES}

Página

APÊNDICE 1 - Valores médios das variáveis comprimento $(m)$, duração $(s)$, velocidade $(\mathrm{m} / \mathrm{s})$ e cadência (passadas/s) da passada e duração do período de apoio (PA) (\%) nos ambientes terrestre (AT) e aquático (AA) para cada participante dos dois grupos (adultos e idosos).....100

APÊNDICE 2 - Valores médios do coeficiente de variação (\%) dos ângulos articulares do tornozelo, joelho e quadril durante os o ciclo do andar nos ambientes terrestre (AT) e aquático (AA) para cada participante dos dois grupos (adultos e idosos). 101

APÊNDICE 3 - Valores médios do coeficiente de variação (\%) das componentes da força de reação do solo vertical (Fz) e horizontal ântero-posterior (Fy A-P) nos ambientes terrestre (AT) e aquático (AA) para cada participante dos dois grupos (adultos e idosos). 102

APÊNDICE 4 - Valores médios do coeficiente de variação (\%) dos músculos gastrocnêmio medial (GM), tibial anterior (TA), cabeça curta do bíceps femoral (BFCC), vasto lateral (VL), cabeça longa do bíceps femoral (BFCL), tensor da fáscia látea (TFL), eretor espinhal $(E E)$ e reto do abdome (RA) durante o ciclo do andar nos ambientes terrestre (AT) e aquático (AA) para cada participante dos dois grupos (adultos e idosos). 103

APÊNDICE 5 - Valores médios da amplitude de movimento articular (graus) do tornozelo, joelho e quadril durante os períodos de apoio e balanço e durante o ciclo completo nos ambientes terrestre (AT) e aquático (AA) para cada participante dos dois grupos (adultos e idosos).....105 
APÊNDICE 6 - Valores médios dos ângulos articulares (graus) do tornozelo, joelho e quadril nas fases de contato inicial $(\mathrm{Cl})$ e balanço inicial $(\mathrm{BI})$ nos ambientes terrestre (AT) e aquático (AA) para cada participante dos dois grupos (adultos e idosos). ...................................................107

APÊNDICE 7 - Valores médios do peso corporal (PC), primeiro pico (Pico 1) e segundo pico (Pico 2) da componente vertical da força de reação do solo normalizados pelo PC (PC aparente para o ambiente aquático), força de impacto (PC/s) e impulso horizontal (PC.s) nos ambientes terrestre (AT), e aquático (AA) para cada participante dos dois grupos (adultos e idosos). 108

APÊNDICE 8 - Valores médios da magnitude da atividade eletromiográfica normalizados pela CVMI dos músculos gastrocnêmio medial (GM), tibial anterior (TA), cabeça curta do bíceps femoral (BFCC), vasto lateral (VL), cabeça longa do bíceps femoral (BFCL), tensor da fáscia látea (TFL), eretor espinhal ( $E E)$ e reto do abdome (RA) durante os períodos de apoio e balanço nos ambientes terrestre (AT), e aquático (AA) para cada participante dos dois grupos (adultos e idosos).....109 


\title{
RESUMO
}

\section{ANÁLISE BIOMECÂNICA DO ANDAR DE ADULTOS E IDOSOS NOS AMBIENTES AQUÁTICO E TERRESTRE}

\author{
Autora: ANA MARIA FORTI BARELA \\ Orientador: Prof. Dr. MARCOS DUARTE
}

Andar na água tem sido utilizado como um método alternativo para treinamento e reabilitação. No entanto, há pouca informação sobre as características biomecânicas do andar em piscina rasa. Em se tratando de indivíduos idosos, a escassez é ainda maior. Informações sobre as características biomecânicas do andar nessa condição ambiental é importante para um melhor entendimento da tarefa. Sendo assim, características espaço-temporais, cinemáticas, da força de reação do solo (FRS) e eletromiográficas (EMG) de adultos e idosos andando em piscina rasa (ambiente aquático - AA) e fora da piscina (ambiente terrestre - AT) foram investigadas. Para tanto, dez adultos (21-38 anos) e dez idosos (60-77 anos) andaram no AT e em seguida no AA (nível do processo xifóide do esterno) com velocidades auto-selecionadas e confortáveis. Em termos gerais, a maioria das variáveis espaço-temporais da passada foi diferente entre os ambientes e entre os grupos. Porém, enquanto que a velocidade entre os adultos e idosos foi diferente no AT, os dois grupos apresentaram a mesma velocidade para andar no AA. Os ângulos articulares investigados variaram conforme o ambiente e/ou grupo. A magnitude dos picos da componente vertical da FRS foi menor no AA do que no AT e a componente horizontal ântero-posterior apresentou apenas uma fase de aceleração no AA. Por 
fim, o padrão de ativação EMG foi diferente entre os ambientes para a maioria dos músculos investigados e a magnitude da atividade EMG dos mesmos foi menor no AA. Os resultados encontrados neste estudo contribuem para um melhor entendimento do andar no AA no contexto de treinamento e reabilitação.

Palavras-chave: marcha, cinemática, força de reação do solo, eletromiografia. 


\title{
ABSTRACT \\ BIOMECHANICAL ANALYSIS OF ADULTS AND ELDERLIES WALKING IN WATER AND ON LAND ENVIRONMENTS
}

\author{
Author: ANA MARIA FORTI BARELA \\ Adviser: Prof. Dr. MARCOS DUARTE
}

Walking in water has been used as an alternative way for both training and rehabilitation. However, there is little information about the biomechanical characteristics of shallow water walking. In terms of elderly individuals, it is even scarcer. Information about the biomechanical characteristics of walking in this environmental condition is important for a better understanding of this task. In this way, spatial-temporal, kinematics, ground reaction force (GRF), and electromyographic (EMG) characteristics of adults and elders walking in shallow water and on land were investigated. As such, ten adults (21-38 years old) and ten elders (60-77 years old) walked on land and then in shallow water (Xiphsternun water level) with self-selected comfortable walking speeds. In general, most stride spatialtemporal variables were different between both environments and groups. Although walking speed was different between adults and the elderly on land, both groups showed the same walking speed in shallow water. The investigated angle joints varied according to environment and/or group. The magnitude of the vertical GRF peaks was lower in shallow water than on land and the anterior-posterior horizontal GRF showed an acceleration phase only in shallow water. Finally, the EMG activation pattern was different for most investigated muscles and the EMG activity magnitude 
of those was smaller in shallow water than on land. The results in the present study contribute to a better understanding of this activity in the context of training and rehabilitation.

Keywords: gait, kinematics, ground reaction force, electromyography 
O ser humano se movimenta constantemente e uma das formas mais comuns de se movimentar é por meio da locomoção. Dentre as várias formas de locomoção, o andar é uma das que mais chama atenção dos estudiosos da área de comportamento motor, provavelmente por ser a forma de locomoção mais utilizada. O andar humano é um processo de locomoção em que o corpo ereto e em movimento é sustentado primeiramente por uma perna e em seguida pela outra perna, permanecendo pelo menos um pé em contato com o chão (INMAN, RALSTON \& TODD, 1994). De modo geral, o andar humano é uma ação motora complexa que requer controle de vários elementos, e a simplicidade aparente dessa ação desaparece quando alguém tenta uma descrição científica de todo o processo (ROSE \& GAMBLE, 1994).

Como se não bastasse a complexidade do andar, há vários fatores intrínsecos e extrínsecos que podem interferir na forma como as pessoas andam. Sendo assim, qualquer distúrbio no sistema motor, músculo-esquelético e/ou sensorial, tipos de superfície em que o andar ocorre, condições que o ambiente favorece e até mesmo a faixa etária de quem está andando (por exemplo, bebês, adultos, idosos) poderiam alterar o padrão do andar.

Quando se trata do andar de idosos, por exemplo, há uma certa preocupação com as quedas que são comuns a esta população. Esta preocupação surge pelo fato de que, na maioria das vezes, as quedas ocorrerem quando se está andando (KERRIGAN, LEE, NIETO, MARKMAN, COLLINS \& RILEY, 2000). Então, as questões que surgem estão relacionadas às principais alterações que ocorrem no padrão do andar relacionadas com o processo de envelhecimento, e como essas alterações podem ser verificadas.

As mudanças que ocorrem com a idade são descritas em vários estudos e o interesse em se estudar os idosos justifica-se pelo fato de que a expectativa de vida vem aumentando nos últimos anos. O interesse em promover programas de atividade física para os idosos é cada vez mais comum, e desta forma, estudos que buscam identificar alterações motoras que ocorrem com o avançar da idade devem ser realizados, principalmente estudos que investigam alterações no andar, uma vez 
que a mobilidade independente é muito importante para os idosos, por favorecer maior autonomia.

Embora haja vários estudos que investigaram o andar em terra (ambiente terrestre) de adultos (ANDRIACCHI, OGLE \& GALANTE, 1977; MARTIN \& MARSH, 1992; PERRY, 1992; ROSE \& GAMBLE, 1994; VAUGHAN, DAVIS \& O'CONNOR, 1999; WINTER, 1983) e estudos que compararam esse andar entre adultos e idosos (HIMANN, CUNNINGHAM, RECHNITZER \& PATERSON, 1988; MILLS \& BARRETT, 2001; NIGG, FISHER \& RONSKY, 1994; RILEY, DELLA CROCE \& KERRIGAN, 2001a; WINTER, PATLA, FRANK \& WALT, 1990), por exemplo, o mesmo não se aplica para o andar em piscina rasa (ambiente aquático). Apesar do ambiente aquático ser cada vez mais utilizado para a prática de atividade física, treinamento e reabilitação, não há muita informação disponível sobre as características biomecânicas que evidenciem as alterações que esse ambiente possa proporcionar a movimentos complexos, como é o caso do andar. Em se tratando de indivíduos idosos, a escassez é ainda maior. Dentro de um programa de reabilitação, por exemplo, o treinamento do andar (ou marcha, como considerada por muitos profissionais) é fundamental quando alterações no aparelho locomotor são verificadas, e para tal o ambiente aquático é comumente utilizado devido às propriedades físicas da água (HEYNEMAN \& PREMO, 1992; WADELL, SUNDELIN, HENRIKSSON-LARSEN \& LUNDGREN, 2004). Provavelmente, a limitação de estudos sobre características biomecânicas do andar no ambiente aquático seja decorrente da grande dificuldade para adaptar equipamentos utilizados na análise do movimento humano dentro da água.

Por outro lado, antes de estabelecer um programa de treinamento ou reabilitação, é necessário ter informações sobre possíveis alterações que o ambiente aquático possa provocar no sistema locomotor de indivíduos sem queixas de comprometimentos motores, sensoriais e/ou músculo-esqueléticos. É importante ressaltar que um ciclo do andar (ou uma passada), que corresponde a dois contatos consecutivos do mesmo membro no solo, apresenta dois períodos distintos: período de apoio (quando o pé está em contato com o solo) e período de balanço (quando o membro em consideração não tem contato algum com o solo e a perna oscila em preparação para o próximo contato desse pé com o chão) (PERRY, 1992). Sendo 
assim, é importante considerar os dois períodos do ciclo, não apenas um desses períodos quando se analisa o andar no ambiente aquático, como já verificado (MIYOSHI, SHIROTA, YAMAMOTO, NAKAZAWA \& AKAI, 2004; YAMAMOTO, NAKAZAWA \& YANO, 1995; YANO, NAKAZAWA \& YAMAMOTO, 1995).

O presente estudo investigou características biomecânicas do andar de adultos e idosos, sem queixas de comprometimento no aparelho locomotor, nos ambientes terrestre e aquático. No ambiente aquático, todos os indivíduos andaram com a água no nível do processo xifóide do esterno e, como o interesse não era de investigar a coordenação inter-membros ou dominância lateral, apenas um lado do corpo foi considerado neste estudo.

A apresentação deste estudo está organizada do seguinte modo: revisão da literatura, objetivos gerais e específicos, métodos adotados, resultados encontrados, discussão desses resultados e conclusão.

\section{REVISÃO DE LITERATURA}

Esta revisão de literatura é apresentada em três itens principais para organizar melhor as informações mais relevantes do presente estudo. Primeiramente, uma descrição do andar de indivíduos adultos sem comprometimento no aparelho locomotor e algumas formas para analisar esse andar são apresentadas. O segundo item enfoca mais especificamente o andar de idosos e, indiretamente, de indivíduos adultos, os quais são os grupos em questão. Por último, as propriedades do ambiente aquático e os estudos que trataram do andar nesse ambiente são apresentados.

\subsection{O andar como forma de locomoção}

A locomoção é o processo em que os seres vivos mudam de um lugar para outro. Portanto, sua finalidade é transportar o corpo pelo espaço. Em se tratando da locomoção ereta bípede, essa pode ser vista como uma ação aprendida (INMAN, RALSTON \& TODD, 1994; WINTER, 1991). Ao se considerar o andar como uma ação aprendida, certas peculiaridades pessoais superimpostas ao andar podem ser observadas, uma vez que cada pessoa tem sua característica comportamental própria para andar. Neste sentido, cada um de nós aprende a integrar muitas 
variáveis que a natureza conferiu aos nossos sistemas neuromusculares individuais (INMAN, RALSTON \& TODD, 1994) para que o andar seja executado com eficiência. Por outro lado, há similaridades na maneira como a maioria das pessoas anda e que são facilmente identificadas. Sendo assim, ao se analisar o andar humano, as similaridades e as diferenças devem ser consideradas com intuito de descrever como essas variações podem representar mudanças no padrão de locomoção.

Aparentemente, o andar parece ser uma ação simples. Porém, ao se considerar as suas características, é possível perceber quão complexo ele é. Por exemplo, quando andamos, dois terços da massa corporal (cabeça, tronco e braços) estão equilibrados sobre dois membros em movimento e, como se não bastasse, o centro de massa do corpo se desloca fora da base de suporte por cerca de $80 \%$ do período de cada ciclo da passada (FRANK \& PATLA, 2003; WINTER, 1983). Portanto, além de complexo, o andar bípede é uma ação instável, uma vez que para se manter ereto, o centro de massa deve ser mantido em equilíbrio sobre a base de suporte, com a tendência de permanecer dentro da pelve (INMAN, RALSTON \& TODD, 1994). Provavelmente, essa é uma das razões porque os infantes começam a andar somente um longo período após o nascimento (GAGE, 1991).

Em indivíduos sem queixas de comprometimento no aparelho locomotor, o andar pode ser definido como um método de locomoção que envolve o uso das duas pernas, alternadamente, para propiciar suporte e propulsão (WHITTLE, 1996b). Sendo assim, dois requisitos básicos são necessários durante o andar: movimento periódico de cada perna de uma posição de suporte à próxima posição de suporte, e forças de reação do solo suficientes, aplicadas nos pés, para sustentar o corpo e propulsioná-lo à frente (INMAN, RALSTON \& TODD, 1994; VAUGHAN, DAVIS \& O'CONNOR, 1999). Esses requisitos básicos são necessários para qualquer forma do andar bípede e ocasionam movimentos específicos do corpo que são observáveis durante a sua ação.

O andar é composto por ciclos repetitivos de passos e passadas. Um ciclo do andar é caracterizado pelo início de um determinado evento por um membro e continua até que o mesmo evento se repita novamente com o mesmo membro (SODERBERG, 1990). Um passo se refere ao início de um evento por um membro até o início do mesmo evento com o membro contralateral e passada se refere a um 
ciclo completo do andar, que se refere ao início de um evento por um membro até o início do mesmo evento com o mesmo membro. Tipicamente, o evento para delimitar o passo ou a passada é o toque do calcanhar no chão (FIGURA 1), mas qualquer evento poderia ser utilizado. Em cada passo, o corpo acelera e desacelera levemente, levanta e abaixa alguns centímetros e ondula levemente de um lado para o outro (INMAN, RALSTON \& TODD, 1994). Em cada passada, três tarefas funcionais devem ser realizadas (PERRY, 1992): 1) aceitação do peso, em que ocorre a transferência do peso corporal sobre um membro; 2) apoio sobre um único membro, uma vez que o membro contralateral perde o contato com o chão; e 3) avanço do membro em balanço, de modo que para avançar o membro à frente, esse oscila no mesmo sentido.

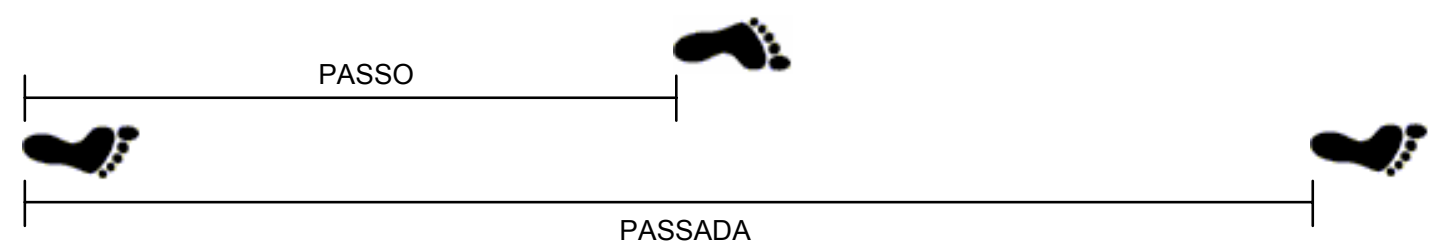

FIGURA 1 - llustração referente ao passo (contato de um pé seguido de contato do pé contralateral na superfície) e da passada (dois contatos sucessivos do mesmo pé na superfície).

Ainda com relação à passada, ela pode ser dividida em períodos e fases do andar. Pelo menos um pé permanece em contato com a superfície durante cada ciclo do andar, conseqüentemente, dois períodos são identificados em cada ciclo: período de apoio e período de balanço (PERRY, 1992). Durante o período de apoio, o pé toca a superfície de contato, enquanto que no período de balanço, o mesmo pé não tem contato algum com essa superfície e a perna oscila em preparação para o próximo contato desse pé com a superfície (FIGURA 2). O período de apoio, por sua vez, pode ser subdividido em três intervalos distintos: apoio duplo inicial, quando os dois pés estão tocando a superfície de contato; apoio simples, quando um pé está oscilando enquanto que o outro está em contato com a superfície; e apoio duplo final, quando os dois pés tocam a superfície de contato novamente. 
Os períodos descritos acima são definidos a partir de fases observadas durante o ciclo do andar. Durante um ciclo do andar, a ocorrência de oito fases podem ser observadas (PERRY, 1992), das quais cinco ocorrem durante o período de apoio e três ocorrem durante o período de balanço (FIGURA 2). Há uma variação com referência à nomenclatura adotada por cada grupo de estudiosos para classificar as divisões e subdivisões do andar, porém, independente da nomenclatura utilizada, a descrição de cada divisão e subdivisão do ciclo do andar é praticamente a mesma. No presente estudo, apenas as nomenclaturas utilizadas por PERRY (1992) para descrever as fases que ocorrem durante os períodos de apoio e de balanço são apresentadas, uma vez que sua nomenclatura pode ser utilizada para descrever também o andar de diferentes populações, independentemente se for referente ao andar patológico ou não, e até mesmo a diferentes condições que o ambiente possa proporcionar ao executante.

\section{PERÍODO DE APOIO}

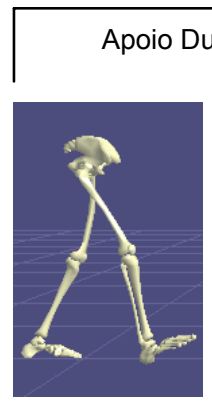

Contato inicial

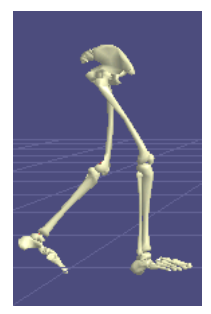

Resposta à carga
Apoio Simples

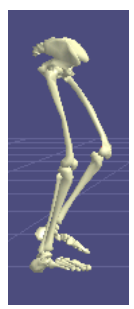

Apoio médio

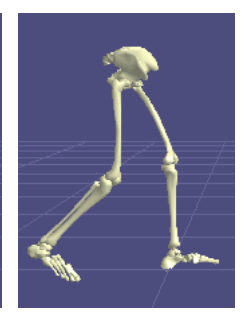

Apoio final
Apoio Duplo Final

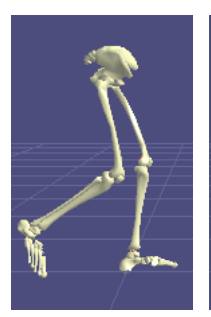

Prébalanço
PERÍODO DE BALANÇO

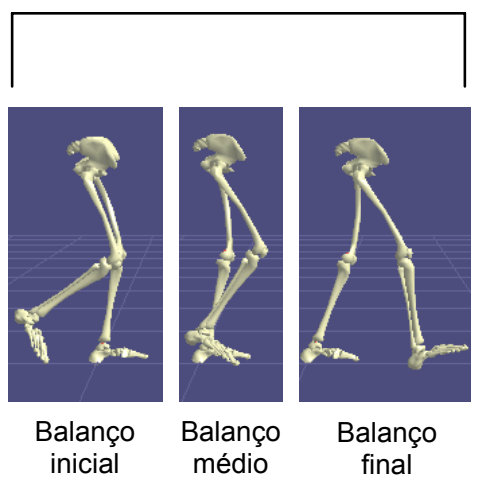

FIGURA 2 - Representação dos períodos (apoio e balanço), dos três intervalos do período de apoio (apoio duplo inicial, apoio simples e apoio duplo final) e das fases (contato inicial, resposta à carga, apoio médio, apoio final, pré-balanço, balanço inicial, balanço médio, e balanço final) do andar.

Conforme PERRY (1992), as oito fases que ocorrem durante um ciclo da passada do andar têm um objetivo funcional. Sendo assim, as fases do período de apoio são: contato inicial, que começa o ciclo da passada; resposta à carga, que é quando a superfície plantar toca a superfície de contato; apoio médio, que ocorre 
quando o pé contralateral (em balanço) passa o pé de apoio; apoio final, que ocorre conforme o pé perde o contato com a superfície; e pré-balanço, que finaliza o período de apoio conforme o pé deixa a superfície de contato. Seguindo a mesma nomenclatura, as fases do período de balanço são: balanço inicial, que começa imediatamente após a perda de contato do pé com a superfície e a perna é acelerada à frente; balanço médio, que ocorre quando o pé passa sob o corpo e coincide com o apoio médio do pé contralateral; e balanço final, que ocorre quando a perna se prepara para o próximo toque do pé na superfície de contato.

Os eventos referentes ao ciclo do andar que foram apresentados são considerados eventos temporais. Dessa maneira, medidas relacionadas à velocidade, duração do período de apoio e do período de balanço, e cadência (ou freqüência) são normalmente investigadas nos estudos sobre o andar. Há também aspectos relacionados às medidas de distância, que são os casos dos comprimentos do passo e da passada. Normalmente, o ciclo do andar é normalizado pela porcentagem do ciclo, iniciando com o primeiro contato do pé no chão $(0 \%)$ até o próximo contato deste no chão (100\%). Com essa normalização, comparações entre indivíduos ou condições que apresentem durações diferentes são possíveis de serem feitas (WINTER, 1991).

As medidas mencionadas acima, portanto, constituem as características da passada dos indivíduos e representam a capacidade básica do andar deles. Sendo assim, a velocidade do andar é considerada como uma medida fundamental, uma vez que ela define a razão do deslocamento das pessoas pelo tempo necessário para percorrer uma determinada distância (PERRY, 1992). Normalmente, os indivíduos são solicitados a selecionarem uma velocidade confortável para andar, que é tratada no presente estudo como velocidade confortável auto-selecionada. Para adultos normais, essa velocidade é em média 1,37 m/s (PERRY, 1992).

A cadência é o número de passos (ou passadas) realizados por um determinado período de tempo e é apresentada, normalmente, como passos/minuto (ou passadas/minuto). Sendo assim, a cadência pode ser calculada pela razão entre a velocidade da passada e o comprimento da passada, ou ainda, pode ser calculada pela razão entre um e a duração da passada. A cadência livre ou natural do andar é aquela que o indivíduo atinge quando for instruído a andar o mais naturalmente 
possível (WINTER, 1991). Para adultos normais, a cadência média é de 113 passos/minuto (PERRY, 1992), ou 1,88 passos/s.

A duração dos períodos de apoio e de balanço é apresentada em relação à porcentagem do ciclo do andar (uma passada). Para cadência natural, a duração do período de apoio é de aproximadamente $60 \%$ enquanto que do período de balanço é de aproximadamente $40 \%$. Dentro do período de apoio, a duração do período de apoio duplo é de aproximadamente $20 \%$ do ciclo do andar, sendo $10 \%$ durante o apoio duplo inicial e 10\% durante o apoio duplo final (WHITTLE, 1996b). É importante notar que à medida que a velocidade do andar aumenta, a duração do período de apoio diminui e a do período de balanço aumenta (ANDRIACCHI, OGLE \& GALANTE, 1977; KIRTLEY, WHITTLE \& JEFFERSON, 1985).

O comprimento da passada, por outro lado, é a distância horizontal percorrida durante uma passada (WINTER, 1991). Essa distância, para adultos normais, é em média 1,41 metros (PERRY, 1992). Finalmente, a duração (em segundos) da passada pode ser definida pela razão entre o comprimento e a velocidade da passada. Conforme as informações apresentadas anteriormente, a duração da passada é em média 1,03 s.

Apesar da importância em se descrever as características temporais e espaciais do andar bípede, cabe mencionar que o andar não se resume apenas a estas características. Pelo contrário, tais características são decorrentes da combinação natural de vários fatores, tais como, mobilidade articular, controle neural, e força muscular (PERRY, 1992), o que torna o andar uma ação complexa. A abordagem que parece ser mais adequada para descrever a complexidade do andar vem do domínio da mecânica clássica, em que a biomecânica tem a maior responsabilidade para estabelecer o conhecimento científico relevante (CAPOZZO, 1984). Desta forma, análises cinemáticas, cinéticas e eletromiográficas podem ser utilizadas para descrever o andar bípede. Apesar do número de variáveis necessário para descrever esta forma de locomoção ser muito grande, a maioria dos estudiosos seleciona apenas algumas variáveis para descrevê-la (CRAIK, 1990). A seguir, algumas formas de análise do andar são apresentadas. 


\subsubsection{Formas para analisar o andar}

Antes de apresentar algumas das formas para analisar o andar, é importante mencionar algumas observações que são consideradas em tais análises. Padrões cíclicos dos movimentos do corpo são realizados durante o andar, passada após passada. Sendo assim, normalmente, os indivíduos são requisitados a andarem em um trecho pré-estabelecido (uma via reta de aproximadamente 10 metros de extensão) por várias ocasiões e apenas uma passada intermediária em cada ocasião é selecionada para análise, pois no início e no fim do referido trecho ocorrem as fases de aceleração e desaceleração do andar, respectivamente. Como os movimentos mais amplos ocorrem no plano sagital, esse plano é normalmente o mais enfatizado nas análises. Ainda, um valor médio de várias repetições realizadas por cada indivíduo é considerado para análise. Por exemplo, para verificar o padrão médio da passada de qualquer variável de interesse com referência a várias repetições (intra-sujeito) e/ou vários indivíduos (inter-sujeitos), é necessário calcular a média das curvas ao longo da passada. Para se obter essa média, e para qualquer variável de interesse, algumas etapas são necessárias. De acordo com WINTER (1991), essas etapas são:

(1) Determinação da duração do contato inicial até o próximo contato inicial (período da passada);

(2) Definição de cada período da passada como sendo $100 \%$ e divisão de intervalos iguais (por exemplo, $1 \%, 2 \%, 5 \%$ );

(3) Cálculo da média e do desvio padrão de cada variável investigada em cada intervalo;

(4) Representação gráfica da referida média e desvio padrão durante o período da passada;

(5) Cálculo da variabilidade média durante o período da passada, que pode ser expressa como uma porcentagem do valor médio do sinal. Geralmente, o coeficiente de variação (CV) é utilizado para representar a variabilidade média durante o período da passada. O CV é um valor único que permite comparar a porcentagem da variabilidade de várias repetições do andar (WINTER et al., 1990) em um único sujeito ou entre vários sujeitos. 
Dentre as várias análises possíveis utilizadas para investigar o andar, a análise cinemática é a análise mais utilizada para descrever tal movimento. Cinemática é considerada como uma área da biomecânica que estuda as posições, deslocamentos e acelerações do corpo ou dos segmentos corporais durante determinado movimento. No caso do andar, por meio da análise cinemática é possível descrever de maneira objetiva como os segmentos corporais se movimentam durante esta ação (PRINCE, CORRIVEAU, HÉBERT \& WINTER, 1997). Por meio desta análise, o movimento pode ser descrito em termos espaciais e temporais, com o auxílio de eletrogoniômetros, acelerômetros, filmagens ou equipamentos optoeletrônicos.

Para descrever os movimentos do corpo, os seus segmentos que são considerados corpos rígidos são geralmente definidos como pé, perna, coxa, pelve, braços, cabeça e tronco. As principais articulações entre os segmentos adjacentes incluem o tornozelo, joelho, quadril, cotovelo e ombro, sendo que na maioria das vezes, somente os movimentos dos segmentos inferiores são considerados na análise do andar. Provavelmente, isto ocorre pelo fato de que funcionalmente os membros inferiores são os responsáveis pelo deslocamento do corpo e os membros superiores são considerados como os passageiros, por serem carregados pelos membros inferiores (PERRY, 1992).

Normalmente, marcadores externos são afixados na superfície cutânea para definir a posição dos segmentos corporais. Ângulos articulares e ângulos segmentares são definidos a partir dos referidos marcadores. Enquanto que ângulos articulares se referem aos ângulos entre dois segmentos e são considerados ângulos relativos, ângulos segmentares se referem aos ângulos com relação à horizontal e são considerados ângulos absolutos (FIGURA 3).

O deslocamento do corpo pelo espaço é descrito como um movimento de translação, decorrente de deslocamentos angulares dos segmentos do corpo ao redor das articulações. Posto que os movimentos de translação são resultantes, entre outros fatores, dos deslocamentos angulares de cada segmento corporal e esses são discerníveis e mensuráveis, eles podem ser usados como um conjunto de parâmetros para a descrição da passada no andar (INMAN, RALSTON \& TODD, 1994). O padrão típico dos ângulos articulares que são observados em adultos 
normais está representado na FIGURA 4. É importante ressaltar que os valores absolutos desses ângulos podem variar entre diferentes indivíduos investigados e condições de medição. No entanto, o comportamento geral das séries temporais dos ângulos articulares, como os apresentados na FIGURA 4, tende a ser reprodutível, motivo pelo qual esse comportamento é referido como padrão.

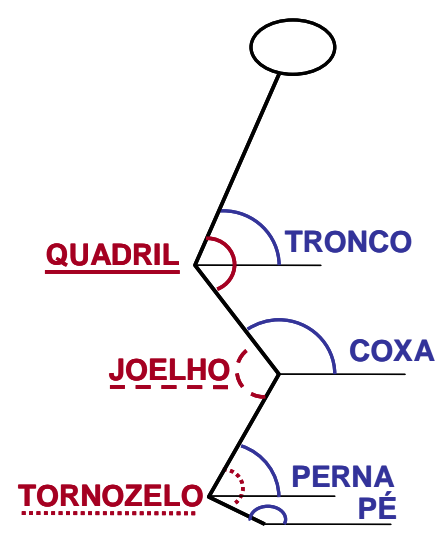

FIGURA 3 - Definições dos ângulos articulares (quadril, joelho e tornozelo) e segmentares (tronco, coxa, perna e pé) dos membros inferiores. Ângulos articulares são os ângulos entre os segmentos corporais adjacentes e ângulos segmentares são os ângulos relativos à horizontal.

Como pode ser observado na referida figura, o tornozelo inicia o ciclo do andar em posição neutra e, em seguida, estende (7 graus, aproximadamente), e ainda no período de apoio, realiza os movimentos de flexão (10 graus, aproximadamente) e extensão novamente (20 graus, aproximadamente). No período de balanço, esta articulação realiza o movimento de flexão até a posição neutra (FIGURA 4, porção superior). O joelho realiza movimentos de flexão e extensão, alternadamente, durante o ciclo do andar. No contato inicial, o joelho se encontra flexionado cerca de 5 graus, e a flexão máxima (65 graus, aproximadamente) ocorre no período de balanço (FIGURA 4, porção intermediária). O quadril inicia o ciclo do andar flexionado (30 graus, aproximadamente), realiza o movimento de extensão durante o período de apoio (por volta de $50 \%$ do ciclo) e ainda durante o mesmo 
período realiza o movimento de flexão até o final do ciclo (FIGURA 4, porção inferior) (PERRY, 1992). A partir das curvas que estão representadas na FIGURA 4, ângulo máximo, ângulo mínimo e amplitude de movimento articular podem ser calculados.
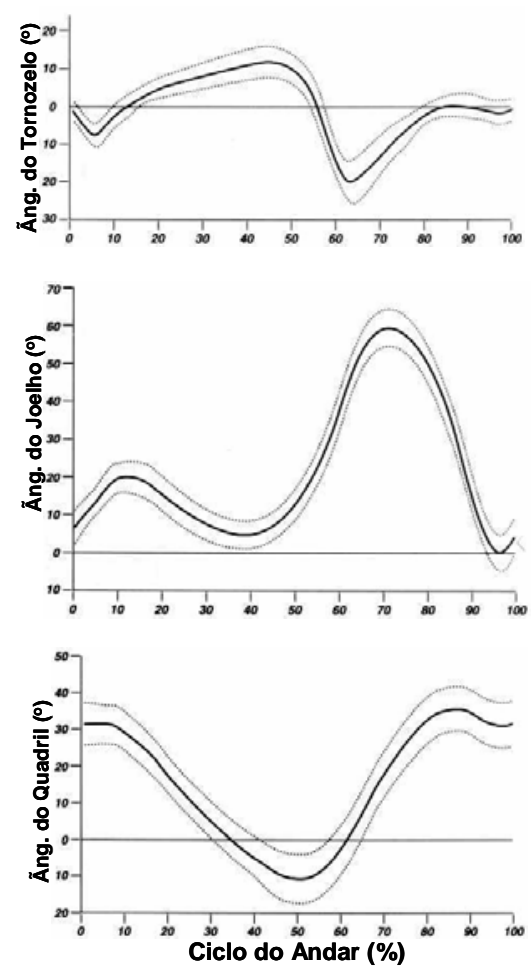

FIGURA 4 - Valores médios ( \pm desvio padrão) dos ângulos articulares (em graus) do quadril, joelho e tornozelo no plano sagital durante um ciclo do andar de indivíduo adulto em velocidade confortável auto-selecionada. Nota: valores positivos e negativos indicam movimentos de flexão e extensão, respectivamente (Adaptado de PERRY, 1992).

Com relação à análise cinética, o interesse é identificar o que causa o padrão de movimento verificado. As forças que atuam no corpo humano durante o andar podem ser divididas em duas categorias: forças externas, que representam todas as interações físicas entre o corpo e o ambiente (por exemplo, força da gravidade e força de reação do solo), e forças internas, que são forças musculares transmitidas pelos tecidos corporais, forças de tensão transmitidas pelos ligamentos e forças transmitidas através das áreas de contato articular (CAPOZZO, 1984). 
Uma das variáveis cinéticas mais comumente investigada na locomoção é a força de reação do solo (WHITTLE, 1996a), que é verificada com a utilização da plataforma de força. Com o auxílio da plataforma de força, as componentes das forças vertical e horizontal que atuam nos três eixos de movimento (longitudinal, médio-lateral e ântero-posterior) de sua superfície são obtidas (FIGURA 5). Normalmente, a força de reação do solo é positiva nos sentidos para cima, para frente e para a direita e essa convenção é adotada no presente estudo. Porém, de acordo com WHITTLE (1996b), não há um acordo geral sobre as convenções dos sinais.

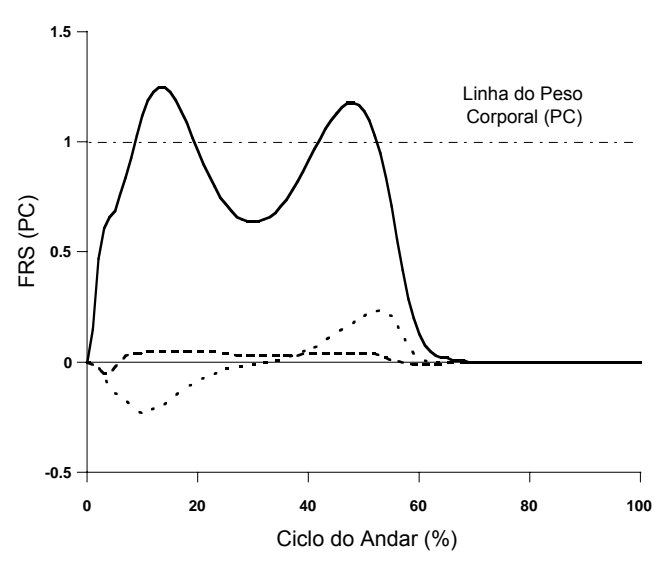

FIGURA 5 - Componentes da força de reação do solo (FRS) normalizadas pelo peso corporal (PC) durante um ciclo do andar. Linha contínua representa a componente vertical, linha pontilhada representa a componente ânteroposterior, e linha tracejada representa a componente médio-lateral da FRS. Dados referentes a adultos normais andando em velocidade confortável auto-selecionada.

A componente vertical da força de reação do solo (FRS), durante o período de apoio do andar, apresenta uma magnitude maior que as demais componentes, e é caracterizada por dois picos e um vale (FIGURA 5, linha contínua). Geralmente, esses dois picos apresentam uma magnitude um pouco maior que o peso corporal, dos quais o primeiro pico é observado durante a primeira metade do período de apoio e caracteriza parte do apoio quando a perna está recebendo o peso 
corporal, logo após o contato do pé com o solo (LARISH, MARTIN \& MUNGIOLE, 1988). O segundo pico é observado no final do período de apoio e representa o impulso contra o solo para iniciar o próximo passo (HAMILL \& KNUTZEN, 1999). O vale entre os dois picos é ligeiramente menor em magnitude que o peso corporal e ocorre quando o pé se encontra na posição plana em relação ao solo.

A componente horizontal ântero-posterior da FRS (FIGURA 5, linha pontilhada) apresenta uma fase negativa (desaceleração) durante a primeira metade do período de apoio e uma fase positiva (aceleração) durante a outra metade desse período. Na primeira metade do período de apoio, o pé empurra o solo para frente e, conseqüentemente, a força de reação da plataforma de força é direcionada para trás. $\mathrm{Na}$ segunda metade do período de apoio, o pé empurra o solo para trás e, conseqüentemente, a força de reação da plataforma de força é direcionada para frente. Sendo assim, a fase negativa representa uma diminuição da velocidade do corpo todo e a fase positiva representa uma aceleração do corpo à frente (WINTER, 1991). Os picos da força de cada uma dessas fases durante o andar equivalem aproximadamente a $15 \%$ da magnitude do peso corporal e quase que coincidem temporalmente com os dois picos da componente vertical da FRS (LARISH, MARTIN \& MUNGIOLE, 1988).

A componente horizontal médio-lateral da FRS (FIGURA 5, linha tracejada), por outro lado, apresenta magnitude muito pequena (WHITTLE, 1996b), e é inconsistente (HAMILL \& KNUTZEN, 1999), tanto intra- quanto inter-indivíduos (NIGG \& HERZOG, 2002), o que dificulta a sua interpretação. Para HAMILL e KNUTZEN (1999), a variabilidade observada nessa componente pode ser em virtude da diversidade no posicionamento do pé, que pode estar apontando para dentro (adução do pé) ou para fora (abdução do pé) durante o período de apoio.

Ainda com relação às componentes da FRS, há um pico nos primeiros instantes do período de apoio, nem sempre evidente no andar, que tem sido associado à força de impacto (NIGG \& HERZOG, 2002). Força de impacto na locomoção humana, segundo esses autores, é uma força que resulta da colisão entre dois corpos (no caso, o pé e o solo) e que atingem magnitude máxima antes de 50 ms após o contato inicial dos dois corpos. A magnitude do pico da força de impacto 
pode sofrer influências de vários fatores, entre eles, velocidade do andar e tipo de calçado (ou descalço).

A terceira e última análise apresentada e que auxilia na descrição do andar é a eletromiografia (EMG). EMG é um método utilizado para verificar o sinal elétrico do músculo ativo e para examinar, portanto, a função muscular por meio da análise desse sinal (BASMAJIAN \& DE LUCA, 1985). Por meio da EMG é possível analisar também os processos fisiológicos que geram a força e produzem movimento (DE LUCA, 1997). Provavelmente, EMG é a melhor forma para representar o sinal neurológico do músculo esquelético (WINTER, 1990), uma vez que informações sobre o sistema neuromuscular podem ser adquiridas a partir de investigações sobre a relação que existe entre os diferentes músculos (VAUGHAN, DAVIS \& O'CONNOR, 1999). Um aspecto de interesse, por exemplo, é verificar se os músculos estão atuando como agonistas ou antagonistas em determinado movimento.

É muito difícil interpretar os sinais EMG brutos e é impossível quantificar qualquer variabilidade desses sinais entre diferentes passadas (WINTER, 1991). Sendo assim, antes de quantificar qualquer sinal EMG, é necessário aplicar algum tratamento. Um tratamento comum consiste em retificar e filtrar esse sinal para se obter o envoltório linear e, posteriormente, normalizar o sinal. Normalmente, duas técnicas de processamento podem ser utilizadas em pesquisas biomecânicas: processamentos no domínio do tempo e no domínio de freqüências (CLARYS \& CABRI, 1993). Conforme os autores, a primeira técnica é utilizada quando o interesse é, por exemplo, em coordenação motora e magnitude de atividade EMG. Já a segunda técnica é apropriada para investigar, por exemplo, fadiga muscular (DE LUCA, 1997). No caso do andar, o envoltório linear parece ser a maneira mais viável para produzir um padrão dos sinais eletromiográficos (WINTER \& YACK, 1987). Esses sinais podem fornecer informações sobre quando ocorre a ativação muscular e qual o nível de ativação muscular durante o andar (CHUNG \& GIULIANI, 1997).

Em se tratando da normalização dos sinais EMG, há diferentes métodos disponíveis para normalizá-los durante 0 andar (BURDEN, TREW \& BALTZOPOULOS, 2003; YANG \& WINTER, 1984). Contudo, apesar de tal normalização ser feita com intuito de facilitar a comparação entre indivíduos e/ou 
entre diferentes condições, há algumas controvérsias sobre o método de normalização mais adequado (BURDEN, TREW \& BALTZOPOULOS, 2003; ROBERTSON, CALDWELL, HAMILL, KAMEN \& WHITTLESEY, 2004). Por exemplo, enquanto que DUBO, PEAT, WINTER, QUANBURY, HOBSON, STEINKE e REIMER (1976) salientaram que normalmente a magnitude do sinal EMG de interesse é normalizado pelo valor obtido durante a contração voluntária máxima isométrica (CVMI) de cada músculo investigado, ROBERTSON et al. (2004) salientaram que esse método pode não ser o mais apropriado para contrações dinâmicas, que é o caso do andar.

No entanto, entre os diferentes métodos que podem ser utilizados para normalizar o sinal EMG, BURDEN, TREW e BALTZOPOULOS (2003) destacaram que se o objetivo da normalização é para se obter um padrão geral da ativação muscular que possa ser comparado entre diferentes populações, o método que deve ser utilizado é o da média do sinal EMG, o qual reduz a variabilidade inter-sujeitos. A normalização pela média do sinal EMG é um método em que o valor médio desse sinal, ao longo do ciclo da passada, é calculado em diferentes intervalos (por exemplo, $1 \%, 2 \%, 5 \%$ ) entre a média de várias repetições de cada sujeito. Porém, como esse método diminui a variabilidade inter-sujeitos, a variação absoluta que pode existir no sinal EMG entre diferentes sujeitos é eliminada (BURDEN, TREW \& BALTZOPOULOS, 2003). Além disso, utilizando-se esse método, não é possível determinar qual é o grau de ativação muscular necessário durante a locomoção (BURDEN, TREW \& BALTZOPOULOS, 2003; YANG \& WINTER, 1984). De acordo com esses autores, se o objetivo da normalização é para determinar quão ativo determinado músculo está durante a locomoção, o método que deve ser utilizado é o da CVMI. A normalização pela CVMI é um método em que o valor do pico obtido durante a contração voluntária máxima isométrica do músculo investigado é calculado. Sendo assim, o método de normalização que deve ser utilizado depende do objetivo da análise do sinal EMG.

Em se tratando de padrão de ativação muscular durante o andar, um dos estudos que procurou determinar de maneira mais precisa o padrão de ativação de alguns músculos envolvidos no andar de indivíduos normais e de diferentes faixas etárias (entre oito e 72 anos de idade) foi o de DUBO et al. (1976). De maneira geral, 
esses autores verificaram que o músculo tibial anterior apresentava dois picos de ativação muscular, sendo o primeiro pico na transição entre o período de balanço e o período de apoio e o segundo pico na transição entre o período de apoio e o período de balanço; o músculo gastrocnêmio lateral apresentava um pico de ativação muscular durante a perda de contato dos dedos; o músculo bíceps femoral apresentava maior ativação muscular durante a desaceleração no período de balanço; e o músculo vasto lateral apresentava pico de ativação muscular na transição entre o período de balanço e o período de apoio. Sendo assim, a maior parte dos músculos que estão envolvidos no andar estão ativos no início ou no final dos períodos de apoio e de balanço, que são os períodos de aceleração e desaceleração das pernas (VAUGHAN, DAVIS \& O'CONNOR, 1999), quando o peso do corpo é transferido de um pé para outro. O músculo gastrocnêmio lateral está ativo durante o apoio médio, o que pode evitar o movimento de flexão excessiva da articulação do tornozelo em preparação para o avanço da perna à frente. Já o músculo tibial anterior, que está ativo durante o balanço médio, auxilia na flexão, evitando assim que os dedos se arrastem (VAUGHAN, DAVIS \& O'CONNOR, 1999). A FIGURA 6 ilustra o padrão de atividade EMG de alguns músculos envolvidos no andar.

Frente ao exposto até o momento, é possível perceber como é complexo analisar um movimento que aparentemente parece ser tão simples. Porém, como se não bastassem as diferentes formas para analisar o andar, juntamente com as inúmeras variáveis que podem ser consideradas nas mesmas, o padrão do andar é modificado ao longo da vida. O bebê, por exemplo, que na maioria dos casos começa a andar de forma independente por volta dos doze meses (FRANKENBURG, DODDS, ARCHER, SHAPIRO \& BRENSNICK, 1992), apresenta um padrão muito diferente de um adulto (SUTHERLAND, 1997). O adulto, por outro lado, pode apresentar um padrão de locomoção diferente do padrão de um indivíduo idoso. Ou ainda, pessoas que apresentam comprometimentos motores, sensoriais, neurais, apresentam padrão diferente de pessoas sem os mesmos comprometimentos. 0 próximo item aborda o andar de idosos que não apresentam qualquer distúrbio que possa interferir na forma de locomoção e que na maioria das vezes é comparado ao andar de indivíduos adultos. 

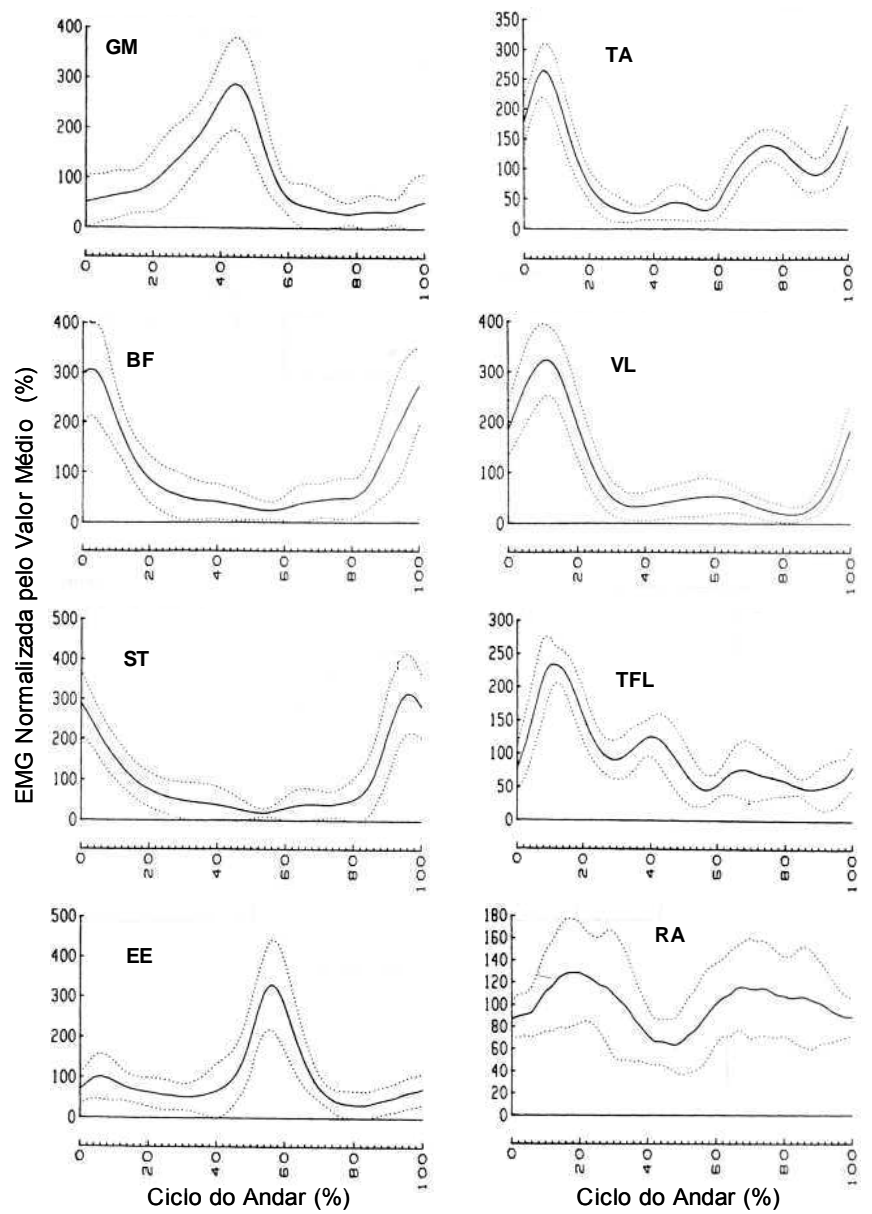

FIGURA 6 - Envoltórios lineares da atividade elétrica (EMG) dos músculos gastrocnêmio medial (GM), tibial anterior (TA), bíceps femoral (BF). vasto lateral (VL), semitendinoso (ST), tensor da fáscia látea (TFL), eretor espinhal (EE) e reto do abdome (RA) durante um ciclo do andar. Nota: linhas contínuas: valores médios; linhas pontilhadas: desvio padrão. (Adaptado de WINTER, 1991).

\section{$2.2 \quad 0$ andar dos idosos}

Ao se tratar de idosos, um primeiro aspecto que pode ser apresentado é com relação ao envelhecimento. O envelhecimento humano foi definido por SPIRDUSO (1995) como sendo o processo ou grupos de processos que ocorrem nos organismos vivos e que com o passar do tempo diminuem a probabilidade de sobrevivência. O envelhecimento é um processo inevitável e irreversível e, portanto, 
é diferente de doenças e distúrbios, que podem ser evitados, ter causas externas e ser curados ou aliviados (SCHULZ \& SALTHOUSE, 1999).

Alguns estudos apontam que com o envelhecimento, o sistema músculoesquelético apresenta um tempo de resposta voluntário mais lento e mais variável (BENTON, 1977), menor força muscular (LARSSON, GRIMBY \& KARLSSON, 1979), diminuição na amplitude de movimento (WALKER, SUE, MILES-ELKOUSY, FORD \& TREVELYAN, 1984), entre outras alterações. O andar humano, como salientado anteriormente, é uma ação complexa que requer controle de vários elementos. Sendo assim, o andar pode estar sujeito também à alteração quando um ou mais componentes do sistema locomotor têm sua função alterada (CRAIK, 1990). Por exemplo, uma redução na amplitude de movimento da articulação do quadril pode estar associada a uma diminuição do comprimento da passada do andar dos idosos (KERRIGAN, LEE, COLLINS, RILEY \& LIPSITZ, 2001).

Dentre os vários estudos que investigaram aspectos biomecânicos referentes à população de idosos, os estudos que trataram de locomoção ocupam lugar de destaque. Um dos motivos para esse fato é, justamente, porque a mobilidade independente é um fator importante para maior autonomia dos idosos. Normalmente, o foco principal dos estudos que trataram do andar desses indivíduos está relacionado às mudanças de padrão do andar e ao aumento no número de quedas. Segundo WINTER (1991), é importante documentar as mudanças que ocorrem no andar dos idosos, uma vez que as mesmas podem estar relacionadas com as causas das quedas observadas nessa população.

Em se tratando de mudanças de padrão do andar, a descoberta mais consistente e que se constata na maioria dos estudos que investigaram o andar de idosos é que a velocidade do andar diminui com o avançar da idade (FERRANDEZ, PAILHOUS \& DURUP, 1990; HIMANN et al., 1988; LAJOIE, TEASDALE, BARD \& FLEURY, 1996; RILEY, DELLA CROCE \& KERRIGAN, 2001a; RILEY, DELLA CROCE \& KERRIGAN, 2001b). Há várias explicações que tentam justificar o porquê da diminuição da velocidade do andar dos idosos. Entre elas, podem ser mencionadas que a velocidade mais lenta, selecionada livremente e adotada pelos idosos, seria decorrente da diminuição na força muscular (NIGG, FISHER \& RONSKY, 1994), seria uma conseqüência da redução na extensão máxima da 
articulação do quadril (RILEY, DELLA CROCE \& KERRIGAN, 2001a), ou proporcionaria menor gasto energético (LARISH, MARTIN \& MUNGIOLE, 1988).

De qualquer forma, quando os idosos são solicitados a andar mais rapidamente, eles são capazes de aumentar a velocidade do andar sem dificuldade (FERRANDEZ, PAILHOUS \& DURUP, 1990; FERRANDEZ, DURUP \& FARIOLI, 1996; NIGG, FISHER \& RONSKY, 1994). É bem provável que os idosos sejam mais precavidos na realização do andar para se adaptarem às possíveis alterações estruturais e funcionais que são decorrentes do processo de envelhecimento. Sendo assim, a diminuição da velocidade do andar da população de idosos não deve ser considerada como algo prejudicial e sim como forma de garantia da estabilidade (FERRANDEZ, DURUP \& FARIOLI, 1996; LARISH, MARTIN \& MUNGIOLE, 1988; WINTER et al., 1990) ou como forma de adaptação às mudanças neuromusculares e músculo-esqueléticas decorrentes da idade (FERRANDEZ, PAILHOUS \& DURUP, 1990; LAJOIE et al., 1996; RILEY, DELLA CROCE \& KERRIGAN, 2001a).

Há alguns aspectos que podem ser considerados com relação à velocidade do andar de indivíduos adultos e idosos. Ao solicitar que indivíduos desses dois grupos andassem em velocidade confortável auto-selecionada, os indivíduos adultos andaram mais rapidamente que os idosos e apresentaram diferenças no comprimento da passada (FERRANDEZ, PAILHOUS \& DURUP, 1990; LAJOIE et al., 1996; RILEY, DELLA CROCE \& KERRIGAN, 2001a). Mais especificamente, LAJOIE et al. (1990) encontraram diferenças entre os grupos no que se referia ao comprimento da passada (1,50 m para adultos e 1,25 m para idosos) e à velocidade da passada (1,39 m/s para adultos e 1,10 m/s para idosos), e RILEY, DELLA CROCE e KERRIGAN (2001a) e FERRANDEZ, PAILHOUS e DURUP (1990), ao verificarem que os idosos andavam mais lentamente que os indivíduos adultos, atribuíram esta diferença à diminuição no comprimento da passada. Ao contrário de FERRANDEZ et al. (1990), RILEY et al. (2001a) e LAJOIE et al. (1996), HIMANN et al. (1988) instruíram idosos e adultos a andarem em três velocidades auto-selecionadas diferentes (lenta, normal e rápida) e verificaram que os indivíduos adultos andaram mais rapidamente que os idosos nas três velocidades. HIMANN et al (1988) sugeriram que a escolha da velocidade do andar foi em função 
da freqüência e do comprimento da passada que poderiam ser adotados pelos indivíduos.

Enquanto que os estudos citados anteriormente sugeriram que a diminuição da velocidade do andar, com o aumento da idade, seria decorrente das mudanças em parâmetros espaciais (comprimento da passada) e temporais (freqüência), há outros estudos que atribuíram a diminuição da velocidade, com o aumento da idade, a alterações no padrão do movimento (ANDRIACCHI, OGLE \& GALANTE, 1977; FERRANDEZ, DURUP \& FARIOLI, 1996; KERRIGAN, TODD, DELLA CROCE, LIPSITZ \& COLLINS, 1998; MILLS \& BARRETT, 2001; NIGG, FISHER \& RONSKY, 1994). Em outras palavras, ao invés de considerar a velocidade como conseqüência das mudanças de padrão do andar, a velocidade foi considerada como causa das mudanças de padrão do andar.

É bem provável que as mudanças na velocidade do andar gerem mudanças no padrão geral do movimento (ANDRIACCHI, OGLE \& GALANTE, 1977). Entre essas mudanças, algumas variáveis que estão relacionadas com essa forma de locomoção podem ser mencionadas. É o caso da duração do período de apoio duplo que aumenta e o comprimento da passada que diminui à medida que a velocidade diminui (FERRANDEZ, DURUP \& FARIOLI, 1996). Porém, quando a velocidade do andar é a mesma para os dois grupos, o que acontece? MILLS e BARRETT (1997), ao analisarem o período de balanço durante o andar de adultos e idosos, não encontraram diferença na velocidade do andar entre os dois grupos e, conseqüentemente, não encontraram diferenças em vários parâmetros investigados, tais como ângulos e velocidades articulares.

Além das variáveis mencionadas anteriormente que podem ser alteradas conforme a mudança na velocidade, variáveis eletromiográficas durante o andar também podem ser consideradas. CHUNG e GIULIANI (1997) verificaram a variabilidade entre vários ciclos do andar de idosos. Entre os aspectos investigados, padrões temporais dos sinais eletromiográficos foram verificados conforme a velocidade do andar: preferido, rápido e lento. Esses estudiosos verificaram que os idosos apresentaram maior variabilidade nos padrões dos sinais eletromiográficos entre os ciclos do andar quando andaram mais lentamente do que quando andaram 
naturalmente ou mais rapidamente. Sendo assim, parece que os padrões dos sinais eletromiográficos também são influenciados pela alteração na velocidade do andar.

Frente às informações apresentadas, parece que a velocidade é um fator importante e que deve ser considerado quando se analisa o andar. Principalmente o andar de idosos, uma vez que esses indivíduos preferem andar mais lentamente e que cada vez mais aderem à caminhada como uma forma de praticar atividade física. Em se tratando de atividade física, um ambiente que pode ser utilizado para a prática da caminhada é o ambiente aquático. A seguir, alguns aspectos desse ambiente são apresentados.

\section{$2.3 \quad 0$ ambiente aquático}

O ambiente aquático é cada vez mais utilizado para a prática de atividade física, treinamento e reabilitação. Porém, há poucos estudos detalhados sobre as vantagens, desvantagens e precauções referentes à prática de atividade física neste ambiente (BATES \& HANSON, 1996; HARRISON, HILLMAN \& BUSTRODE, 1992; SKINNER \& THOMSON, 1985). Um dos principais fatores para a escassez de estudos sobre atividade física no ambiente aquático pode estar relacionado às dificuldades encontradas para adaptar os equipamentos necessários para a aquisição de dados na água. Uma vez que o ambiente aquático é utilizado no presente estudo, algumas propriedades e alguns estudos referentes a esse ambiente são apresentados.

Quando um corpo se encontra imerso na água, esse corpo percebe uma pressão que a água exerce sobre ele. Tal pressão é definida como uma força que atua perpendicularmente em cada ponto da superfície desse corpo dividida pela área dessa superfície. A maneira como a pressão é transmitida em um fluido (no caso, a água) é enunciada pelo princípio de Pascal. De acordo com esse princípio, a pressão aplicada a um fluido confinado em um recipiente é transmitida sem qualquer alteração a todos os pontos do fluido e às paredes do recipiente. Sendo assim, se a pressão dentro de uma piscina for alterada pela ação de uma pessoa que simplesmente movimenta a mão em um de seus cantos, o aumento de pressão será o mesmo em todos os pontos da água da piscina. Ainda, a pressão aumenta conforme a profundidade aumenta. Portanto, para sustentar o peso de uma pessoa 
parada na posição vertical na água, a pressão sob a extremidade inferior (base) dessa pessoa é maior do que na extremidade superior (ápice).

Diferentemente do ambiente terrestre, no ambiente aquático, além da pressão há também a força empuxo que atua sobre o corpo imerso e parado na água. A força empuxo, é uma força com a mesma direção que a força peso (produto da massa de um corpo pela ação da gravidade), mas com sentido contrário, e é enunciada como o princípio de Arquimedes. Conforme esse princípio, um corpo que está parcial ou totalmente submerso na água experimentará uma força de empuxo para cima que é igual ao peso do volume de água deslocado por esse corpo (KREIGHBAUM \& BARTHELS, 1996). Essas autoras apresentam uma outra maneira de expressar o conceito de empuxo: se a densidade de um corpo imerso for igual ou menor que a densidade da água, o corpo irá flutuar, e se a densidade for maior, ele irá afundar. A densidade mede quanto de massa de um corpo há por unidade de volume (massa/volume). A força empuxo é a conseqüência da pressão do fluido ser maior na base do que no ápice de um corpo (TIPLER, 2000).

De acordo com a definição da força empuxo, pode-se afirmar que a força total que atua sobre um corpo parado e imerso na água é a diferença entre o peso desse corpo e o empuxo. O resultado dessa diferença é o peso corporal aparente, não sendo, portanto, correto dizer que o peso do corpo diminui quando imerso na água. Na verdade, o que diminui é o peso corporal aparente. Por exemplo, as porcentagens de imersão do corpo humano na água na altura da crista ilíaca, do processo xifóide do esterno e da sétima vértebra cervical $(C 7)$ são respectivamente $57 \%, 71 \%$ e $85 \%$ (HARRISON, HILLMAN \& BUSTRODE, 1992). De acordo com esses autores, a redução do peso aparente do corpo imerso na altura da crista ilíaca, do processo xifóide e da C7 corresponde a $75-100 \%, 50-75 \%$ e $0-25 \%$ do peso corporal, respectivamente.

Além da pressão e do empuxo, quando um corpo ou seus segmentos se movimentam imersos no meio líquido, há forças que interferem nos movimentos desse corpo. Essas forças são forças de arrasto, que atuam na mesma direção do movimento, mas com sentido contrário, o que proporciona resistência ao movimento; e forças de propulsão, que atuam na mesma direção e no mesmo sentido do 
movimento, o que facilita o movimento. A força de arrasto depende da densidade da água, da área frontal e da velocidade do corpo em movimento.

No caso do andar em ambiente aquático, as forças de arrasto são as forças que mais se destacam, uma vez que quando o corpo se movimenta na água, os movimentos são resistidos pela água. Dessa forma, é importante destacar que quanto mais submerso o corpo estiver na água, maior é a força de arrasto sobre ele. Um outro aspecto importante referente à força de arrasto é sua relação com a velocidade do movimento. Essa velocidade é o fator que mais interfere na força de arrasto. Sendo assim, ao se duplicar a velocidade de locomoção na água, por exemplo, se quadruplica a força de arrasto (KREIGHBAUM \& BARTHELS, 1996).

Por causa das forças presentes no ambiente aquático, algumas vantagens e desvantagens podem ser encontradas durante a prática de atividade física dentro da água. A força empuxo se opõe à força da gravidade e reduz o peso corporal aparente (como já mencionado anteriormente). Conseqüentemente, há diminuição das forças de compressão nas articulações (SHELDAHL, 1986), e os movimentos podem ser realizados mais livremente na água do que na terra (WHITE, 1995). Em contrapartida, a força de arrasto proporciona resistência ao movimento, dificultando-o e podendo reduzir a sua velocidade. Em compensação, tal resistência pode propiciar fortalecimento muscular, e tempo maior para execução dos movimentos. Ainda, ao se movimentar contra a resistência da água, o ambiente aquático é alterado constantemente, o que pode melhorar a capacidade de manutenção do equilíbrio.

No caso dos idosos, o medo de quedas pode limitar seus movimentos. Nesse sentido, o ambiente aquático pode ser considerado um ambiente seguro para a prática de atividade física para esta população, pois possibilita que os movimentos sejam realizados mais amplamente e sem o risco de lesão decorrente das quedas (SIMMONS \& HANSEN, 1996).

\subsubsection{0 andar no ambiente aquático}

Andar na água pode ser uma forma de praticar atividade física e de intervenção muito comum na hidroterapia. Vários estudos trataram de aspectos que relacionam os efeitos da prática de atividade física na pressão arterial (MCMURRAY, FIESELMAN \& AVERY, 1988; RISCH, KOUBENEC, BECKMANN, LANGE \& 
GAUER, 1978), no ritmo cardíaco (BUTTS, TUCKER \& GREENING, 1991), no gasto energético (GLEIN \& NICHOLAS, 1989), entre outros. No que se refere aos aspectos relacionados à análise do movimento em si, há estudos que foram realizados, apesar das dificuldades encontradas na adaptação dos equipamentos na água para aquisição de dados. No entanto, cabe ressaltar que os estudos que analisaram o andar na água limitaram-se a um tipo de descrição em particular sobre cinemática (DEGANI \& BARELA, 2001; GEHM, BECKER, MARTINEZ \& LOSS, 2003; MCMURRAY, FIESELMAN \& AVERY, 1988; YAMAMOTO, NAKAZAWA \& YANO, 1995), força de reação do solo (NAKAZAWA, YANO \& MYASHITA, 1994; YAMAMOTO, NAKAZAWA \& YANO, 1995), atividade elétrica de alguns músculos dos membros inferiores (ERVILHA, DUARTE \& AMADIO, 2002; YANO, NAKAZAWA \& YAMAMOTO, 1995), ou até mesmo uma análise envolvendo todos os aspectos já mencionados e momentos articulares, mas apenas durante o período de apoio do andar (MIYOSHI et al., 2004). Tais aspectos referentes à realização do andar no ambiente aquático são apresentados na seqüência.

Com relação aos aspectos temporais e espaciais do andar, diferenças foram encontradas entre os ambientes terrestre e aquático. Sendo assim, a velocidade adotada para andar no ambiente aquático é mais lenta do que a velocidade adotada para andar no ambiente terrestre (DEGANI \& BARELA, 2001; GEHM et al., 2003; MIYOSHI et al., 2004). Tal diferença encontrada entre os dois ambientes foi observada para diferentes faixas etárias e níveis de imersão do corpo na água. E mesmo quando se solicitou aos executantes que andassem mais lentamente ou mais rapidamente, a velocidade foi menor no ambiente aquático do que no ambiente terrestre (MIYOSHI et al., 2004).

A duração do período de apoio é maior no ambiente aquático (GEHM et al., 2003), mas não é diferente entre diferentes níveis de imersão (BECKER, GEHM, MARTINEZ \& LOSS, 2003) para os adultos. Porém, para idosos, não há diferença na duração deste período entre os ambientes aquático e terrestre (DEGANI \& BARELA, 2001). Da mesma forma que o período de apoio, a duração do período de balanço foi maior no ambiente aquático do que no terrestre para os adultos (GEHM et al., 2003), porém não se alterou frente a diferentes profundidades (BECKER et al., 2003), e foi a mesma entre os dois ambientes para os idosos (DEGANI \& BARELA, 2001). 
Informações sobre duração e cadência da passada no ambiente aquático foram verificadas somente para idosos (DEGANI \& BARELA, 2001). Segundo esses estudiosos, a duração da passada é maior e a cadência é menor quando os idosos andam no ambiente aquático do que quando andam no ambiente terrestre. Já com relação ao comprimento da passada, GEHN et al. (2003) verificaram que esse foi maior no ambiente aquático do que no terrestre para os adultos, e DEGANI e BARELA (2001) verificaram que foi menor no ambiente aquático do que no ambiente terrestre para os idosos. Quando se comparou o comprimento da passada no ambiente aquático em diferentes profundidades, nenhuma diferença foi encontrada (BECKER et al., 2003).

Em se tratando de movimento articular, o padrão e a amplitude de movimento foram investigados, e mais uma vez, diferenças foram encontradas entre - andar nos ambientes terrestre e aquático para a maioria das articulações investigadas (DEGANI \& BARELA, 2001; YAMAMOTO, NAKAZAWA \& YANO, 1995). O padrão de movimento das articulações do joelho e tornozelo, no período de apoio, de adultos andando em velocidades auto-selecionadas confortável ou rápida (YAMAMOTO, NAKAZAWA \& YANO, 1995) foi diferente na água em relação à terra. Já a articulação do quadril, de acordo com os mesmos estudiosos, não apresentou qualquer diferença entre os dois ambientes. YAMAMOTO, NAKAZAWA e YANO (1995) salientaram que as diferenças constatadas foram observadas principalmente durante o contato inicial do pé com a superfície. Sendo assim, a articulação do joelho apresentou maior flexão e a do tornozelo apresentou maior flexão quando se andou na água do que quando se andou fora da água. O mesmo resultado foi encontrado para idosos com relação à articulação do joelho (DEGANI \& BARELA, 2001).

A amplitude de movimento da articulação do tornozelo foi observada durante o período de apoio (YAMAMOTO, NAKAZAWA \& YANO, 1995), no início do período de balanço (GEHM et al., 2003) do andar de adultos e durante o ciclo completo do andar de idosos (DEGANI \& BARELA, 2001). Enquanto que para os adultos a amplitude de movimento desta articulação foi maior no ambiente aquático, independentemente do período considerado, para os idosos, esta amplitude foi menor nesse ambiente durante todo o ciclo. Para as articulações do joelho e quadril, a amplitude de movimento foi maior no ambiente aquático do que no ambiente 
terrestre para o andar dos adultos na velocidade confortável e rápida apenas (YAMAMOTO, NAKAZAWA \& YANO, 1995).

Em se tratando das componentes da força de reação do solo, a componente vertical foi a mais investigada até o momento (BRITO, ROESLER, HAUPENTHAL \& SOUZA, 2004; MIYOSHI et al., 2004; NAKAZAWA, YANO \& MYASHITA, 1994; YAMAMOTO, NAKAZAWA \& YANO, 1995). O que se constatou foi que a magnitude dessa componente foi menor durante o andar na água do que na terra (MIYOSHI et al., 2004; YAMAMOTO, NAKAZAWA \& YANO, 1995), e que diminuiu conforme se aumentou o nível de imersão do corpo na água (BRITO et al., 2004; NAKAZAWA, YANO \& MYASHITA, 1994). A força de impacto foi menor quando se andou no ambiente aquático do que no ambiente terrestre (YAMAMOTO, NAKAZAWA \& YANO, 1995) da mesma forma que o peso corporal aparente também diminuiu no ambiente aquático e de acordo com o nível de imersão do corpo na água (BRITO et al., 2004; NAKAZAWA, YANO \& MYASHITA, 1994).

Com relação ao padrão da atividade eletromiográfica (EMG) muscular durante o andar nos ambientes aquático e terrestre, diferenças em alguns músculos investigados foram constatadas. Enquanto que os músculos vasto lateral, bíceps femoral e tibial anterior apresentaram padrões diferentes entre os dois ambientes, 0 músculo gastrocnêmio lateral não apresentou diferença (ERVILHA, DUARTE \& AMADIO, 2002). Enquanto que no ambiente terrestre o músculo sóleo foi considerado o músculo principal pela extensão, no ambiente aquático o músculo gastrocnêmio medial passou a ser o músculo principal para essa ação (YANO, NAKAZAWA \& YAMAMOTO, 1995).

Ainda com relação à atividade EMG, alguns músculos foram investigados durante $O$ andar no ambiente aquático (ERVILHA, DUARTE \& AMADIO, 2002; MIYOSHI, SATOH, NAKAZAWA, KOMEDA \& YANO, 2000; MIYOSHI et al., 2004; YANO, NAKAZAWA \& YAMAMOTO, 1995). Dentre esses músculos, durante o período de apoio do andar, o músculo gastrocnêmio medial (MIYOSHI et al., 2004; YANO, NAKAZAWA \& YAMAMOTO, 1995), o músculo tibial anterior (YANO, NAKAZAWA \& YAMAMOTO, 1995) e o músculo bíceps femoral (MIYOSHI et al., 2004) aumentaram a magnitude da atividade EMG com o aumento da velocidade do andar no ambiente aquático, enquanto que o músculo sóleo diminuiu esta magnitude 
nas mesmas condições (YANO, NAKAZAWA \& YAMAMOTO, 1995). Por outro lado, o músculo bíceps femoral apresentou maior magnitude de atividade EMG no ambiente aquático do que no ambiente terrestre e não houve diferença nessa magnitude nos músculos tibial anterior e reto femoral entre os ambientes aquático e terrestre (MIYOSHI et al., 2004).

Como pode ser notado, nenhum estudo envolvendo uma análise mais detalhada durante o ciclo completo do andar no ambiente aquático foi realizado ainda. Embora esse ambiente seja muito utilizado para a prática de atividades físicas e reabilitação, há poucas informações disponíveis sobre os aspectos biomecânicos que evidenciam as alterações que esse ambiente possa provocar em movimentos complexos como o andar. Em se tratando da população de idosos, a limitação é ainda maior. Estudos que buscam identificar as alterações que ocorrem no andar com o avançar da idade devem ser realizados, uma vez que a mobilidade independente é imprescindível para a autonomia dos idosos. É importante ressaltar que a expectativa de vida tem aumentado e já é grande o número de idosos em nossa sociedade. Até o momento, não há constatações sobre possíveis diferenças no padrão do andar entre adultos e idosos, por exemplo, quando as duas populações andam na água.

Além disso, um conhecimento mais aprofundado sobre o andar de adultos e idosos, que não apresentam qualquer comprometimento no sistema locomotor, em ambiente aquático, é de grande importância para verificar as possíveis alterações que esse ambiente possa provocar no sistema locomotor, antes de estabelecer um programa de treinamento ou reabilitação para indivíduos que necessitem de cuidados especiais. Sendo assim, uma descrição mais completa e uma análise mais detalhada do andar no ambiente aquático são necessárias. A seguir, os objetivos do presente estudo são apresentados.

\section{OBJETIVOS}

\subsection{Objetivo geral}

O objetivo geral do presente estudo foi analisar aspectos biomecânicos de indivíduos adultos e idosos, sem queixas de comprometimento no aparelho 
locomotor, andando no ambiente terrestre e no ambiente aquático, com a água no nível do processo xifóide do esterno.

\subsection{Objetivos específicos}

Mais especificamente, os objetivos deste estudo foram:

- Analisar as séries temporais e a variabilidade das mesmas durante o ciclo do andar de adultos e idosos nos ambientes terrestre e aquático referentes a:

- Os ângulos articulares do tornozelo, joelho e quadril;

- As componentes vertical e horizontal ântero-posterior da força de reação do solo (FRS);

- A atividade eletromiográfica (EMG) dos músculos gastrocnêmio medial, tibial anterior, bíceps femoral (cabeças curta e longa), vasto lateral, tensor da fáscia látea, eretor espinhal e reto do abdome.

- Investigar características espaciais, temporais e cinemáticas durante o ciclo do andar;

- Investigar as magnitudes do primeiro e segundo picos da componente vertical da FRS, da força de impacto e do impulso horizontal;

- Investigar a magnitude da atividade EMG dos músculos selecionados.

\section{$4 \quad$ MÉTODOS}

\subsection{Participantes}

Para a seleção dos participantes deste estudo, alguns critérios de inclusão e de exclusão foram estabelecidos. Os critérios de inclusão foram: idade, entre 20 e 40 anos para os adultos e entre 60 e 80 anos para os idosos (BRASIL, Lei N. ${ }^{\circ}$ 10.741); estado de saúde, que foi avaliado com base nas respostas à anamnese elaborada para estudos conduzidos no Laboratório de Biofísica, da Escola de Educação Física e Esporte, Universidade de São Paulo (EEFE-USP) (WIECZOREK, 2003) (ANEXO I); ser voluntário; e não ter medo de entrar na piscina. O critério de exclusão foi qualquer queixa de comprometimento músculo-esquelético, cardiovascular, sensorial e/ou motor, que pudesse comprometer a forma de 
locomoção dos adultos e idosos, que também foi avaliado com base nas respostas à referida anamnese.

Sendo assim, inicialmente 24 voluntários divididos em dois grupos de 12 adultos e 12 idosos participaram do presente estudo. No entanto, por motivos técnicos, 10 adultos (seis do gênero masculino e quatro do gênero feminino), com idade entre 21 e 38 anos, e 10 idosos (seis do gênero masculino e quatro do gênero feminino), com idade entre 60 e 77 anos, participaram do estudo e foram considerados nas análises. A média ( \pm 1 desvio padrão) da idade, massa corporal e estatura foi, respectivamente, 28,5 \pm 6,2 anos, 63,1 $\pm 10,2 \mathrm{~kg}$ e 164,8 \pm 8,0 cm para os adultos, e $70,4 \pm 6,5$ anos, $64,7 \pm 12,8 \mathrm{~kg}$ e $160,0 \pm 9,2 \mathrm{~cm}$ para os idosos. A maioria dos adultos era estudante universitário nos cursos de Bacharelado em Educação Física e Esporte da EEFE-USP ou com graduação em Educação Física, e os idosos eram praticantes de atividade física no Centro de Prática Desportiva da USP e/ou programa de educação física para idosos há pelo menos um ano. A TABELA 1 apresenta o tipo de atividade física e a freqüência de prática de cada um dos idosos.

TABELA 1 - Informações sobre tipo de atividade física e freqüência de prática (número de vezes por semana) dos participantes idosos. Nota: Educação física se refere às aulas do programa de Educação Física para Idosos oferecidas na EEFE-USP (mais detalhes sobre essas aulas no ANEXO II).

\begin{tabular}{cccll}
\hline Idoso & Gênero & Idade & Tipo de atividade física praticada & $\begin{array}{c}\text { Freqüência de } \\
\text { prática }\end{array}$ \\
\hline 1 & M & 65 & Educação física; hidroginástica; yoga & 2 cada \\
2 & M & 76 & Caminhada; educação física & $3 ; 2$ \\
3 & F & 60 & Caminhada; educação física & $3 ; 2$ \\
4 & M & 77 & Caminhada; educação física; yoga & 2 cada \\
5 & F & 74 & Educação física; hidroginástica & 2 cada \\
6 & M & 65 & Educação física & 2 \\
7 & F & 77 & Educação física & 4 \\
8 & F & 71 & Dança; hidroginástica & $1 ; 2$ \\
9 & M & 63 & Caminhada; educação física & Diariamente; 2 \\
10 & M & 76 & Alongamento; educação física; & $4 ; 2 ; 2$ \\
& & & saltos em altura e distância & \\
\hline
\end{tabular}




\subsection{Procedimentos}

Os participantes vieram às dependências da EEFE-USP e a aquisição de dados foi feita primeiramente no Laboratório de Biofísica e, em seguida, em uma piscina semi-olímpica, coberta e aquecida. Antes de se iniciar tal aquisição, todos os participantes foram informados sobre os objetivos e procedimentos do experimento, que foram aprovados pelo Comitê de Ética da EEFE-USP (ANEXO III), e assinaram um termo de consentimento (ANEXO IV).

A FIGURA 7 ilustra uma representação do arranjo experimental para a aquisição de dados no ambiente terrestre. Um tapete de borracha $(6 \mathrm{~m} \times 0,60 \mathrm{~m} \times$, $0,15 \mathrm{~cm}$, comprimento, largura e espessura, respectivamente) foi colocado sobre o chão do laboratório e formou uma passarela. Uma plataforma de força (AMTI, modelo OR62000) estava embutida na região central dessa passarela, sob o tapete de borracha para a aquisição dos dados referentes às componentes vertical e horizontais da força de reação do solo. Duas câmeras digitais (JVC, modelo DVR9800U) foram posicionadas em uma mesma lateral do laboratório para filmar o lado direito dos participantes e adquirir os dados cinemáticos dos segmentos inferiores direitos do corpo.

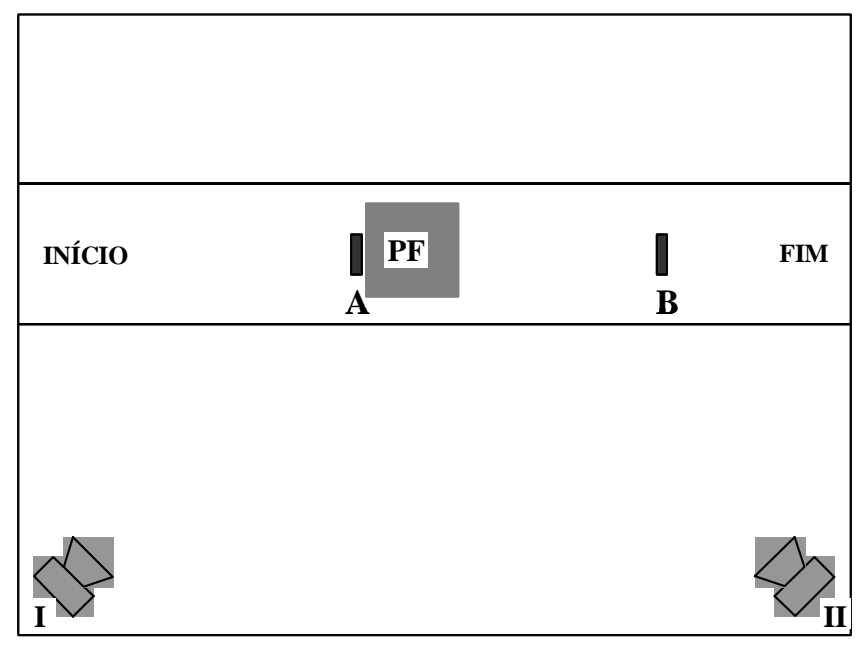

FIGURA 7 - Representação esquemática do arranjo experimental para a aquisição de dados no ambiente terrestre, indicando início e fim do percurso, 0 posicionamento da plataforma de força (PF), das câmeras (I e II), e do trecho considerado para análise da passada (A e B). 
$\mathrm{Na}$ água, uma passarela $(5 \mathrm{~m} \times 0,90 \mathrm{~m}$, comprimento e largura, respectivamente) foi construída de modo que ficasse nivelada com a superfície de locomoção e uma plataforma de força à prova d'água (AMTI, modelo OR6WP) foi embutida nessa passarela, (FIGURA 8). Essa passarela foi feita com a utilização de plataformas redutoras de profundidade (Aquática Slade Confecções Ltda), revestidas com um tapete de borracha antiderrapante $(0,5 \mathrm{~cm}$ de espessura), que foram encaixadas entre si. Como a piscina utilizada possui profundidade variada, a sua inclinação foi medida, e os pés de cada plataforma foram cortados de acordo com essa inclinação para que a passarela não ficasse inclinada. A passarela foi posicionada perpendicularmente ao comprimento da piscina e foi ajustada para cada participante para que o nível da água ficasse na altura do processo xifóide do esterno de cada um. Uma câmera digital (JVC, modelo DVR9800U) foi posicionada no plano sagital, dentro de um invólucro à prova d’água (Ikelite, modelo JVC9800 Digital), para aquisição dos dados cinemáticos dos segmentos inferiores direito do corpo.

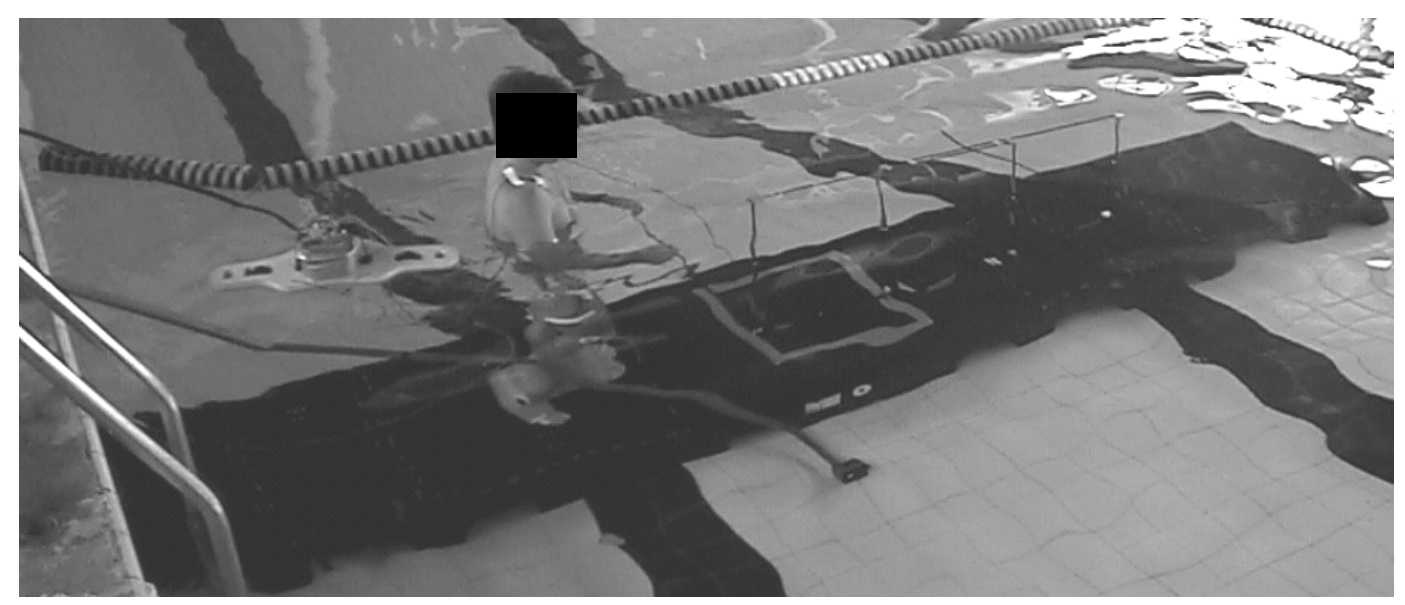

FIGURA 8 - Ilustração parcial do arranjo experimental para a aquisição de dados no ambiente aquático, com a plataforma de força embutida na região central da passarela redutora de profundidade.

Os participantes vestiram roupa de banho para a realização da tarefa nas duas condições experimentais (ambientes terrestre e aquático). Inicialmente, medidas referentes à massa corporal, estatura e altura do processo xifóide do 
esterno foram adquiridas. Essa última medida foi utilizada como informação para posicionar a passarela na piscina. Como apenas o lado direito foi investigado no presente estudo, todo o procedimento para preparação dos participantes está centrado para os segmentos inferiores direitos do corpo e porção inferior direita do tronco. Os participantes foram solicitados a se deitarem sobre uma maca, primeiramente em decúbito dorsal e posteriormente em decúbito ventral, para que fossem preparados para a aquisição de dados.

Para registro da atividade eletromiográfica, oito músculos relacionados aos movimentos das articulações do tornozelo, joelho e quadril foram selecionados para serem investigados no presente estudo: tibial anterior (flexão do tornozelo), gastrocnêmio medial (extensão do tornozelo), cabeça curta do bíceps femoral (flexão do joelho), vasto lateral (extensão do joelho), cabeças longa do bíceps femoral (extensão do quadril), tensor da fáscia látea (flexão do quadril), reto do abdome (flexão do tronco) e eretor espinhal (nível da primeira vértebra lombar, L1) (extensão do tronco), e eletrodos superficiais foram afixados no ventre de cada músculo no sentido das fibras musculares, como sugerido nas normas do projeto SENIAM (surface EMG for a non-invasive assessment of muscles) (FRERIKS \& HERMENS, 1999). Ainda com relação aos eletrodos, eram todos bipolares, auto-adesivos e descartáveis $\mathrm{Ag} / \mathrm{AgCl}$, com $1 \mathrm{~cm}$ de diâmetro e espaço de $2 \mathrm{~cm}$ de centro a centro (dual electrode \#272, Noraxon). Um eletrodo monopolar de referência auto-adesivo e descartável $\mathrm{Ag} / \mathrm{AgCl}$, com $1 \mathrm{~cm}$ de diâmetro (Kendal, Meditrace 200) foi afixado no processo espinhoso da sétima vértebra cervical. A região muscular em que cada eletrodo foi afixado foi depilada e limpa com gaze embebida em álcool. Todos os eletrodos foram conectados por cabos a uma unidade transmissora que pré-amplifica e transmite sinais gerados pela ativação da musculatura por ondas de rádio ao receptor (Telemyo 900, Noraxon). Os eletrodos e cabos adjacentes a eles foram isolados cuidadosamente do meio aquático com uma proteção (dimensões, $10 \times 12$ $\mathrm{cm}^{2}$ ) transparente e auto-adesiva (Tegaderm, 3M). Os segmentos do corpo próximos à região em que os eletrodos e cabos se encontravam foram envoltos levemente por faixas elásticas para evitar movimento dos cabos durante a realização da tarefa, uma vez que a movimentação desses cabos poderia favorecer entrada de água nos eletrodos e produzir ruído no sinal EMG. Os sinais EMG foram registrados por meio 
de um sistema telemétrico de oito canais (Telemyo 900, Noraxon), com ganho de 1000 vezes, largura de banda $(-3 \mathrm{~dB})$ de 10 a $500 \mathrm{~Hz}$ e taxa de rejeição de modo comum > $85 \mathrm{~dB}$. Sendo assim, nenhum participante foi submetido a potenciais elétricos, não havendo, portanto, qualquer risco de choque elétrico. Os sinais analógicos foram convertidos por uma placa de aquisição de 12 bits (Computer Boards, Inc., modelo PCM-DAS16/330). Esses sinais foram armazenados em um computador para processamento posterior. Nas aquisições feitas no ambiente terrestre, os participantes carregaram a unidade transmissora do sistema EMG em uma mochila de tecido, e no ambiente aquático, essa unidade flutuava dentro de um container à prova d'água posicionada atrás dos participantes.

Para registro dos dados cinemáticos, marcadores circulares de couro sintético branco (5 cm de diâmetro) com centro preto $(1 \mathrm{~cm}$ de diâmetro) foram afixados com fita adesiva apropriada sobre os seguintes pontos anatômicos: quinto metatarso e maléolo lateral, epicôndilo lateral, trocanter maior e na porção lateral do tronco (altura da quinta vértebra lombar). Para a aquisição dos mesmos dados no ambiente terrestre, marcadores refletivos esféricos (1 $\mathrm{cm}$ de diâmetro) foram afixados sobre os de tecido sintético. Após a aquisição nesse ambiente, os marcadores refletivos foram removidos, permanecendo apenas os de couro sintético, que foram utilizados na aquisição de dados no ambiente aquático. Tal procedimento foi adotado para garantir que as mesmas posições dos pontos anatômicos fossem registradas nos dois ambientes.

A freqüência de aquisição das filmagens foi de $60 \mathrm{~Hz}$ e dos sinais da plataforma de força e dos sinais EMG foi de $1000 \mathrm{~Hz}$. As filmagens, os sinais da plataforma de força e os sinais EMG foram sincronizados via um gatilho, acionado manualmente pela experimentadora, que emitia simultaneamente um sinal luminoso para as câmeras e um sinal elétrico para o computador. A aquisição dos sinais da plataforma de força e eletromiográficos foi realizada com a utilização do programa Ariel Performance Analysis System - APAS (Ariel Dynamics, Inc.).

Após a preparação dos participantes, eles iniciaram a tarefa, de se desolocar andando com velocidade confortável auto-selecionada, primeiro no laboratório e depois na piscina com a água no nível do processo xifóide do esterno. $\mathrm{A}$ escolha dessa velocidade foi feita com intuito de eliminar qualquer possível alteração 
de padrão do andar decorrente de uma velocidade pré-determinada pelo experimentador, uma vez que a velocidade do andar pode provocar alterações, como salientado na seção da revisão de literatura.

Antes de iniciar a aquisição de dados em cada uma das condições, os participantes realizaram quantas tentativas práticas julgassem necessárias para que se familiarizassem com a tarefa. Durante estas tentativas práticas, a posição inicial de cada participante na passarela foi definida, de modo que o primeiro contato do pé direito fosse sobre a plataforma de força. Como a plataforma de força estava sob um tapete de borracha, os participantes não estavam cientes de sua existência. O tempo para familiarização não foi diferente entre os adultos e idosos, porém, todos levaram mais tempo para se familiarizarem com o ambiente aquático. Dez repetições de cada participante foram adquiridas em cada ambiente (terrestre e aquático), portanto, os participantes tiveram que andar 10 vezes do início ao final de cada passarela.

Ao término das repetições no ambiente terrestre, cada participante se deitou novamente na maca e um teste muscular manual foi realizado. Uma contração voluntária máxima isométrica (CVMI) durante três segundos foi realizada utilizando esse teste e, novamente, as posições específicas para testar cada músculo investigado estavam de acordo com as normas do programa SENIAM (FRERIKS \& HERMENS, 1999). Os dados da CVMI foram utilizados posteriormente para normalizar os dados EMG obtidos durante as repetições nos dois ambientes.

Ainda, após a aquisição das repetições em cada ambiente, uma aquisição em que o participante permaneceu parado na posição ereta sobre a plataforma de força durante 15 segundos foi realizada. Essa aquisição foi utilizada posteriormente para medir e comparar o peso corporal e o peso corporal aparente dos participantes entre os ambientes terrestre e aquático, respectivamente, e para obter a posição dos marcadores colocados nos pontos anatômicos para calcular os ângulos articulares na posição neutra.

A duração total do experimento para cada participante foi de aproximadamente duas horas e, durante esse período, houve intervalos entre as repetições e/ou ambientes sempre que necessário. 


\subsection{Tratamento dos dados}

\subsubsection{Dados da filmagem}

Após a realização de todas as aquisições de dados, um ciclo intermediário de cada repetição de cada participante e em cada ambiente foi selecionado. Primeiramente, as filmagens realizadas nos dois ambientes foram transferidas para um computador para serem tratadas posteriormente. Em seguida, trechos da filmagem que continham imagens referentes a instantes que correspondiam ao primeiro e ao segundo contatos iniciais do mesmo pé (uma passada) e imagens da aquisição em que os participantes permaneceram parados sobre a plataforma de força (posição neutra) foram selecionados em cada repetição do andar, nos dois ambientes, com a utilização do programa APAS. As repetições em que o participante não iniciava a passada tocando a plataforma de força com o pé direito foram descartadas.

Na seqüência, os marcadores posicionados sobre os pontos anatômicos dos segmentos inferiores e do tronco das aquisições selecionadas foram digitalizados com a utilização do programa APAS. Os dados referentes a esses marcadores digitalizados foram transformados e filtrados com o filtro Butterworth de $4^{\text {a }}$ ordem, passa-baixa de $10 \mathrm{~Hz}$ e atraso de fase zero, com a utilização do programa Matlab 6.5 (Mathworks, Inc.). O procedimento para a transformação das coordenadas reais dos dados adquiridos foi o da transformação linear direta (DLT, direct linear transformation), e teve que ser diferente entre os dois ambientes devido à refração da água (KWON, 1999) no ambiente aquático. Dessa forma, o procedimento DLT para os dados referentes ao ambiente terrestre utilizou um sistema de referência com 15 pontos de controle e volume de 2,0 x 2,0 x 0,5 $\mathrm{m}^{3}$ (comprimento, altura e profundidade, respectivamente), e para o ambiente aquático utilizou um sistema de referência bi-dimensional com 24 pontos de controle e área de $1,5 \times 1 \mathrm{~m}^{2}$ (comprimento e altura, respectivamente). Para o caso bidimensional, o procedimento DLT adaptado foi implementado para procurar pelos quatro pontos de controle mais próximos de cada marcador digitalizado em cada instante.

Os dados cinemáticos foram calculados para obtenção das variáveis descritivas e angulares (ver mais adiante). Os dados angulares foram normalizados temporalmente de 0 a $100 \%$ com intervalos de $1 \%$. A amplitude dos ângulos foi 
subtraída pelos respectivos ângulos dos participantes na posição neutra. As médias e os desvios padrão das curvas dos ângulos articulares durante cada passada de todas as repetições consideradas para análise de cada participante e em cada ambiente foram calculados.

\subsubsection{Dados da plataforma de força}

Os dados adquiridos por meio da plataforma de força foram arquivados em planilhas, de modo que cada arquivo armazenasse dados das componentes da força de reação do solo (FRS) de cada repetição, de cada participante e em cada ambiente. Com a utilização do programa Matlab 6.5, esses dados foram filtrados com o filtro Butterworth de $4^{\mathrm{a}}$ ordem e com um filtro passa-baixa de $30 \mathrm{~Hz}$ e atraso de fase zero.

Em seguida, os dados das componentes da FRS foram normalizados temporalmente de 0 a $100 \%$ com intervalos de 1\%. A magnitude da FRS foi normalizada pelo peso corporal (ambiente terrestre) e pelo peso corporal aparente (ambiente aquático) de cada participante a partir das aquisições da posição neutra. As médias e os desvios padrão das curvas das componentes vertical e horizontal ântero-posterior durante cada passada de todas as repetições consideradas para análise de cada participante e em cada ambiente foram calculados.

\subsubsection{Dados eletromiográficos}

Da mesma forma que os dados da plataforma de força foram arquivados em planilhas, os dados eletromiográficos também o foram, de modo que cada arquivo armazenasse dados da atividade EMG dos músculos investigados de cada repetição, de cada participante e em cada ambiente. Esses dados foram filtrados com o filtro Butterworth de $4^{\text {a }}$ ordem e com um filtro passa-banda de $20-400 \mathrm{~Hz}$ e atraso de fase zero. Ainda, esses dados foram retificados e, subseqüentemente, filtrados novamente com um filtro passa-baixa de $5 \mathrm{~Hz}$ e atraso de fase zero, para se obter o envoltório linear.

Posteriormente, os dados eletromiográficos foram normalizados temporalmente de 0 a $100 \%$ com intervalos de 1\%. A magnitude dos dados EMG também foi normalizada utilizando-se dois métodos distintos: método da média do 
sinal EMG, para obter o padrão geral de ativação muscular, e o método da contração voluntária máxima isométrica (CVMI), para obter o nível de ativação de cada músculo em cada grupo e em cada ambiente. Todo o processamento dos dados eletromiográficos foi realizado com a utilização do programa Matlab 6.5. As médias e os desvios padrão das curvas da atividade EMG de cada músculo selecionado durante cada passada de todas as repetições consideradas para análise de cada participante e em cada ambiente foram calculados.

Apesar de não ter sido possível analisar as 10 aquisições realizadas em cada ambiente para todos os participantes (principalmente no ambiente aquático) devido a algum tipo de problema técnico, pelo menos oito aquisições foram consideradas para cada participante em cada condição. Posteriormente, os valores médios das aquisições consideradas para análise foram considerados no tratamento estatístico.

\subsubsection{Variáveis dependentes}

As variáveis dependentes foram agrupadas em variáveis descritivas, variáveis angulares, variáveis cinéticas e variáveis eletromiográficas. Sendo assim, comprimento, duração, velocidade e cadência da passada e duração da fase de apoio durante o ciclo do andar são as variáveis descritivas consideradas no presente estudo; amplitude de movimento articular do tornozelo, joelho e quadril, durante os períodos de apoio e balanço e durante o ciclo do andar, e ângulos das mesmas articulações, nas fases de contato inicial e balanço inicial, são consideradas as variáveis angulares; redução do peso aparente no ambiente aquático, o padrão das curvas das componentes vertical e horizontal ântero-posterior da FRS, magnitudes do primeiro e do segundo picos da componente vertical da FRS, da força de impacto e o impulso, durante o período de apoio do andar são consideradas as variáveis cinéticas; e o padrão das curvas e magnitude da atividade EMG são consideradas as variáveis eletromiográficas. A seguir, o modo como cada uma destas variáveis foi calculada é apresentado.

Com relação às variáveis descritivas, o comprimento e a duração da passada foram calculados a partir da coordenada na direção horizontal $(X)$ da marca posicionada no maléolo lateral, sendo a distância entre o primeiro contato do pé na 
plataforma de força e o segundo contato do mesmo pé na passarela. A velocidade da passada foi calculada a partir da razão entre o comprimento e a duração da passada, e a cadência da passada foi calculada a partir da razão entre um e a duração (em segundos) da passada. Finalmente, a duração da fase de apoio foi calculada a partir dos dados referentes à componente vertical da FRS entre o contato inicial e o contato final do pé na plataforma de força.

Em se tratando das variáveis cinemáticas, o padrão das curvas dos ângulos articulares do tornozelo, joelho e quadril foi analisado qualitativamente para os adultos e idosos nos dois ambientes. A diferença entre os valores máximo e mínimo dessas curvas, durante os períodos de apoio e de balanço e durante o ciclo completo do andar foi calculada para cada uma das articulações, e o resultado foi a amplitude de movimento articular das mesmas em cada período e durante o ciclo completo; o ângulo das articulações do tornozelo, joelho e quadril foi calculado durante a fase de contato inicial (primeiro instante em que o pé tocou a plataforma de força) e durante a fase de balanço inicial (primeiro instante que o pé perdeu o contato com a plataforma de força).

No que se refere às variáveis cinéticas, o peso corporal (ambiente terrestre) e o peso corporal aparente (ambiente aquático) de cada participante foram calculados a partir dos dados adquiridos com a plataforma de força, e a redução do peso corporal aparente foi calculada. O padrão das curvas das componentes vertical e horizontal ântero-posterior da força de reação do solo foi analisado qualitativamente para os adultos e idosos nos dois ambientes, e a magnitude do primeiro e do segundo picos da componente vertical da força de reação do solo foi calculada com base nos valores máximos do sinal dessa componente na primeira e na segunda metades do período de apoio, respectivamente. Uma estimativa da força de impacto foi feita a partir da inclinação da reta da componente vertical da força de reação do solo (ajuste por mínimos quadrados) no intervalo referente aos primeiros 100 ms em função do tempo. Ainda, a partir da componente horizontal ânteroposterior da força de reação do solo, o impulso foi calculado como a área da curva da força pelo tempo de apoio.

Com relação às variáveis eletromiográficas, o padrão das curvas da atividade EMG de cada músculo selecionado foi analisado qualitativamente para os 
adultos e idosos nos dois ambientes. Ainda, o pico de atividade eletromiográfica de cada músculo durante os períodos de apoio e de balanço foi calculado, o que determinou a magnitude da atividade eletromiográfica.

Finalmente, o coeficiente de variação (CV) foi utilizado para verificar a variabilidade dos grupos e ambientes. Sendo assim, os dados cinemáticos, cinéticos e eletromiográficos foram analisados como médias das séries temporais de cada ciclo da passada de todas as tentativas realizadas por cada participante em cada ambiente. A seguinte equação foi utilizada para calcular o CV:

$$
C V=\frac{\sqrt{\frac{1}{N} \sum_{i=1}^{N} \sigma_{i}^{2}}}{\frac{1}{N} \sum_{i=1}^{N}\left|X_{i}\right|}
$$

onde, $N$ é o número de dados (instantes) no ciclo médio do andar, $X_{i}$ é o valor médio da variável no instante em consideração, e $\sigma_{i}$ é o desvio padrão da variável $X$ em $X_{i}$.

\subsection{Tratamento estatístico}

A primeira fase do tratamento estatístico constou de análise descritiva (medidas de tendência central e variabilidade). Primeiramente, testes para verificar a normalidade da distribuição dos dados (teste de Shapiro-Wilk) e a homogeneidade das variâncias (teste de Levene) foram realizados. Com exceção dos dados referentes à magnitude da atividade EMG que não apresentou distribuição normal, mas apresentou homogeneidade das variâncias, todas as demais variáveis apresentaram distribuição normal e homogeneidade das variâncias. Transformação logarítmica foi empregada nos dados referente à amplitude da atividade EMG, e após essa transformação ambos pressupostos foram atendidos.

Para comparar as variáveis descritivas, angulares, referentes à magnitude da componente vertical da FRS, magnitude de atividade EMG e coeficiente de variabilidade das séries temporais nos dois ambientes (terrestre e aquático) com relação aos dois grupos (adultos e idosos), 16 análises de variâncias múltiplas (MANOVAs) 2x2 foram utilizadas, em que o fator ambiente foi considerado como medida repetida. A primeira MANOVA teve como variáveis dependentes: comprimento, duração, velocidade e cadência da passada e duração do período de 
apoio. A segunda MANOVA teve como variáveis dependentes: amplitude de movimento das articulações do tornozelo, joelho e quadril durante o período de apoio. A terceira MANOVA teve como variáveis dependentes: amplitude de movimento das mesmas articulações durante o período de balanço. A quarta MANOVA teve como variáveis dependentes: amplitude de movimento das mesmas articulações durante o ciclo completo do andar. A quinta MANOVA teve como variáveis dependentes: ângulo das articulações do tornozelo, joelho e quadril na fase de contato inicial. A sexta MANOVA teve como variáveis dependentes: ângulo das mesmas articulações na fase de balanço inicial. A sétima MANOVA teve como variáveis dependentes: magnitudes do primeiro pico e do segundo pico da componente vertical da FRS e força de impacto. A oitava MANOVA teve como variáveis dependentes: magnitude de atividade EMG dos músculos gastrocnêmio medial e tibial anterior durante os períodos de apoio e de balanço. A nona MANOVA teve como variáveis dependentes: magnitude de atividade EMG dos músculos bíceps femoral (cabeça curta) e vasto lateral durante os períodos de apoio e de balanço. A décima MANOVA teve como variáveis dependentes: magnitude de atividade EMG dos músculos bíceps femoral (cabeça longa) e tensor da fáscia látea durante os períodos de apoio e de balanço. A décima primeira MANOVA teve como variáveis dependentes: magnitude de atividade EMG do músculo eretor espinhal durante os períodos de apoio e de balanço. A décima segunda MANOVA teve como variáveis dependentes: coeficiente de variabilidade das séries temporais dos ângulos do tornozelo, joelho e quadril. A décima terceira MANOVA teve como variáveis dependentes: coeficiente de variabilidade das séries temporais das componentes vertical e horizontal antero-posterior. A décima quarta MANOVA teve como variáveis dependentes: coeficiente de variabilidade das séries temporais da atividade EMG dos músculos gastrocnêmio medial e tibial anterior. A décima quinta MANOVA teve como variáveis dependentes: coeficiente de variabilidade das séries temporais da atividade EMG dos músculos bíceps femoral (cabeça curta) e vasto lateral. A décima sexta MANOVA teve como variáveis dependentes: coeficiente de variabilidade das séries temporais da atividade EMG dos músculos bíceps femoral (cabeça longa) e tensor da fáscia látea. Em todas essas análises, análises univariadas foram realizados quando necessário. 
Para comparar as variáveis peso corporal (peso corporal aparente para o ambiente aquático), impulso e coeficiente de variabilidade da série temporal da atividade EMG do músculo eretor espinhal nos dois ambientes (terrestre e aquático) referentes aos dois grupos (adultos e idosos), três análises de variâncias (ANOVAs) $2 \times 2$ foram utilizadas, em que o fator ambiente foi considerado como medida repetida. Essas ANOVAs tiveram como variável dependente, o peso corporal (peso corporal aparente para o ambiente aquático), impulso e coeficiente de variabilidade, respectivamente. Para comparar a redução do peso corporal aparente entre os grupos, ANOVA com um fator foi realizada.

Quando análises univariadas indicaram diferença para interação entre grupo e ambiente, testes post hoc de Tukey para comparações pareadas (HINKLE, WIERSMA \& JURS, 1994) foram utilizados para verificar diferenças entre os grupos e ambientes. Em todas as análises, o nível de significância foi mantido em 0,05 e o programa SPSS 10.0 (SPSS, Inc.) foi utilizado para o tratamento estatístico.

5

\section{RESULTADOS}

Todos os participantes foram capazes de andar no ambiente terrestre (AT) e no ambiente aquático (AA) com a água no nível do processo xifóide do esterno nas velocidades confortáveis e auto-selecionadas para cada condição ambiental. Ainda, os grupos constituídos por adultos e idosos não apresentaram diferenças nas medidas antropométricas estatura e massa corporal. Sendo assim, ANOVA não apontou qualquer diferença entre os adultos e os idosos com relação à estatura, $F(1,18)=1,55, p>0,05$, e à massa corporal, $F(1,18)=0,97, p>0,05$.

Com intuito de facilitar a interpretação dos resultados, esses foram agrupados de acordo com as variáveis dependentes analisadas. Dessa forma, quatro grupos de variáveis são apresentados: 1) variáveis descritivas: comprimento, duração, velocidade e cadência da passada, e duração do período de apoio; 2) variáveis angulares: padrão dos ângulos articulares do tornozelo, joelho e quadril e o coeficiente de variação desses ângulos durante o ciclo do andar, amplitude de movimento articular do tornozelo, joelho e quadril durante os períodos de apoio e de balanço e durante o ciclo do andar, e ângulos dessas articulações nas fases de contato inicial e de balanço inicial; 3) variáveis cinéticas: padrão das componentes 
vertical e horizontal ântero-posterior da força de reação do solo e o coeficiente de variação durante o ciclo do andar dessas componentes, redução do peso corporal aparente, magnitude do primeiro e do segundo picos da componente vertical da força de reação do solo, força de impacto e impulso horizontal; e 4) variáveis eletromiográficas: padrão da atividade elétrica (EMG) dos músculos gastrocnêmio medial, tibial anterior, bíceps femoral (cabeças curta e longa), vasto lateral, tensor da fáscia látea, eretor espinhal e reto do abdome, e o coeficiente de variação para a maioria desses músculos (exceto o músculo reto do abdome) durante o ciclo do andar, e magnitude da atividade EMG dos mesmos músculos nos períodos de apoio e balanço. Os valores das médias e dos desvios padrão (D.P.) dos dois grupos nos dois ambientes são representados nas respectivas FIGURAS no decorrer da apresentação dos resultados de cada variável, e os valores médios de cada participante são apresentados nas TABELAS que se encontram nos APÊNDICES. Finalmente, os resultados dos testes post hoc de Tukey são apresentados nas TABELAS que se encontram no ANEXO V.

\subsection{Variáveis descritivas}

A FIGURA 9 apresenta os valores médios (D.P.) do comprimento, duração, velocidade e cadência da passada, e duração do período de apoio para os dois grupos (adultos e idosos) nos dois ambientes (AT e AA). Para essas variáveis, MANOVA apontou diferença entre os grupos, Wilks' Lambda=0,31, $F(5,14)=6,15$, $p<0,005$, entre os ambientes, Wilks' Lambda=0,01, $F(5,15)=252,53, p<0,001$, e interação entre grupos e ambientes, Wilks' Lambda=0,32, $F(5,14)=5,92, p<0,005$. Análises univariadas para os grupos apontaram diferença para comprimento, $F(1,18)=17,33, p<0,005$, duração, $F(1,18)=5,72, p<0,05$, e velocidade da passada, $F(1,18)=7,40, p<0,05$, e para duração do período de apoio, $F(1,18)=6,84, p<0,05$. Análises univariadas para os ambientes apontaram diferença para comprimento, $F(1,18)=16,26, \quad p<0,005$, duração, $\quad F(1,18)=608,75, \quad p<0,001$, velocidade, $F(1,18)=476,11, p<0,001$, e cadência da passada, $F(1,18)=1447,61, p<0,001$. Finalmente, análises univariadas para interação entre grupos e ambientes apontaram diferença para duração, $F(1,18)=17,74, p<0,005$, velocidade, $F(1,18)=6,30, p<0,05$, e cadência da passada, $F(1,18)=19,38, p<0,001$. 


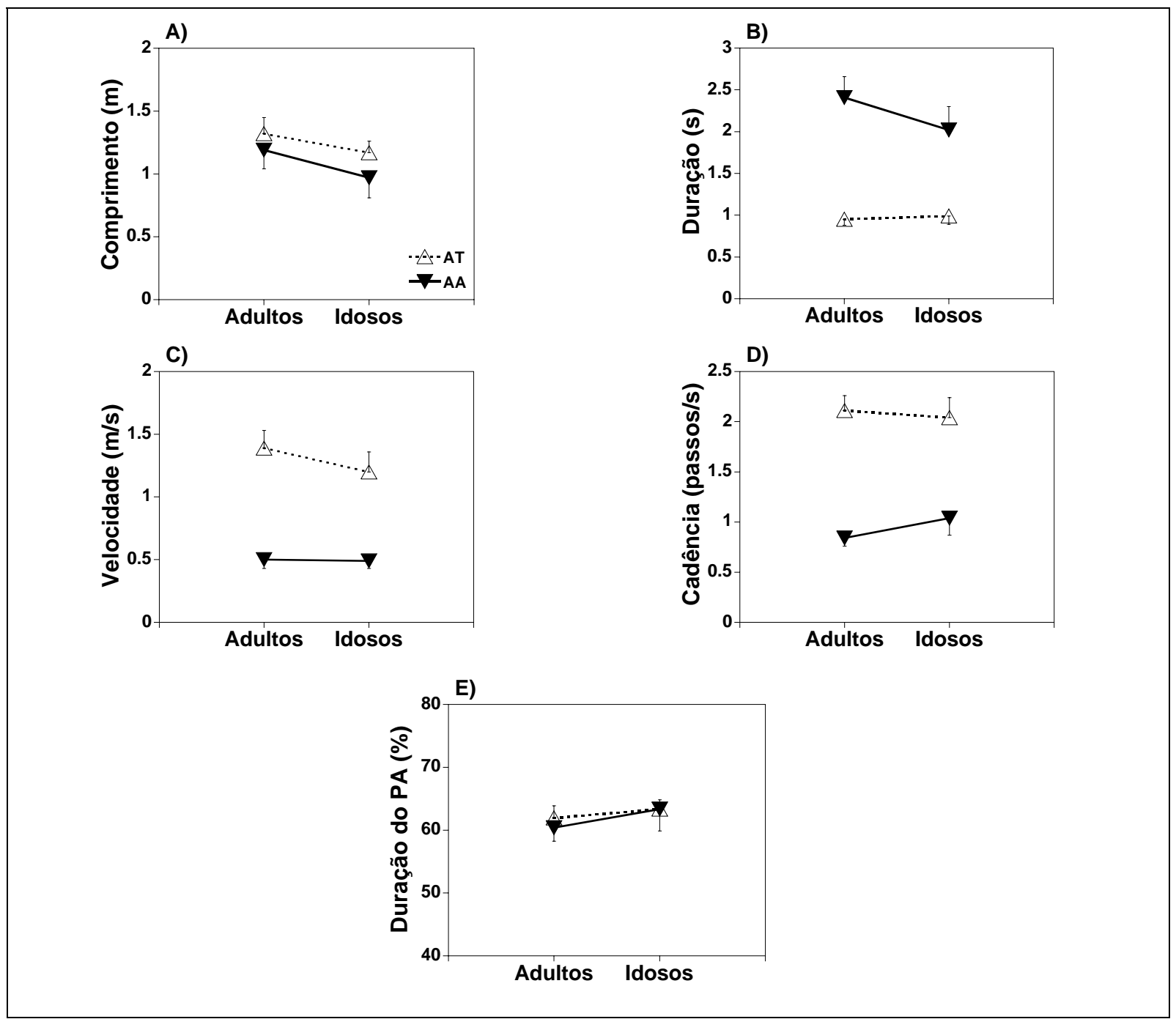

FIGURA 9 - Valores médios (D.P.) das variáveis descritivas: comprimento (A), duração (B), velocidade (C) e cadência (D) da passada, e duração do período de apoio (PA) (E) durante o ciclo completo do andar dos adultos e idosos nos ambientes terrestre (AT) e aquático (AA).

Os adultos apresentaram comprimento da passada maior que os idosos e os dois grupos apresentaram comprimento da passada maior no AT do que no AA (FIGURA 9-A). Com relação à duração da passada, os adultos e os idosos levaram um tempo menor para andar no AT do que para andar no AA. Ainda com relação à duração da passada, testes post hoc indicaram que enquanto não houve diferença 
na duração da passada entre adultos e idosos no AT, os adultos apresentaram duração da passada maior que os idosos no AA (FIGURA 9-B).

Em se tratando da velocidade da passada, os adultos e os idosos andaram mais rapidamente no AT do que no AA. Ainda, testes post hoc apontaram que enquanto os adultos andaram mais rapidamente que os idosos no $A T$, os dois grupos andaram na mesma velocidade no AA (FIGURA 9-C).

Com relação à cadência da passada, os adultos e os idosos apresentaram cadência maior no AT do que no AA. Testes post hoc indicaram que enquanto os adultos e os idosos apresentaram a mesma cadência da passada no AT, os adultos apresentaram cadência menor que os idosos no AA (FIGURA 9-D). Finalmente, com relação à duração do período de apoio, os adultos apresentaram duração desse período menor que os idosos nos dois ambientes (FIGURA 9-E).

\subsection{Variáveis angulares}

A FIGURA 10 apresenta os valores médios ( \pm D.P.) das curvas referentes aos ângulos articulares do tornozelo, joelho e quadril durante o ciclo completo dos adultos (coluna à esquerda) e dos idosos (coluna à direita) andando no AT e no AA. Qualitativamente, os adultos e os idosos apresentaram padrões similares para as três articulações nos dois ambientes durante o período de balanço. Porém, o mesmo não foi observado durante o período de apoio. Durante esse período, a articulação do tornozelo dos adultos e dos idosos estava em flexão no AT e praticamente na posição neutra no AA na fase de contato inicial, e permaneceu mais em flexão no AT do que no AA durante todo o período (FIGURA 10, porção superior). Com relação ao comportamento do joelho, essa articulação dos adultos estava mais flexionada no AT do que no $A A$, na primeira metade do período de apoio e foi similar durante a segunda metade desse período. Por outro lado, a articulação do joelho dos idosos apresentou padrão diferente entre os ambientes somente na fase de contato inicial, quando o joelho estava na posição neutra no AT e flexionado no AA (FIGURA 10, porção intermediária), e foi similar durante o período de apoio remanescente. Por fim, a articulação do quadril dos adultos e dos idosos, na fase de contato inicial, estava flexionada nos dois ambientes. No entanto, essa articulação flexionou inicialmente e 
depois estendeu no AT, e apenas estendeu no AA. Isso foi observado para os dois grupos durante o período de apoio (FIGURA 10, porção inferior).

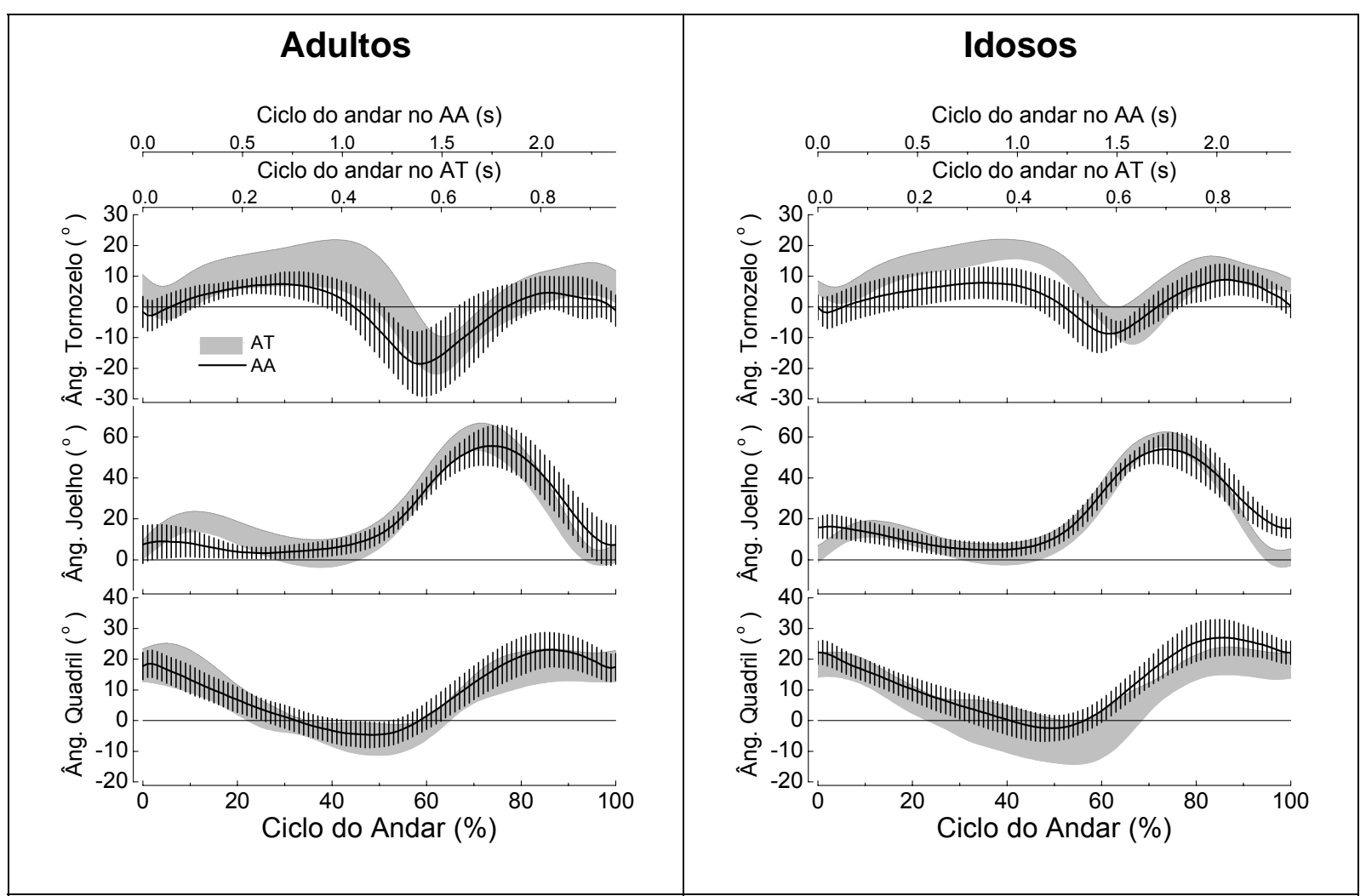

FIGURA 10 - Média ( \pm D.P) dos ângulos articulares do tornozelo, joelho e quadril durante um ciclo do andar dos adultos (coluna à esquerda) e dos idosos (coluna à direita) nos ambientes terrestre (AT, sombreado) e aquático (AA, preto). Nota: valores positivos indicam flexão do tornozelo e flexão do joelho e quadril.

A TABELA 2 apresenta a porcentagem média do coeficiente de variação (CV) dos ângulos articulares do tornozelo, joelho e quadril para os dois grupos nos dois ambientes. MANOVA para o CV dos ângulos dessas articulações não indicou diferença entre os grupos, Wilks' Lambda=0,76, $F(3,16)=1,67, p>0,10$, indicou diferença entre os ambientes, Wilks' Lambda=0,11, $F(3,16)=44,52, p<0,001$, e interação entre grupos e ambientes, Wilks' Lambda=0,40, $F(3,16)=7,99, p<0,005$. Análises univariadas para os ambientes indicaram diferença para os ângulos do 
tornozelo, $F(1,18)=123,68, p<0,001$, e do joelho, $F(1,18)=31,97, p<0,001$. Análises univariadas para interação entre grupos e ambientes indicaram diferença apenas para o ângulo do tornozelo, $F(1,18)=17,13, p<0,005$.

Os adultos e idosos apresentaram menor variabilidade no padrão das curvas dos ângulos do tornozelo e do joelho no AT do que no AA. Ainda com relação ao ângulo do tornozelo, testes post hoc indicaram que enquanto não houve diferença entre os adultos e idosos no AT, os adultos apresentaram menor variabilidade que os idosos no AA. Finalmente, nenhuma diferença foi constatada para a variabilidade no padrão do ângulo do quadril (TABELA 2).

TABELA 2 - Porcentagem média do coeficiente de variação dos ângulos articulares do tornozelo, joelho e quadril durante o ciclo do andar dos adultos $\mathrm{e}$ idosos nos ambientes terrestre (AT) e aquático (AA).

\begin{tabular}{ccccc}
\hline CV (\%) & \multicolumn{2}{c}{ Adultos } & \multicolumn{2}{c}{ Idosos } \\
\cline { 2 - 5 } Ambiente & AT & AA & AT & AA \\
Ângulos Articulares & & & & \\
\hline Tornozelo & 23 & 50 & 16 & 75 \\
Joelho & 12 & 21 & 11 & 22 \\
Quadril & 24 & 26 & 23 & 24 \\
\hline
\end{tabular}

Os valores médios (D.P.) da amplitude de movimento articular (ADM) do tornozelo, joelho e quadril durante os períodos de apoio e de balanço e durante o ciclo completo do andar dos adultos e dos idosos no AT e no AA são apresentados na FIGURA 11. Para a ADM das três articulações durante o período de apoio (FIGURA 11, coluna à esquerda), MANOVA indicou diferença entre os grupos, Wilks' Lambda=0,60, $F(3,16)=3,58, p<0,05$, entretanto não indicou diferença entre os ambientes, Wilks' Lambda=0,66, $F(3,16)=2,78, p>0,1$, e interação entre grupos e ambientes, Wilks' Lambda=0,64, $F(3,16)=2,95, p>0,1$. Análises univariadas para os grupos indicaram diferença apenas para a ADM do tornozelo, $F(1,18)=8,56, p<0,01$. Durante o período de apoio, os adultos apresentaram ADM do tornozelo maior que os idosos nos dois ambientes (FIGURA 11-A). Em se tratando da ADM do joelho e do quadril, os adultos e os idosos apresentaram a mesma ADM para cada uma dessas articulações no AT e no AA (FIGURA 11-D e FIGURA 11-G, respectivamente). 


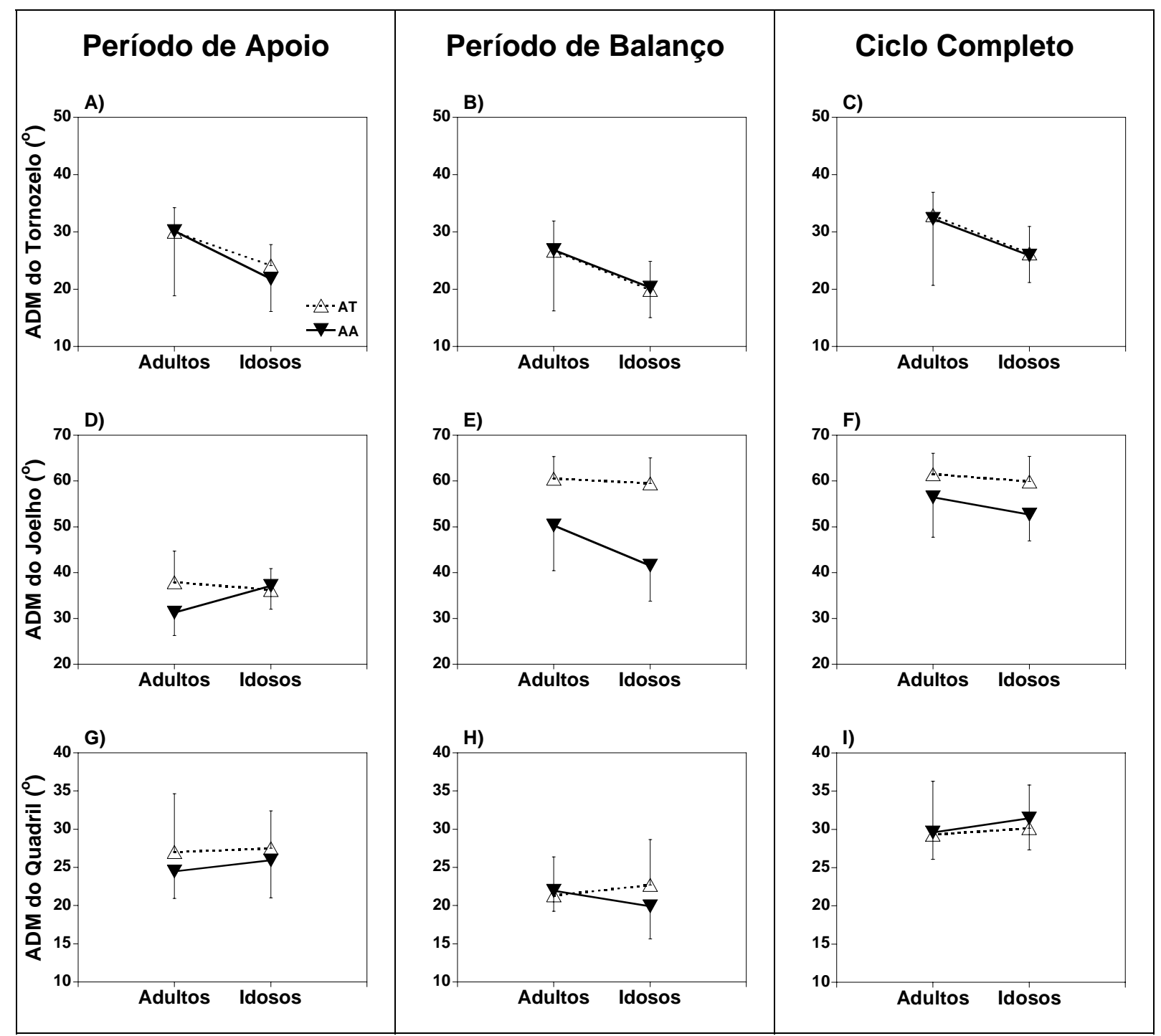

FIGURA 11 - Valores médios (D.P) da amplitude de movimento articular (ADM) do tornozelo $(A, B, C)$, joelho $(D, E, F)$ e quadril $(G, H, I)$, durante 0 período de apoio (coluna à esquerda), período de balanço (coluna central) e ciclo completo (coluna à direita) do andar dos adultos e idosos nos ambientes terrestre (AT) e aquático (AA). Nota: a escala do eixo vertical varia conforme a articulação em consideração.

Para a ADM das três articulações durante o período de balanço (FIGURA 11, coluna central), MANOVA indicou diferença entre os ambientes, Wilks' Lambda=0,26, $F(3,16)=15,48, p<0,001$, não indicou diferença entre os grupos, Wilks' 
Lambda=0,70, $F(3,16)=2,24, p>0,05$, e interação entre grupos e ambientes, Wilks' Lambda=0,79, $F(3,16)=1,43, \quad p>0,1$. Análises univariadas para os ambientes indicaram diferença apenas para a articulação do joelho, $F(1,18)=35,22, p<0,001$. Assim, durante o período de balanço, a ADM do tornozelo não foi diferente entre os adultos e os idosos e entre os ambientes (FIGURA 11-B). Por outro lado, a ADM do joelho foi maior no AT do que no AA (FIGURA 11-E). Da mesma forma que a ADM do tornozelo, a ADM do quadril não foi diferente entre os grupos e entre os ambientes (FIGURA 11-H).

Finalmente, para a ADM das três articulações durante o ciclo completo do andar (FIGURA 11, coluna à direita), MANOVA indicou diferença entre os ambientes, Wilks' Lambda=0,37, $F(3,16)=9,22, p<0,005$, não indicou diferença entre os grupos, Wilks' Lambda=0,67, $F(3,16)=2,58, p>0,05$, e interação entre os grupos e ambientes, Wilks' Lambda=0,90, $F(3,16)=0,61, p>0,5$. Análises univariadas para os ambientes indicaram diferença para a ADM do joelho, $F(1,18)=8,70, p<0,05$. Durante o ciclo completo do andar, a ADM das três articulações apresentou os mesmos resultados que foram constatados durante o período de balanço. Sendo assim, a ADM do joelho foi maior no AT do que no AA (FIGURA 11-F), enquanto que a ADM do tornozelo (FIGURA 11-C) e do quadril (FIGURA 11-I) não foi diferente entre os grupos e entre os ambientes.

Em se tratando dos ângulos das articulações do tornozelo, joelho e quadril durante as fases de contato inicial e balanço inicial dos dois grupos nos dois ambientes, os valores médios (D.P.) são apresentados na FIGURA 12. Para o ângulo de cada articulação durante a fase de contato inicial, MANOVA não apontou diferença entre os grupos, Wilks' Lambda=0,90, $F(3,16)=0,60, p>0,5$, apontou diferença entre os ambientes, Wilks' Lambda=0,06, $F(3,16)=76,29, p<0,001$, e interação entre grupos e ambientes, Wilks' Lambda=0,33, $F(3,16)=10,83, p<0,001$. Análises univariadas para os ambientes apontaram diferença para o ângulo do tornozelo, $F(1,18)=41,61, p<0,001$, e para o ângulo do joelho, $F(1,18)=20,27$, $p<0,001$. Análises univariadas para interação entre grupos e ambientes apontaram diferença apenas para o ângulo do joelho, $F(1,18)=13,64, p<0,005$. 


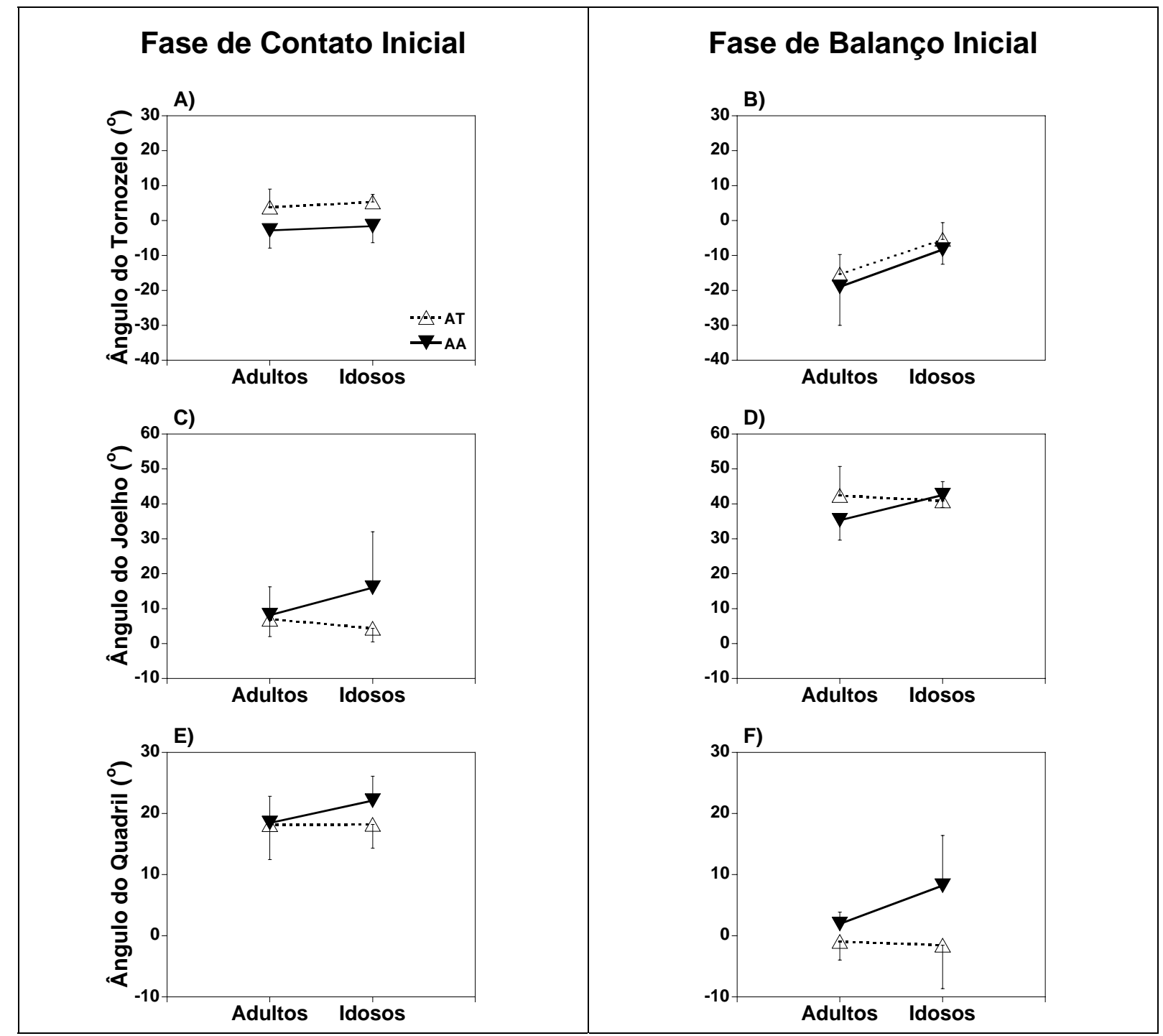

FIGURA 12 - Valores médios (D.P) dos ângulos articulares do tornozelo (A, B), joelho $(C, D)$ e quadril $(E, F)$ durante as fases de contato inicial (coluna à esquerda) e de balanço inicial (coluna à direita) do andar dos adultos e idosos nos ambientes terrestre (AT) e aquático (AA). Nota: a escala do eixo vertical varia conforme a articulação em consideração; valores positivos indicam flexão do tornozelo e flexão do joelho e quadril.

Durante a fase de contato inicial, os adultos e os idosos apresentaram ângulo do tornozelo em flexão no AT e em extensão no AA (FIGURA 12-A). Em se tratando do ângulo do joelho, testes post hoc indicaram que os adultos e os idosos apresentaram o mesmo ângulo do joelho no AT, e os adultos apresentaram ângulo 
do joelho menor que os idosos no AA (FIGURA 12-C). Por outro lado, enquanto que os adultos apresentaram o mesmo ângulo do joelho nos dois ambientes, os idosos apresentaram ângulo dessa articulação menor no AT do que no AA. Finalmente, o ângulo do quadril não apresentou diferença entre os grupos e entre os ambientes (FIGURA 12-E).

Com relação aos ângulos das articulações do tornozelo, joelho e quadril durante a fase de balanço inicial, MANOVA apontou diferença entre os grupos, Wilks' Lambda=0,54, $F(3,16)=4,50, p<0,05$, entre os ambientes, Wilks' Lambda=0,29, $F(3,16)=13,28, p<0,001$, e interação entre grupos e ambientes, Wilks' Lambda=0,61, $F(3,16)=, p<0,05$. Análises univariadas para os grupos apontaram diferença para 0 ângulo do tornozelo, $F(1,18)=14,92, \quad p<0,005$. Análises univariadas para os ambientes apontaram diferença para o ângulo do quadril, $F(1,18)=22,09, p<0,001$. $E$, finalmente, análises univariadas para interação entre grupos e ambientes apontaram diferença para os ângulos do joelho, $F(1,18)=7,28, \quad p<0,05$, e do quadril, $F(1,18)=6,47, p<0,05$.

Durante a fase de balanço inicial, os adultos apresentaram extensão do tornozelo maior do que os idosos (FIGURA 12-B). Em se tratando do ângulo do joelho, testes post hoc apontaram que enquanto os adultos apresentaram ângulo dessa articulação maior no AT do que no AA, os idosos não apresentaram diferença entre os ambientes. Por outro lado, os adultos e os idosos apresentaram o mesmo ângulo do joelho no AT e os adultos apresentaram ângulo dessa articulação menor que os idosos no AA (FIGURA 12-D). Já com relação ao ângulo do quadril, testes post hoc indicaram que os adultos e os idosos apresentaram o mesmo ângulo no AT, e os adultos apresentaram ângulo menor que os idosos no AA. Ainda, enquanto que os adultos apresentaram o mesmo ângulo do quadril nos dois ambientes, os idosos apresentaram ângulo do quadril menor no AT do que no AA (FIGURA 12-F).

\subsection{Variáveis cinéticas}

Os valores médios ( \pm D.P.) do peso corporal no AT e peso corporal aparente no AA para os adultos foram $556 \pm 85 \mathrm{~N}$ e $205 \pm 40 \mathrm{~N}$, respectivamente e para os idosos foram $577 \pm 109 \mathrm{~N}$ e $216 \pm 40 \mathrm{~N}$, respectivamente. Os valores médios 
( \pm D.P.) da redução do peso corporal aparente dos adultos e dos idosos foram $63 \pm$ $2 \%$ e $62 \pm 3 \%$, respectivamente. Com relação ao peso corporal (peso corporal aparente para o AA), ANOVA revelou diferença entre os ambientes, $F(1,18)=589,45$, $p<0,001$, e não revelou diferença entre os grupos, $F(1,18)=0,31, p>0,1$, e interação entre grupos e ambientes, $F(1,18)=0,109, p>0,1$. Em se tratando da redução do peso corporal aparente, ANOVA não revelou qualquer diferença entre os grupos, $F(1,18)=0,40, p>0,5$. O peso corporal (AT) foi maior que o peso corporal aparente (AA) para os dois grupos, e houve mais que $60 \%$ de redução do peso corporal aparente no AA com a água no nível do processo xifóide do esterno.

A FIGURA 13 apresenta os valores médios ( \pm D.P.) das curvas referentes às componentes vertical e horizontal ântero-posterior da força de reação do solo (FRS) durante o ciclo do andar dos adultos (coluna à esquerda) e dos idosos (coluna à direita) no AT e no AA. Os dados referentes a essas curvas foram normalizados pelo peso corporal (AT) e pelo peso corporal aparente (AA) de cada participante. Os dados referentes ao AA também foram normalizados pelo peso corporal e são indicados na FIGURA 13 pelo eixo vertical à direita.

Com relação à componente vertical da FRS, os adultos e os idosos apresentaram os picos e vale mais bem definidos no AT do que no AA (FIGURA 13, porção superior). Em se tratando da componente horizontal ântero-posterior, os adultos e os idosos apresentaram uma fase negativa na primeira metade do período de apoio e uma fase positiva na segunda metade desse período no AT, enquanto que eles apresentaram apenas uma fase positiva durante todo o período de apoio no AA (FIGURA 13, porção inferior). 


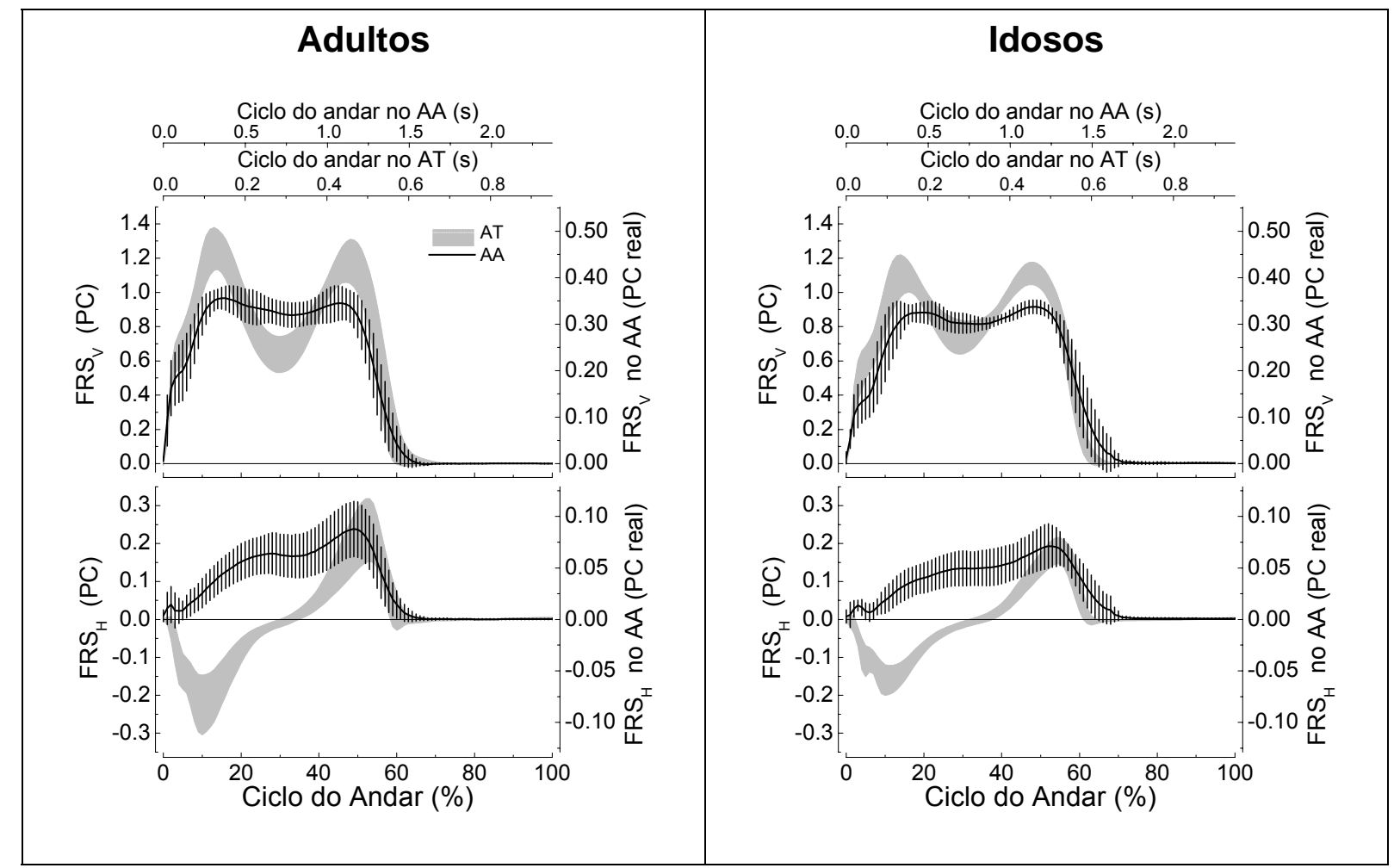

FIGURA 13 - Média ( \pm D.P) das componentes vertical e horizontal antero-posterior da FRS durante o ciclo do andar dos adultos (coluna à esquerda) e dos idosos (coluna à direita) nos ambientes terrestre (AT, sombreado) e aquático (AA, preto). Os eixos verticais à esquerda indicam as forças normalizadas pelo peso corporal (PC) no AT e pelo PC aparente no AA, e os eixos à direita indicam as forças normalizadas pelo PC.

A TABELA 3 apresenta a porcentagem média do CV das componentes da FRS vertical e horizontal ântero-posterior para os adultos e idosos nos AT e AA. MANOVA para o CV dessas componentes não indicou diferença entre os grupos, Wilks' Lambda=0,89, $F(2,17)=1,02, p>0,10$, e interação entre grupos e ambientes, Wilks' Lambda=0,91, $F(2,17)=0,88, p>0,10$, e indicou diferença entre os ambientes, Wilks' Lambda=0,23, $F(2,17)=28,66, p<0,001$, Análises univariadas para os ambientes indicaram diferença para a componente vertical, $F(1,18)=59,23, p<0,001$, e horizontal ântero-posterior, $F(1,18)=38,05, p<0,001$. Os adultos e os idosos apresentaram menor variabilidade no padrão das curvas das componentes vertical e horizontal ântero-posterior no AT do que no AA (TABELA 3). 
TABELA 3 - Porcentagem média do coeficiente de variação das componentes da força de reação do solo (FRS) vertical $\left(F_{z}\right)$ e horizontal ântero-posterior $\underline{F}_{y}$ A-P) durante o ciclo do andar dos adultos e idosos nos ambientes terrestre (AT) e aquático (AA).

\begin{tabular}{crrrr}
\hline CV (\%) & \multicolumn{3}{c}{ Adultos } & \multicolumn{2}{c}{ Idosos } \\
\cline { 3 - 5 } Ambiente & AT & AA & AT & AA \\
Componentes da FRS & & & & \\
\hline$F_{\mathrm{z}}$ & 8 & 14 & 7 & 17 \\
$\mathrm{~F}_{\mathrm{y}}$ A-P & 17 & 27 & 18 & 31 \\
\hline
\end{tabular}

Os valores médios (D.P.) do primeiro e segundo picos da componente vertical da FRS, da força de impacto e do impulso horizontal, normalizados pelo peso corporal (peso corporal aparente para AA) de cada participante, durante o período de apoio do andar dos adultos e idosos no AT e no AA são apresentados na FIGURA 14 MANOVA para os dois picos da componente vertical da FRS e para força de impacto apontou diferença entre os grupos, Wilks' Lambda=0,55, $F(3,16)=4,39, p<0,05$, e entre os ambientes, Wilks' Lambda=0,11, $F(3,16)=41,15, p<0,001$, e não apontou interação entre grupos e ambientes, Wilks' Lambda=0,83, $F(3,16)=1,11, p>0,05$. Análises univariadas para os grupos apontaram diferença para o primeiro pico, $F(1,18)=11,75, p<0,001$, e para a força de impacto, $F(1,18)=10,23, p<0,05$. Análises univariadas para os ambientes apontaram diferença para o primeiro pico, $F(1,18)=48,03, p<0,001$, para o segundo pico, $F(1,18)=35,20, p<0,001$, e para a força de impacto, $F(1,18)=88,80, p<0,001$.

Em se tratando do primeiro pico da componente vertical da FRS, os adultos apresentaram maior pico que os idosos no AT, e os dois grupos apresentaram maior pico no AT do que no AA (FIGURA 14-A). Por outro lado, o segundo pico da componente vertical da FRS foi maior no AT do que no AA (FIGURA 14-B). Finalmente, a força de impacto dos adultos foi maior que a dos idosos nos dois ambientes, e essa força foi maior no AT do que no AA para os dois grupos (FIGURA 14-C).

Com relação ao impulso horizontal, ANOVA revelou diferença entre os grupos, $F(1,18)=6,66, p<0,05$, entre os ambientes, $F(1,18)=218,10, p<0,001$, e 
interação entre grupos e ambientes, $F(1,18)=5,94, p<0,05$. Testes post hoc indicaram que esse impulso foi menor no $A T$ do que no $A A$, e que enquanto não houve diferença entre os grupos no AT, os adultos apresentaram impulso maior que os idosos no AA (FIGURA 14-D).

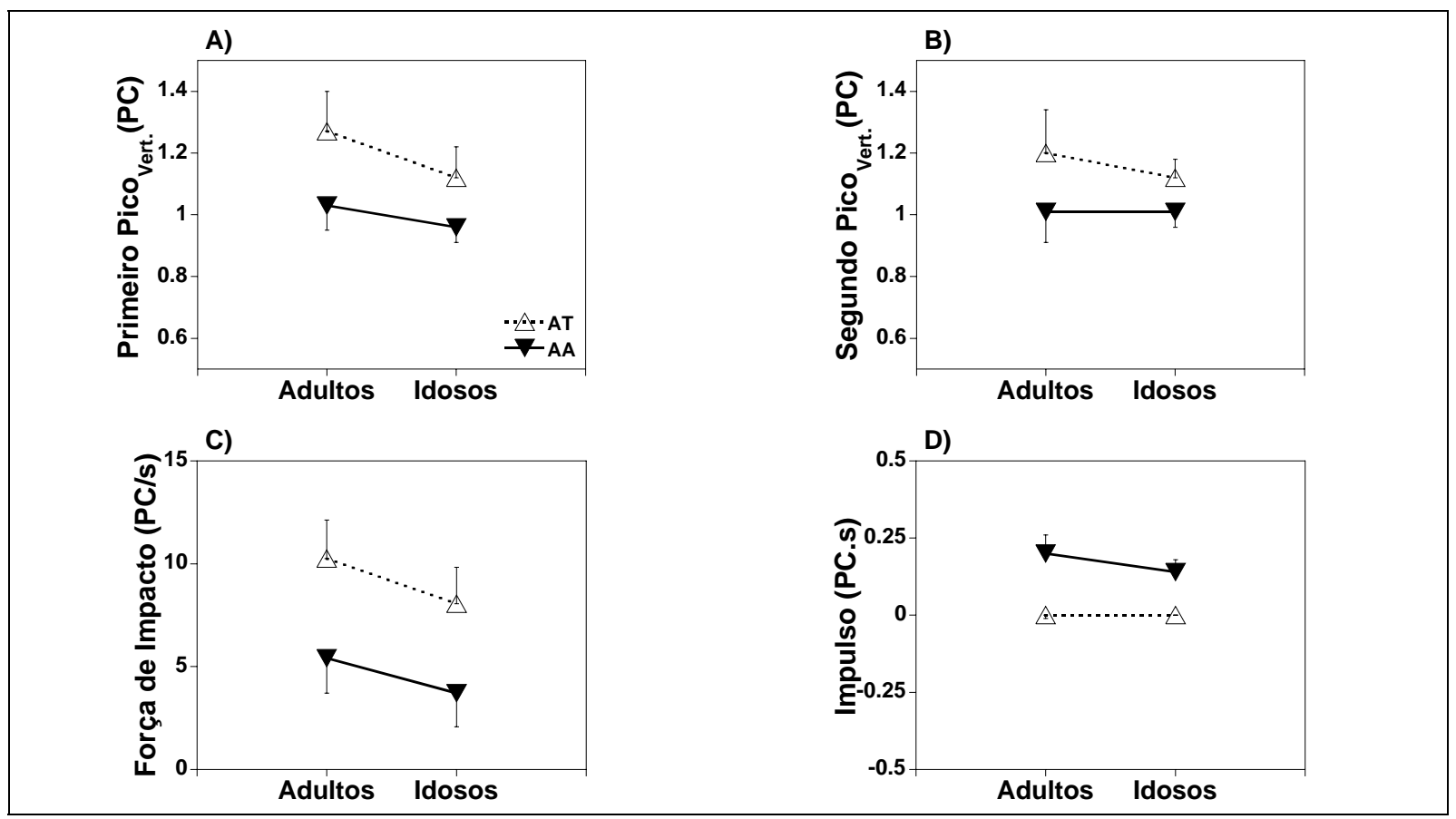

FIGURA 14 - Valores médios (D.P) do primeiro pico (A) e do segundo pico (B) da componente vertical da FRS, da força de impacto (C) e do impulso horizontal (D) durante o período de apoio do andar de adultos e idosos nos ambientes terrestre (AT) e aquático (AA). Nota: os valores foram normalizados pelo peso corporal (PC) dos participantes no AT e pelo PC aparente no AA.

\subsection{Variáveis eletromiográficas}

Antes de apresentar os resultados referentes às variáveis eletromiográficas, é importante informar que não foi possível adquirir os dados da atividade EMG de todos os músculos para todos os participantes idosos no AA e para o músculo reto do abdome (RA) para a maioria dos participantes nos dois ambientes (TABELA 4). Para o músculo RA, especificamente, os dados da atividade 
EMG foram adquiridos para seis adultos no AT e três adultos no AA (três repetições para um adulto e duas repetições para os outros dois). Em se tratando dos idosos, esses dados foram adquiridos apenas para a minoria dos participantes nos dois ambientes e em menos de três repetições (apenas um idoso apresentou sinal EMG desse músculo em todas as repetições no AT e dois idosos apresentaram sinal EMG em uma repetição no $A A)$. Sendo assim, o músculo RA não foi considerado no tratamento estatístico e, conseqüentemente, não é apresentado no decorrer dos resultados quantitativos.

TABELA 4 - Número de adultos e idosos nos ambientes terrestre (AT) e aquático (AA) em que foi possível adquirir dados da atividade eletromiográfica dos músculos gastrocnêmio medial (GM), tibial anterior (TA), cabeça curta do bíceps femoral (BFCC), vasto lateral (VL), cabeça longa do bíceps femoral (BFCL), tensor da fáscia látea (TFL), eretor espinhal (EE) e reto do abdome (RA).

\begin{tabular}{ccccc}
\hline & \multicolumn{2}{c}{ Adultos } & \multicolumn{2}{c}{ Idosos } \\
\hline $\begin{array}{c}\text { Ambiente } \\
\text { Músculo }\end{array}$ & AT & AA & AT & AA \\
\hline GM & 10 & 10 & 10 & 10 \\
TA & 10 & 10 & 10 & 9 \\
BFCC & 10 & 10 & 10 & 10 \\
VL & 10 & 10 & 10 & 9 \\
BFCL & 10 & 10 & 10 & 10 \\
TFL & 10 & 10 & 10 & 10 \\
EE & 10 & 10 & 10 & 8 \\
RA & 6 & $3^{*}$ & 7 & $2^{*}$ \\
\hline \multicolumn{4}{c}{ menos de três repetições } \\
\end{tabular}

A FIGURA 15 apresenta os valores médios ( \pm D.P.) das curvas referentes à atividade eletromiográfica (EMG) dos oito músculos selecionados para os adultos (coluna à esquerda) e idosos (coluna à direita) durante o ciclo do andar no AT e no AA. Os dados referentes a essas curvas foram normalizados pelo valor médio da atividade EMG durante o ciclo do andar. Os padrões da atividade EMG foram 
similares entre os adultos e idosos para a maioria dos músculos investigados. Porém, esses padrões foram diferentes entre AT e AA para a maioria desses músculos.

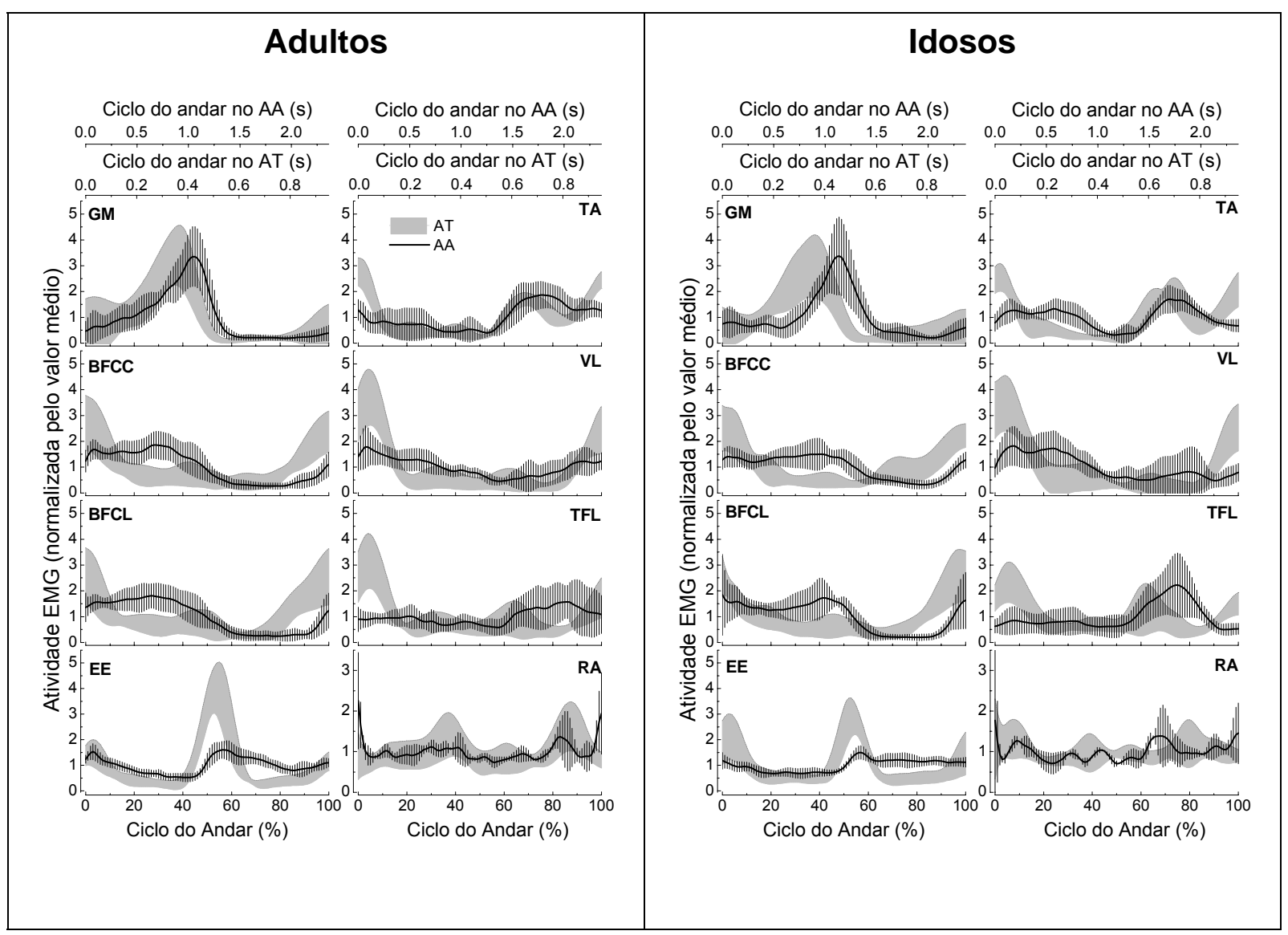

FIGURA 15 - Média (tD.P.) da atividade eletromiográfica (EMG) normalizada pelo valor médio dos músculos gastrocnêmio medial (GM), tibial anterior (TA), cabeça curta do bíceps femoral (BFCC), vasto lateral (VL), cabeça longa do bíceps femoral (BFCL), eretor espinhal (EE) e reto do abdome (RA) durante o ciclo do andar dos adultos (coluna à esquerda) $\underline{\mathrm{e} \text { idosos (coluna à direita) nos ambientes terrestre (AT, área }}$ sombreada) e aquático ( $\mathrm{A} A$, linha preta).

Em se tratando dos músculos que apresentaram padrões similares entre os adultos e idosos, o músculo GM apresentou um padrão similar entre os dois ambientes. No entanto, o pico de atividade desse músculo ocorreu em instantes diferentes tanto entre os grupos como entre os ambientes. Os músculos BFCC, VL e 
BFCL apresentaram picos mais definidos no $A T$ do que no $A A$, e o músculo $T F L$ pareceu estar mais ativo durante o período de apoio no AT do que no AA e menos ativo durante o período de balanço no AT do que no AA.

Em se tratando dos músculos que não apresentaram padrões similares entre os adultos e idosos, os músculos TA e EE apresentaram padrões diferentes no AA e no AT, respectivamente. Sendo assim, o músculo TA apresentou um pico de ativação na fase de contato inicial e permaneceu ativo durante o período de balanço quando os adultos e idosos andaram no AT. Porém, quando eles andaram no AA, esse músculo foi ativado durante o período de balanço pelos adultos, enquanto que foi ativado nos períodos de apoio e de balanço pelos idosos. Por outro lado, o músculo EE apresentou um pico de ativação na fase de contato inicial e no final do período de apoio pelos adultos e pelos idosos quando os dois grupos andaram no AT, enquanto que esse músculo pareceu estar mais ativado no final do período de apoio e durante o período de balanço. Por fim, o músculo RA pareceu estar mais ativado na fase de contato inicial (0 e 100\% do ciclo) para os dois grupos, porém, os dados apresentados para esse músculo não são referentes a todos os participantes nem todas as repetições nos dois ambientes.

A TABELA 5 apresenta a porcentagem média do CV dos músculos GM, TA, BFCC, VL, BFCL, TFL e EE para os adultos e idosos nos AT e AA. MANOVA para o CV dos músculos GM e TA indicou diferença entre os grupos, Wilks' Lambda=0,50, $F(2,16)=8,14, p<0,005$, e entre os ambientes, Wilks' Lambda=0,17, $F(2,16)=39,02, p<0,001$, e não indicou interação entre grupos e ambientes, Wilks' Lambda=0,93, $F(2,16)=0,64, p>0,10$. Análises univariadas para os grupos indicaram diferença para os músculos $\mathrm{GM}, F(1,17)=8,51, p<0,05$, e TA, $F(1,17)=5,66, p<0,05$. Análises univariadas para os ambientes também indicaram diferença para os músculos $G M, F(1,17)=48,50, p<0,001$, e TA, $F(1,17)=12,37, p<0,005$. Os adultos apresentaram menor variabilidade no padrão de ativação elétrica dos músculos $\mathrm{GM}$ e TA que os idosos, e os dois grupos apresentaram menor variabilidade no AT do que no AA (TABELA 5). 
TABELA 5 - Porcentagem média do coeficiente de variação dos músculos gastrocnêmio medial (GM), tibial anterior (TA), cabeça curta do bíceps femoral (BFCC), vasto lateral (VL), cabeca longa do bíceps femoral (BFCL) e eretor espinhal (EE) durante o ciclo do andar dos adultos e idosos nos ambientes terrestre (AT) e aquático (AA).

\begin{tabular}{ccccc}
\hline CV (\%) & \multicolumn{2}{c}{ Adultos } & \multicolumn{2}{c}{ Idosos } \\
\cline { 2 - 5 } $\begin{array}{c}\text { Ambiente } \\
\text { Músculos }\end{array}$ & AT & AA & AT & AA \\
\hline GM & 24 & 51 & 32 & 67 \\
TA & 29 & 35 & 38 & 46 \\
BFCC & 30 & 37 & 30 & 37 \\
VL & 28 & 36 & 29 & 40 \\
BFCL & 36 & 39 & 39 & 42 \\
TFL & 27 & 55 & 26 & 46 \\
EE & 30 & 35 & 34 & 29 \\
\hline
\end{tabular}

MANOVA para o CV dos músculos BFCC e VL indicou diferença entre os ambientes, Wilks' Lambda $=0,33, F(2,16)=15,96, p<0,001$, e não indicou diferença entre os grupos, Wilks' Lambda $=0,96, F(2,16)=0,32, p>0,10$, e interação entre grupos e ambientes, Wilks' Lambda $=0,99, F(2,16)=0,07, p>0,10$. Análises univariadas para os ambientes indicaram diferença para os músculos BFCC, $F(1,17)=10,69, p<0,01$, e VL, $F(1,17)=12,79, \quad p<0,005$. Os adultos e os idosos apresentaram menor variabilidade no padrão de ativação elétrica dos músculos BFCC e VL no AT do que no AA TABELA 5).

MANOVA para o $\mathrm{CV}$ dos músculos BFCL e TFL indicou diferença entre os ambientes, Wilks' Lambda=0,37, $F(2,17)=16,81, p<0,001$, e não indicou diferença entre os grupos, Wilks' Lambda=0,91, $F(2,17)=0,80, p>0,10$, e interação entre grupos e ambientes, Wilks' Lambda $=0,94, F(2,17)=0,52, p>0,10$. Análises univariadas para os ambientes indicaram diferença para o músculo TFL, $F(1,18)=35,21, p<0,001$. Os adultos e os idosos apresentaram menor variabilidade no padrão de ativação elétrica do músculo TFL no AT do que no $A A$, enquanto que nenhuma diferença foi constatada para variabilidade do músculo BFCL (TABELA 5)

Finalmente, ANOVA para o CV do músculo EE não indicou diferença entre os ambientes, $F(1,16)=0,02, p>0,10$, e entre os grupos, $F(1,16)=0,16, p>0,10$, e 
indicou interação entre grupos e ambientes, $F(1,16)=6,08, p<0,05$. No entanto, testes post hoc não apontaram qualquer diferença entre os grupos e entre os ambientes (TABELA 5).

A FIGURA 16 apresenta os valores médios (D.P.) da magnitude da atividade EMG dos músculos GM e TA nos períodos de apoio e balanço para os dois grupos (adultos e idosos) nos dois ambientes (AT e AA). Para esses músculos e nesses períodos, MANOVA apontou diferença entre os ambientes, Wilks' Lambda=0,23, $F(4,14)=11,43, p<0,001$, e interação entre grupos e ambientes, Wilks' Lambda=0,50, $F(4,14)=3,52, p<0,05$, e não apontou diferença entre os grupos, Wilks' Lambda=0,91, $F(4,14)=0,36, p>0,10$. Análises univariadas para os ambientes apontaram diferença para o músculo GM durante o período de apoio, $F(1,17)=12,43$, $p<0,005$, e para o músculo TA durante os períodos de apoio, $F(1,17)=28,18$, $p<0,001$, e de balanço, $F(1,17)=32,25, p<0,001$. Análises univariadas para interação entre grupos e ambientes apontaram diferenças para o músculo GM durante o período de balanço, $F(1,17)=7,43$, $p<0,05$, e para o músculo TA durante os períodos de apoio, $F(1,17)=8,87, p<0,01$, e de balanço, $F(1,17)=10,26, p<0,01$.

Os adultos e os idosos apresentaram magnitude da atividade EMG do músculo GM maior no AT do que no AA durante o período de apoio (FIGURA 16-A), e não apresentaram diferença nessa magnitude no período de balanço. Porém, testes post hoc indicaram que enquanto não houve diferença, durante o período de balanço, na magnitude da atividade EMG desse músculo entre adultos e idosos no AT, os adultos apresentaram magnitude da atividade EMG desse músculo menor que os idosos no AA durante o período de balanço (FIGURA 16-B).

Com relação à magnitude da atividade EMG do músculo TA durante o período de apoio, testes post hoc indicaram que enquanto os adultos apresentaram magnitude desse sinal maior no $A T$ do que no $A A$, os idosos não apresentaram diferença entre os ambientes, e os adultos apresentaram magnitude menor que os idosos no AA (FIGURA 16-C). Finalmente, o mesmo resultado para o músculo TA encontrado durante o período de apoio foi encontrado durante o período de balanço. Sendo assim, testes post hoc indicaram que enquanto os adultos apresentaram magnitude desse sinal maior no $A T$ do que no $A A$, os idosos não apresentaram 
diferença entre os ambientes e, ainda, os adultos apresentaram magnitude menor que os idosos no AA (FIGURA 16-D).

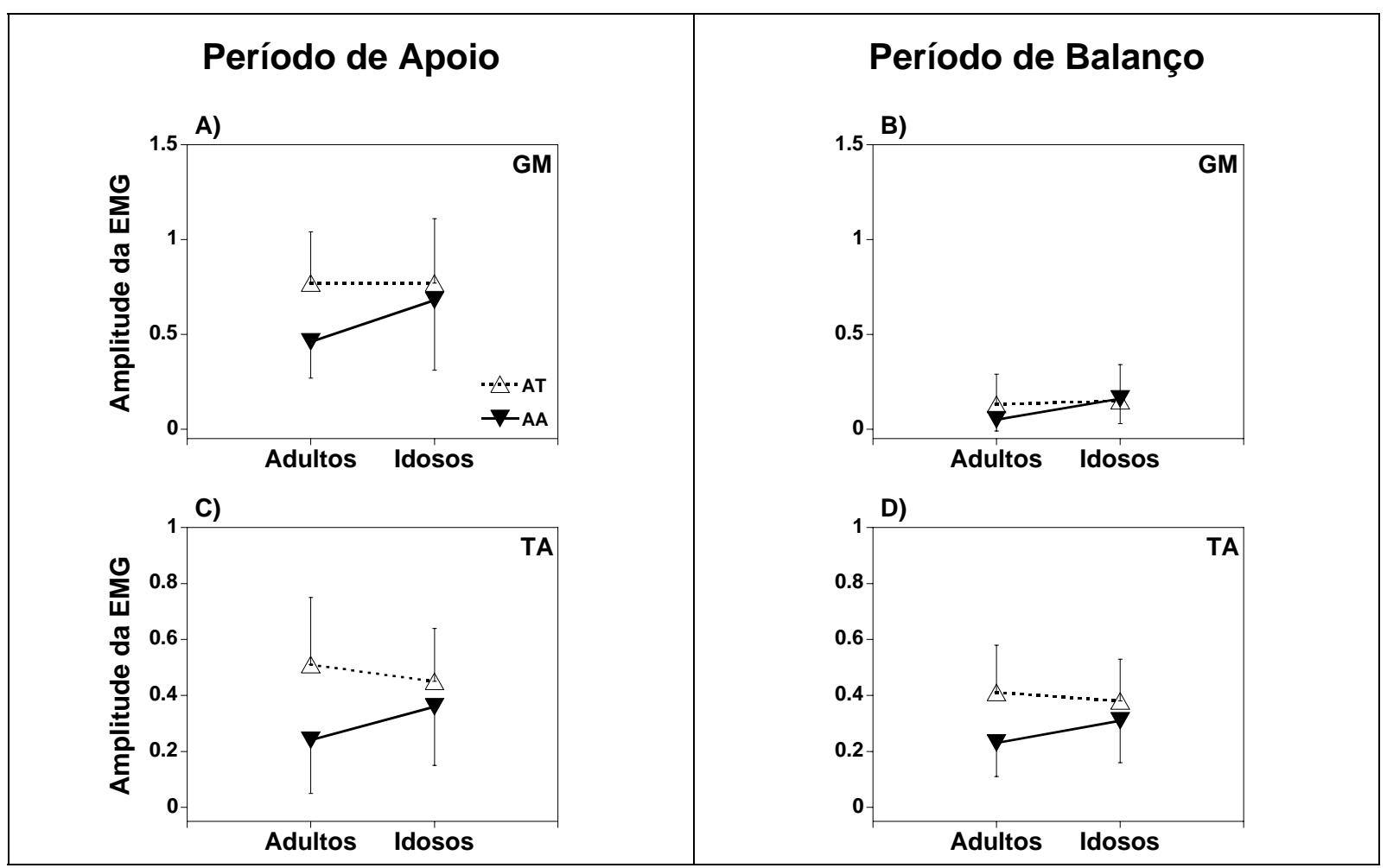

FIGURA 16 - Valores médios (D.P) da magnitude da atividade eletromiográfica (EMG) normalizados pela contração voluntária máxima isométrica (CVMI) dos músculos gastrocnêmio medial (GM) e tibial anterior (TA) durante os períodos de apoio (coluna à esquerda) e de balanço (coluna à direita) do andar dos adultos e idosos nos ambientes terrestre (AT) e aquático (AA).

Os valores médios (D.P.) da magnitude da atividade EMG dos músculos BFCC e VL durante os períodos de apoio e balanço dos adultos e idosos nos dois ambientes são apresentados na FIGURA 17. Para esses músculos e nesses períodos, MANOVA indicou diferença entre os grupos, Wilks' Lambda=0,33, $F(4,14)=7,03, p<0,005$, e entre os ambientes, Wilks' Lambda=0,17, $F(4,14)=17,62$, $p<0,001$, e não indicou interação entre grupos e ambientes, Wilks' Lambda=0,63, $F(4,14)=2,06, p>0,10$. Análises univariadas para os grupos indicaram diferença para 
o músculo VL durante os períodos de apoio, $F(1,17)=30,32, p<0,001$, e de balanço, $F(1,17)=16,77, p<0,005$. Ainda, análises univariadas para os ambientes indicaram diferença para o músculo BFCC durante o período de balanço, $F(1,17)=30,83$, $p<0,001$, e para o músculo VL durante os períodos de apoio, $F(1,17)=41,40, p<0,001$, e de balanço, $F(1,17)=20,76, p<0,001$.

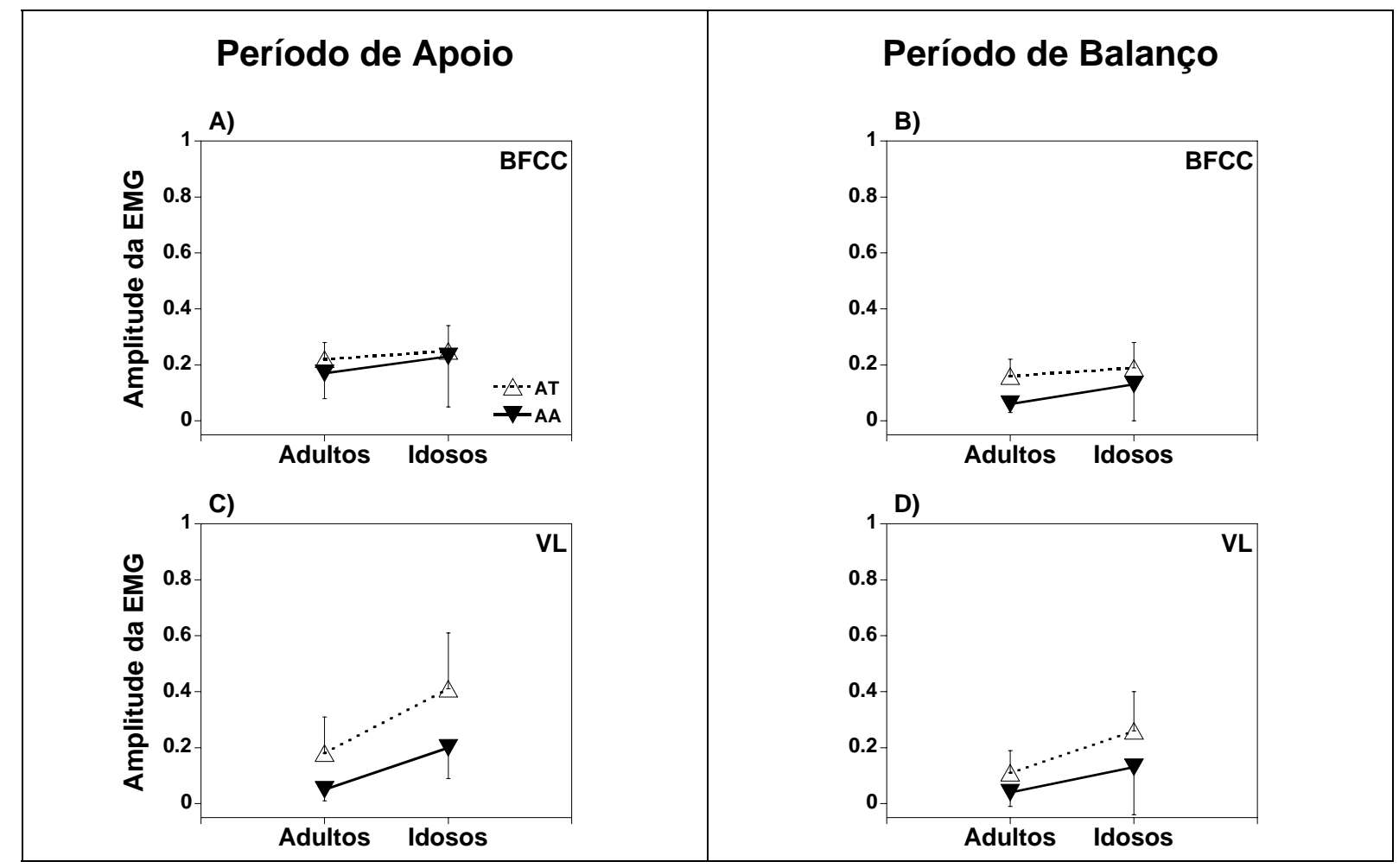

FIGURA 17 - Valores médios (D.P.) da magnitude da atividade eletromiográfica (EMG) normalizados pela CVMI dos músculos cabeça curta do bíceps femoral (BFCC) e vasto lateral (VL) durante os períodos de apoio (coluna à esquerda) e de balanço (coluna à direita) do andar dos adultos e idosos nos ambientes terrestre (AT) e aquático (AA).

Os adultos e os idosos não apresentaram diferença na magnitude da atividade EMG do músculo BFCC entre os dois ambientes durante o período de apoio (FIGURA 17-A), e os dois grupos apresentaram essa magnitude maior no AT do que no $A A$ durante o período de balanço (FIGURA 17-B). Com relação ao músculo VL, o mesmo resultado foi encontrado para os períodos de apoio e de 
balanço. Sendo assim, os adultos apresentaram magnitude da atividade EMG desse músculo menor que os idosos, e os dois grupos apresentaram essa magnitude maior no AT do que no AA durante os dois períodos (FIGURA 17-C e FIGURA 17-D).

A FIGURA 18 apresenta os valores médios (D.P.) da magnitude da atividade EMG dos músculos BFCL e TFL durante os períodos de apoio e balanço para os dois grupos nos dois ambientes. Para esses músculos e nesses períodos, MANOVA apontou diferença entre os ambientes, Wilks' Lambda=0,09, $F(4,15)=38,30, p<0,001$, e interação entre grupos e ambientes, Wilks' Lambda=0,41, $F(4,15)=5,44, p<0,05$, e não apontou diferença entre os grupos, Wilks' Lambda=0,79, $F(4,15)=1,01, p>0,10$. Análises univariadas para os ambientes apontaram diferença para o músculo BFCL durante o período de balanço, $F(1,18)=10,81, p<0,005$, e para o músculo TFL durante os períodos de apoio, $F(1,18)=5,47, p<0,05$, e de balanço, $F(1,18)=7,97, p<0,05$. Análises univariadas para interação entre grupos e ambientes apontaram diferenças somente para o músculo TFL durante o período de apoio, $F(1,18)=7,65, p<0,05$.

Durante o período de apoio, nenhuma diferença foi constatada para o músculo BFCL (FIGURA 18-A). Porém, durante o período de balanço, os adultos e os idosos apresentaram magnitude da atividade EMG desse músculo maior no AT do que no AA (FIGURA 18-B). Em se tratando do músculo TFL durante o período de apoio, testes post hoc indicaram que os adultos apresentaram magnitude da atividade EMG do músculo TFL maior no $A T$ do que no $A A$, enquanto que os idosos não apresentaram diferença entre os ambientes, e ainda, os adultos apresentaram menor magnitude que os idosos no AA (FIGURA 18-C). Finalmente, durante 0 período de balanço, os adultos e os idosos apresentaram magnitude da atividade EMG do músculo TFL menor no AT do que no AA (FIGURA 18-D). 


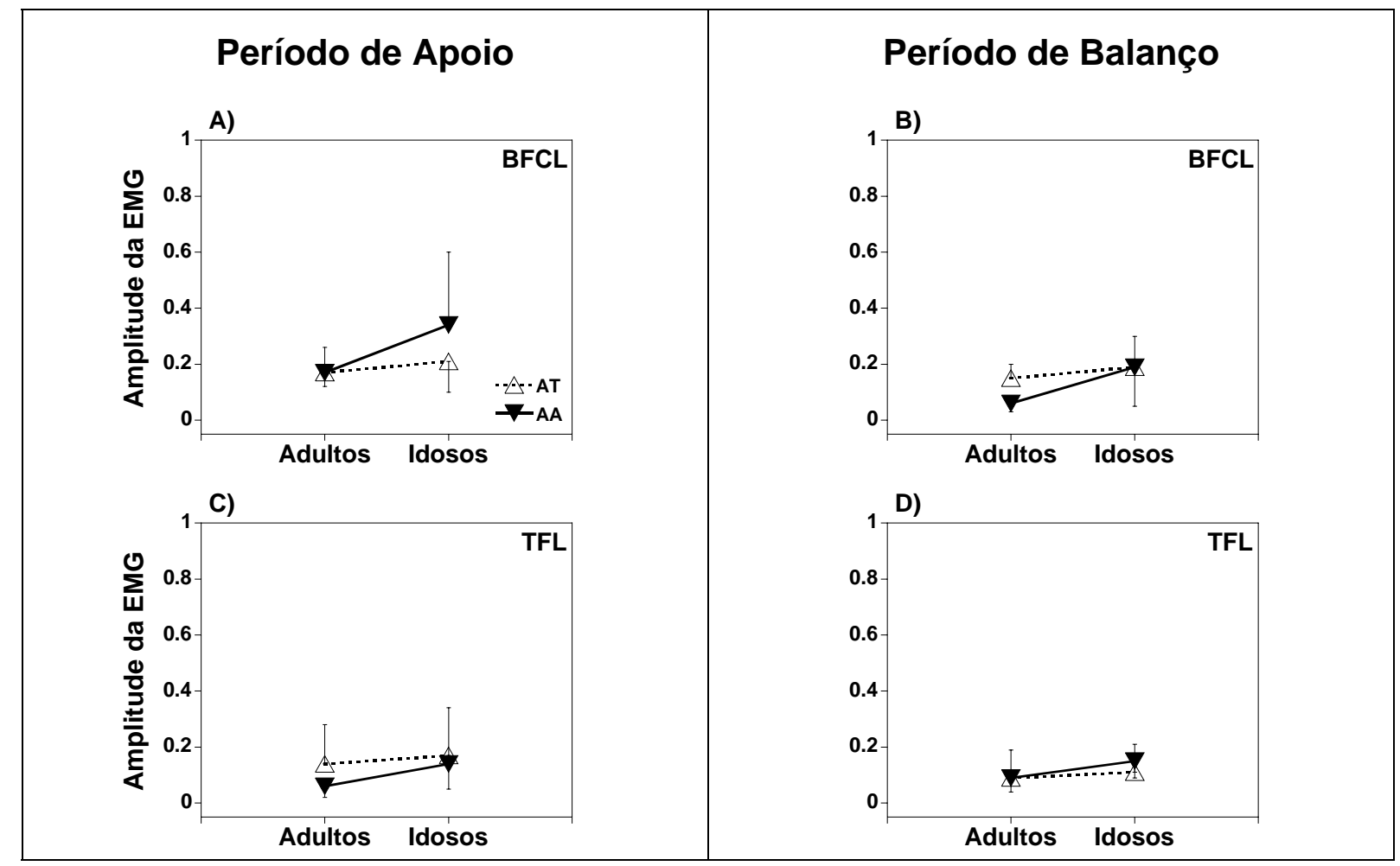

FIGURA 18 - Valores médios (D.P) da magnitude da atividade eletromiográfica (EMG) normalizados pela CVMI dos músculos bíceps femoral-cabeça longa ( $\mathrm{BFCL}$ ) e tensor da fáscia látea (TFL) durante os períodos de apoio (coluna à esquerda) e de balanço (coluna à direita) do andar dos adultos e idosos nos ambientes terrestre (AT) e aquático (AA).

A FIGURA 19 apresenta os valores médios (D.P.) da magnitude da atividade EMG do músculo EE durante os períodos de apoio e balanço para os dois grupos nos dois ambientes. MANOVA para esse músculo nos dois períodos indicou diferença entre os ambientes, Wilks' Lambda $=0,18, F(2,15)=33,51, p<0,001$, e não indicou diferença entre os grupos, Wilks' Lambda=0,99, $F(2,15)=0,04, p>0,50$, e interação entre grupos e ambientes, Wilks' Lambda=0,79, $F(2,15)=2,03, p>0,10$. Análises univariadas para os ambientes indicaram diferença para o período de balanço, $F(1,16)=8,92, p<0,01$. 


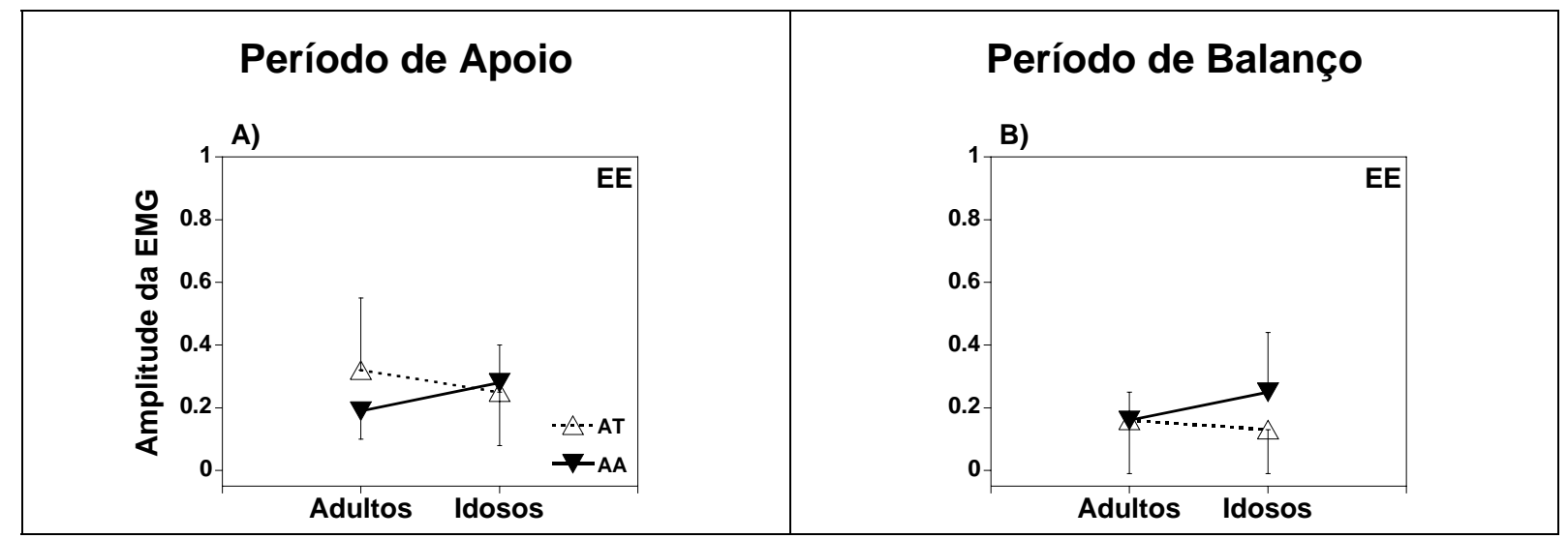

FIGURA 19 - Valores médios (D.P) da magnitude da atividade eletromiográfica (EMG) normalizados pela CVMI do músculo eretor espinhal (EE) durante os períodos de apoio (coluna à esquerda) e de balanco (coluna à direita) do andar dos adultos e idosos nos ambientes terrestre (AT) e aquático (AA).

Durante o período de apoio, nenhuma diferença foi encontrada entre os grupos e os ambientes para a magnitude da atividade EMG do músculo EE (FIGURA 19-A). Por outro lado, durante o período de balanço, os adultos e os idosos apresentaram magnitude da atividade EMG desse músculo menor no AT do que no AA (FIGURA 19-B).

6

\section{DISCUSSÃO}

No presente estudo, características biomecânicas do andar de adultos e idosos nos ambientes terrestre (AT) e aquático (AA) foram investigadas. Várias diferenças foram encontradas entre os dois ambientes para os dois grupos, e essas diferenças são decorrentes das forças atuantes no corpo, conforme esse se movimenta. No corpo humano, os músculos, quando ativados, desenvolvem tensão que gera forças e momentos nas articulações. As forças articulares e os momentos causam o movimento dos segmentos e esses exercem forças no ambiente (VAUGHAN, DAVIS \& O'CONNOR, 1999), que no caso do andar no AT são as forças de reação do solo. Essa seqüência de eventos resulta no padrão de movimento observado durante o andar. No caso do $A A$, além dessa seqüência de eventos 
decorrentes das forças musculares produzidas, há outras forças que devem ser consideradas. Nesse sentido, as diferenças encontradas neste estudo podem ser atribuídas principalmente à força de arrasto, que é desconsiderada no AT em condições normais, e à força empuxo. Enquanto que a força de arrasto na água proporciona resistência ao movimento e, conseqüentemente diminui a sua velocidade, a força empuxo reduz o peso corporal aparente.

É importante ressaltar que todos os participantes foram instruídos a selecionar uma velocidade confortável para andar nos dois ambientes, e em fazendo isso, eles andaram mais lentamente no $A A$, como verificado em estudos anteriores (DEGANI \& BARELA, 2001; GEHM et al., 2003; MIYOSHI et al., 2004). Em se tratando da redução do peso corporal aparente, a porcentagem de redução desse peso encontrada no presente estudo, com o nível da água na altura do processo xifóide do esterno, correspondeu à porcentagem de redução apresentada por HARRISON et al. (1992). A seguir a discussão dos principais resultados encontrados para os adultos e para os idosos, nos dois ambientes é apresentada. Ênfase maior é dada aos resultados referentes ao AA, uma vez que os resultados referentes ao AT foram similares aos resultados encontrados na literatura para a maioria das variáveis investigadas e já foram discutidos amplamente em diversos estudos (PERRY, 1992; WINTER, 1983, 1991).

\section{1 $O$ andar dos adultos nos ambientes terrestre e aquático}

Para se locomover no AA, os adultos apresentaram uma passada mais curta, andaram mais lentamente do que no AT, e mantiveram a mesma organização temporal, uma vez que a duração do período de apoio não foi diferente entre os ambientes. A relação entre os segmentos corporais adjacentes foi parecida ao longo do ciclo nos dois ambientes, com exceção dos segmentos perna e coxa, pois a magnitude de movimento (ADM) do joelho foi menor no AA. Contudo, em dois momentos críticos da passada, fase de contato inicial e fase de balanço inicial, a relação entre pé e perna (tornozelo) e entre perna e coxa (joelho) se diferenciaram do AT. Enquanto que o tornozelo estava em maior extensão quando o pé tocou a superfície de contato, o joelho estava mais estendido na perda desse contato. Em se tratando das componentes da força de reação do solo (FRS), a componente vertical 
não apresentou os dois picos bem definidos como observado no AT, sendo esses picos menores, e a componente horizontal ântero-posterior não apresentou as fases de desaceleração e aceleração como no AT, mas sim uma única fase de aceleração e, conseqüentemente, o impulso horizontal foi maior no AA. A força de impacto, como era de se esperar, foi menor no AA. Em termos de atividade eletromiográfica (EMG), o padrão de ativação foi diferente para a maioria dos músculos investigados, e a magnitude dessa atividade foi menor para a maioria desses músculos no AA. $O$ padrão de ativação dos músculos investigados, quando os adultos andaram no AT com a velocidade auto-selecionada confortável, foi o mesmo verificado em outros estudos nas mesmas condições (WINTER, 1991; WINTER \& YACK, 1987; YANG \& WINTER, 1985).

As diferenças encontradas entre os AT e AA foram decorrentes das propriedades físicas do AA e como forma de adaptação dos adultos para andar nesse ambiente. Sendo assim, os adultos andaram mais lentamente na água, uma vez que tinham que vencer a resistência imposta pela força de arrasto. 0 comprimento da passada também diminuiu em decorrência dessa força e provavelmente em decorrência da maior instabilidade que esse ambiente oferece, visto que em condições instáveis, as pessoas diminuem o comprimento da passada (BUNTERNGCHIT, LOCKHART, WOLDSTAD \& SMITH, 2000). Contudo, a diminuição da velocidade não interferiu na duração do período de apoio, como ocorre com o andar no AT (ANDRIACCHI, OGLE \& GALANTE, 1977; KIRTLEY, WHITTLE \& JEFFERSON, 1985). Diferentemente do andar no AT em que a mudança na velocidade interfere diretamente na duração do período de balanço (KIRTLEY, WHITTLE \& JEFFERSON, 1985), a diminuição da velocidade do andar no AA interferiu no ciclo completo do andar. Ainda com relação ao comprimento da passada, é importante salientar que o deslocamento vertical do centro de massa do corpo diminui à medida que o comprimento da passada diminui (INMAN, RALSTON \& TODD, 1994). Sendo assim, como o comprimento da passada foi menor para andar no AA, provavelmente o centro de massa do corpo abaixou menos quando os adultos andaram nesse ambiente.

Um outro aspecto que também pode ser modificado em decorrência do comprimento da passada é o posicionamento do pé na fase de contato inicial. Como 
os adultos apresentaram uma passada mais curta, eles tocaram a superfície de contato com o pé paralelo a essa superfície, ao contrário do AT em que eles tocaram o chão com o calcanhar, que é o que ocorre com os indivíduos sem qualquer comprometimento no aparelho locomotor (PERRY, 1992), conseqüentemente, o ângulo do tornozelo foi diferente na fase de contato inicial. Além disso, o músculo tibial anterior foi menos ativado durante o período de apoio no AA.

Os picos e o vale da componente vertical da FRS não foram tão distintos no AA como no AT em decorrência da velocidade mais lenta e da força empuxo. Esses fatores interferiram também na força de impacto que foi menor nesse ambiente, como constatado anteriormente (NAKAZAWA, YANO \& MYASHITA, 1994). Com uma velocidade mais lenta e um deslocamento vertical do centro de massa do corpo menor, a aceleração nessa direção foi menor e, em conseqüência desses fatores, os dois picos foram menores.

A componente horizontal, por outro lado, foi influenciada pela posição do pé para tocar a superfície de contato e pela força de arrasto. A ausência da fase de desaceleração nessa componente, como observada também por MYOSHI et al. (2004), foi porque o pé empurrou a superfície de contato mais verticalmente do que horizontalmente durante a fase de contato inicial e porque a força de arrasto contribuiu para diminuir a velocidade horizontal no momento em que o pé tocou a superfície de contato, ao contrário do que ocorreu no AT. Porém, assim que o pé tocou essa superfície, uma aceleração horizontal se iniciou para que os adultos continuassem a andar. Neste sentido, enquanto que a força de arrasto facilitou no início do período de apoio, ela dificultou no restante desse período freando o deslocamento do corpo à frente. Isso, contudo, não resultou em maior magnitude da atividade EMG muscular, mas provavelmente da ativação praticamente constante da maioria dos músculos investigados. Enquanto que no AT, pelo menos teoricamente, um pré-requisito para manter uma velocidade constante durante o andar é que as fases de desaceleração e aceleração sejam semelhantes, o que resulta em impulso horizontal próximo de zero (NILSSON \& THORSTENSSON, 1989), no AA, os adultos tiveram que gerar um impulso horizontal maior para superar a força de arrasto e manter uma velocidade constante durante a passada. 
$\mathrm{Na}$ fase de balanço inicial e durante o período de balanço, o joelho flexionou menos do que quando os adultos andaram no AT. Ao contrário do AT, em que o joelho flexiona durante o período de balanço para encurtar o comprimento do membro inferior e evitar que o pé se arraste pela superfície de contato (SUTHERLAND, KAUFMAN \& MOITOZA, 1994), no AA, os adultos não precisaram flexionar o joelho da mesma forma que flexionaram para andar no $A T$, visto que o comprimento da passada foi mais curto e o deslocamento vertical do centro de massa do corpo foi menor.

\section{2 $O$ andar dos idosos nos ambientes terrestre e aquático}

Quando os idosos andaram no AA, eles apresentaram comprimento da passada mais curto, duração mais longa, velocidade mais lenta e cadência mais baixa do que quando eles andaram no AT e mantiveram a mesma duração do período de apoio. A relação entre os segmentos corporais adjacentes, foi parecida ao longo do ciclo, com exceção dos segmentos perna e coxa, uma vez que a ADM do joelho foi menor no AA, como constatado para os adultos entre o AT e o AA. Porém, nas fases de contato inicial e balanço inicial, a relação entre pé e perna (tornozelo), perna e coxa (joelho) e coxa e tronco (quadril) se diferenciaram do AT. Sendo assim, o tornozelo estava em maior extensão e o joelho estava mais flexionado quando o pé tocou a superfície de contato, e o quadril estava mais flexionado quando o pé perdeu esse contato. Com relação às componentes da FRS, assim como para os adultos entre o AT e o AA, a componente vertical não apresentou os dois picos bem definidos, esses picos foram menores, e a componente horizontal ântero-posterior apresentou a fase de aceleração somente. Em termos de atividade EMG, o padrão de ativação foi diferente do apresentado no AT para a maioria dos músculos investigados, e a magnitude dessa atividade foi menor para a maioria desses músculos, novamente, como verificado para os adultos entre o AT e o AA.

Da mesma forma que o andar dos adultos no AT e no AA, as diferenças encontradas foram decorrentes das propriedades físicas do $A A$ e como forma de adaptação dos idosos para andar no AA. Desta forma, a discussão apresentada para o andar dos adultos no AT e no AA pode ser considerada para o andar dos idosos nos mesmos ambientes para a maioria das variáveis investigadas, e somente os 
resultados que foram diferentes dos encontrados para os adultos são discutidos nesse item. Esses resultados estão relacionados ao ângulo do joelho na fase de contato inicial e aos ângulos do joelho e quadril na fase de balanço inicial.

$\mathrm{Na}$ fase de contato inicial, os idosos flexionaram mais o joelho no AA do que no AT. O que ocorreu foi que os idosos mantiveram no AA a mesma flexão que apresentaram no AT durante o período de balanço e, somente após o contato do pé no solo, foi que eles o estenderam. Possivelmente, os idosos utilizaram o contato do pé com a superfície como uma das únicas formas de informação sensorial disponível para se sentirem seguros, uma vez que a informação visual não estava totalmente disponível ou era diferente daquela para andar no AA. Dessa forma, o AA interferiu na informação proprioceptiva desses indivíduos e eles precisaram de uma informação a mais para estender o joelho, que no caso foi o contato do pé com a superfície. Essa possibilidade pode justificar o comportamento do joelho no início do período de apoio no AA, que foi diferente do apresentado no AT. Enquanto que no AT os idosos tocaram a superfície de contato com o joelho estendido e em seguida o flexionaram, no $A A$, eles tocaram a superfície de contato com o joelho flexionado e em seguida o estenderam. É como se houvesse um atraso temporal no movimento articular do joelho. No período de apoio remanescente, o joelho apresentou padrão similar, e tal similaridade contribuiu para que a ADM dessa articulação não fosse alterada durante o período de apoio. DEGANI (2000) encontrou o mesmo resultado em seu estudo, porém, não analisou essa variável em específico.

Em se tratando da fase de balanço inicial, apesar de não haver necessidade de flexionar o joelho quando o pé deixou de tocar a superfície de contato como quando se andou no AT, e como já discutido para o andar dos adultos entre os dois ambientes, os idosos flexionaram o joelho da mesma forma que o flexionaram no AT. Provavelmente, os idosos apresentaram a mesma flexão do joelho por falta de "flexibilidade" para se adaptar às novas condições ambientais, por falta de informação proprioceptiva, ou simplesmente por precaução para evitar que o pé se arrastasse na superfície de contato. Além da flexão do joelho, o quadril estava mais flexionado no AA. Mais uma vez, é provável que os idosos não conseguiram controlar o movimento dessa articulação e então a flexionaram mais do que o necessário, ou pode ter sido uma estratégia adotada por esses indivíduos para 
vencer a resistência da água, uma vez que quanto menor a área frontal, menor a resistência do movimento. Se essa última suposição estiver correta, isso explica o comportamento do quadril ao longo do ciclo do andar. Apesar de diferenças estatísticas não terem sido constatadas entre o AT e o AA, o quadril dos idosos pareceu estar mais flexionado no AA do que no AT na maior parte do ciclo.

\subsection{O andar dos idosos e adultos no ambiente terrestre}

Quando os idosos andaram no AT, várias diferenças foram encontradas em relação aos adultos andando no mesmo ambiente. Eles andaram mais lentamente, com passadas mais curtas e com período de apoio mais longo do que os adultos. A relação entre os segmentos corporais adjacentes foi diferente entre os grupos somente para os segmentos pé e perna durante o período de apoio e no início do período de balanço, uma vez que a ADM do tornozelo foi menor durante o período de apoio e essa articulação apresentou menor extensão quando o pé deixou de tocar a superfície de contato. Em relação às componentes da FRS, as componentes vertical e horizontal ântero-posterior apresentaram o mesmo padrão dos adultos, porém, a magnitude do primeiro pico da componente vertical foi menor e o impacto também foi menor que o dos adultos. Em termos de atividade EMG, 0 padrão de ativação foi o mesmo para a maioria dos músculos investigados (exceto o músculo reto do abdome), e a magnitude dessa atividade foi menor apenas para o músculo vasto lateral (nos períodos de apoio e balanço).

Os resultados encontrados para as variáveis descritivas investigadas nesse estudo referentes às diferenças entre os idosos e adultos andando no AT também foram encontradas em estudos anteriores (FERRANDEZ, PAILHOUS \& DURUP, 1990; LAJOIE et al., 1996; RILEY, DELLA CROCE \& KERRIGAN, 2001a). Ao contrário do que muitos autores sugeriram, é bem provável que os idosos apresentaram tais diferenças como forma de adaptação às mudanças estruturais e funcionais decorrentes da idade e como forma de garantir estabilidade quando estão andando (WINTER et al., 1990).

Em termos de movimentos articulares, os resultados encontrados no presente estudo estão de acordo com resultados de outros estudos para as articulações do tornozelo e do joelho, que encontraram diferenças apenas para a 
articulação do tornozelo (KERRIGAN et al., 1998, 2001; WINTER, 1991), e para a articulação do quadril (ÖBERG, KARSZNIA e ÖBERG, 1994). As diferenças encontradas entre os grupos foram apenas para a ADM do tornozelo e o ângulo dessa articulação na fase de balanço inicial, e essas diferenças podem ser atribuídas à estratégia adotada pelos idosos para manter contato maior com a superfície durante o período de apoio (KERRIGAN et al., 1998). Um contato maior do pé com a superfície pode proporcionar mais estabilidade e garantir melhor equilíbrio durante 0 andar.

Em se tratando das componentes da FRS, não há muita informação disponível sobre essas componentes relacionadas aos idosos andando com velocidade auto-selecionada e confortável. No entanto, os resultados referentes ao primeiro e segundo picos da componente vertical da FRS correspondem aos resultados encontrados anteriormente para idosos andando com velocidades mais lentas que a velocidade adotada pelos idosos no presente estudo (LARISH, MARTIN \& MUNGIOLE, 1988). Entre as variáveis cinéticas investigadas neste estudo, apenas duas apresentaram diferenças entre os grupos no AT: o primeiro pico da componente vertical e a força de impacto, que foram menores para os idosos do que para os adultos. MARTIN e MARSH (1992) sugeriram que é importante considerar os resultados referentes ao comprimento e à freqüência da passada quando se compara as características das componentes da FRS entre diferentes grupos ou condições. Sendo assim, as diferenças encontradas neste estudo foram atribuídas à velocidade mais lenta adotada pelos idosos para andar no AT (ANDRIACCHI, OGLE \& GALANTE, 1977) e ao comprimento da passada (MARTIN \& MARSH, 1992) que foi mais curto para esses indivíduos.

Com relação às variáveis da atividade EMG, YANG e WINTER (1985) verificaram que a cadência do andar interferiu no padrão e na magnitude da atividade EMG dos músculos investigados. Esse fato pode explicar os resultados encontrados no presente estudo, uma vez que os idosos e adultos apresentaram a mesma cadência e não apresentaram diferenças no padrão e magnitude da atividade EMG da maioria dos músculos investigados. Diferenças foram encontradas para o músculo reto do abdome, que pode ser justificado pelo fato de não ter sido todos os participantes, principalmente os idosos, que apresentaram atividade EMG desse 
músculo. Esse fato pode ter sido decorrente da camada de gordura que se concentra na região abdominal, o que dificulta aquisição da atividade EMG, e do fato que o nível de atividade desse músculo foi menor que 5\% da CVMI na maioria dos indivíduos e repetições, como também verificado em um estudo anterior (WHITE \& MCNAIR, 2002).

\section{4 $O$ andar dos idosos e adultos no ambiente aquático}

Finalmente, ao se comparar os idosos e os adultos andando no $A A$, os idosos apresentaram comprimento e duração da passada menores, cadência mais alta e duração do período de apoio mais longo. Porém, a velocidade foi a mesma entre os dois grupos. Em se tratando da relação entre os segmentos corporais adjacentes, o joelho estava mais flexionado na fase de contato inicial, o tornozelo apresentou menor extensão durante o período de apoio, e o tornozelo estava em menor extensão e o joelho e quadril estavam mais flexionados na fase de balanço inicial. Com relação às componentes da FRS, apenas a força de impacto e o impulso foram menores, as demais características não apresentaram diferenças. Em termos de atividade EMG, o padrão de ativação foi similar para a maioria dos músculos investigados e a magnitude dessa atividade foi diferente para vários músculos. Sendo assim, os idosos apresentaram magnitude da atividade EMG maior durante o período de apoio para os músculos tibial anterior, vasto lateral e tensor da fáscia látea, e também apresentaram magnitude dessa atividade maior durante o período de balanço para os músculos gastrocnêmio medial, tibial anterior e vasto lateral.

Algumas diferenças encontradas entre o andar dos idosos e adultos no AT foram encontradas também no $\mathrm{AA}$. Tais diferenças podem estar diretamente relacionadas à questão de estabilidade e adaptação para andar no AA. É o caso, por exemplo, do comprimento da passada, da ADM do tornozelo no período de apoio e do ângulo dessa articulação em extensão na fase de balanço inicial, que foram menores para os idosos do que para os adultos. Provavelmente, os idosos foram mais cautelosos do que os adultos para andar no $A A$, da mesma forma que foram para andar no AT. Conseqüentemente, o ângulo do tornozelo na fase de contato inicial foi menor em extensão, como foi verificado para o andar no AT. Novamente, as estratégias adotadas pelos idosos para garantir estabilidade e equilíbrio durante o 
andar no AT, mantendo o maior contato do pé com a superfície por meio de menor extensão (KERRIGAN et al., 1998), foram mantidas no AA.

Um outro aspecto que também pode estar relacionado à estabilidade é a duração do período de apoio. Da mesma forma que os idosos apresentaram a duração desse período mais longa que os adultos no AT, eles também a apresentaram no AA. Mais uma vez, a duração do período de apoio não pode ser atribuída à velocidade do andar, uma vez que a velocidade que os adultos e os idosos adotaram para andar no AA foi a mesma. Sendo assim, a duração desse período foi decorrente do comprimento da passada, conforme sugerido por MARTIN e MARSH (1992), que foi menor para os idosos do que para os adultos.

Em se tratando da velocidade adotada pelos idosos e adultos para andar no $A A$, alguns fatores podem ter contribuído para que essa velocidade fosse a mesma. Como mencionado anteriormente, os idosos apresentaram maior flexão do joelho e do quadril quando retiraram o pé da superfície. Com essas articulações mais flexionadas, os segmentos perna e coxa estavam mais inclinados e uma área frontal menor teve que ir contra a resistência da água. Considerando que quanto maior a área frontal, maior a resistência encontrada para andar na água, os idosos apresentarem uma área frontal menor porque flexionaram mais o joelho e o quadril. Com uma área frontal menor, os idosos tiveram que vencer uma resistência menor e, portanto, a velocidade de movimento desses indivíduos sofreu menor interferência do que a velocidade de movimento dos adultos. Esse fato pode ter compensado a diferença na velocidade que foi encontrada no AT entre os idosos e adultos e que não foi encontrada no $A A$, e pode ter influenciado na cadência da passada que também foi mais alta para os idosos no $A A$.

Em termos de atividade EMG, os idosos apresentaram magnitude da atividade EMG maior que os adultos para alguns músculos enquanto que não houve diferença entre os grupos para outros músculos. Os músculos que apresentaram diferenças foram os músculos que estão diretamente relacionados aos movimentos articulares do tornozelo, joelho e quadril. Esses resultados corroboram a observação das diferenças verificadas nos movimentos articulares dessas articulações.

Ainda com relação à atividade EMG, é importante ressaltar que o uso de uma proteção adesiva à prova d'água para isolar os eletrodos no AA não interferiu 
nas diferenças encontradas entre os ambientes. De fato, RAINOLDI, CESCON, BOTTIN, CASALE e CARUSO (2004) verificaram que os sinais EMG que foram registrados com eletrodos sem proteção apresentaram maior interferência na magnitude e na freqüência do sinal em decorrência da condutividade e do movimento da água, e sugeriram a necessidade de utilização de proteção adesiva à prova d'água.

\subsection{Implicações para andar no ambiente aquático}

Os idosos e adultos apresentaram maior variabilidade para andar no AA do que para andar no AT. Esse resultado pode ser atribuído a dois aspectos: primeiro, o AA não é um ambiente comum do dia-a-dia para a maioria das pessoas, independentemente da faixa etária em que elas se encontram, uma vez que somos mais acostumados a andar no AT do que no AA. Segundo, o AT é um ambiente mais estável que o AA, ou seja, enquanto que o AT, utilizado no presente estudo, ofereceu condições previsíveis aos idosos e adultos que participaram do estudo, o AA era alterado constantemente à medida que esses indivíduos se deslocavam nesse ambiente por decorrência da movimentação do meio líquido e, conseqüentemente, das forças produzidas pela movimentação da água. Nesse sentido, o AA pode ser considerado um ambiente instável, o que provoca um desafio para quem se locomove nele e, portanto, pode auxiliar na melhora do controle postural dos indivíduos.

Para andar em um ambiente instável, algumas precauções foram tomadas pelos dois grupos. Provavelmente, a diminuição do comprimento da passada foi influenciada por essa instabilidade. A diminuição do comprimento da passada e as forças atuantes no AA, principalmente as forças de arrasto e empuxo, contribuíram para as alterações verificadas quando os participantes andaram no AA. Os idosos sofreram maior interferência do $A A$ na fase de contato inicial, e foram mais conservativos na fase de balanço inicial. Ao que tudo indica, os idosos se deixaram influenciar pelas condições ambientais enquanto a força de arrasto estava agindo como facilitador do movimento e à medida que essa força começou a dificultar o movimento, proporcionando maior resistência, os idosos tentaram reproduzir o padrão de movimento que apresentaram no AT. 
Independentemente da faixa etária, os participantes deste estudo tiveram que alterar a estratégia utilizada no AT quando andaram no AA. Com isso, a ativação muscular foi alterada para a maioria dos músculos investigados da mesma forma que as componentes da FRS foram também alteradas. Os participantes dos dois grupos apresentaram picos de ativação EMG definidos (padrão fásico) quando andaram no AT e apresentaram padrão de ativação quase que constante (padrão tônico) para a maioria dos músculos quando andaram no AA. Conseqüentemente, os movimentos articulares foram os componentes do movimento que sofreram menor interferência do AA quando comparados aos demais componentes.

\section{CONCLUSÃO}

Com base nos resultados do presente estudo, pode-se concluir que:

- O andar na água se difere do andar na terra devido principalmente às forças de arrasto e empuxo;

- A maioria das diferenças encontradas entre os ambientes foi constatada durante dois instantes críticos do andar: quando o pé tocou a superfície de contato (fase de contato inicial) e quando o pé perdeu o contato com essa superfície (fase de balanço inicial). Sendo assim, ao invés de analisar o ciclo completo do andar, é preferível dividir esse ciclo em diferentes períodos e/ou fases;

- Os idosos apresentaram a mesma velocidade que os adultos para andar no AA, provavelmente em decorrência da postura adotada para os segmentos perna e coxa. Esses segmentos estavam mais inclinados nos idosos do que nos adultos e, com isso, uma área frontal menor se movimentou contra a força de arrasto;

- As alterações encontradas entre os ambientes no presente estudo foram decorrentes das características do $\mathrm{AA}$, uma vez que todos os participantes não apresentaram qualquer queixa no aparelho locomotor. Um próximo passo seria investigar indivíduos com algum tipo de comprometimento no aparelho locomotor para verificar quais as influências possíveis desse ambiente;

- Apenas um nível de imersão foi utilizado neste estudo, nível este considerado intermediário. Diferentes níveis de imersão podem ser utilizados para verificar a 
influência das forças de arrasto e empuxo quando uma área menor ou maior for imersa na água. 


\section{REFERÊNCIAS}

ANDRIACCHI, T. P.; OGLE, J. A.; GALANTE, J. O. Walking speed as a basis for normal and abnormal gait measurements. Journal of Biomechanics, New York, v. 10, p. 261-268, 1977.

BASMAJIAN, J. V.; DE LUCA, C. J. Muscles alive. Their functions revealed by electromyography. 5. ed. Baltimore: Williams \& Wilkins, 1985.

BATES, A.; HANSON, N. Aquatic exercise therapy. Ontario: Saunders, 1996.

BECKER, R. A.; GEHM, F.; MARTINEZ, F. G.; LOSS, J. F. Análise cinemática da marcha humana em ambiente aquático. Parte II: diferentes profundidades. In: CONGRESSO BRASILEIRO DE BIOMECÂNICA, 10., 2003, 2003. Ouro Preto. Anais... Ouro Preto: UFMG, 2003. p. 111-114.

BENTON, A. L. Interactive effects of age and brain disease in reaction time. Archives of Neurology, Chicago, v. 34, p. 369-370, 1977.

BRASIL. Lei N ${ }^{\circ} 10.741$, de $1^{\circ}$ de outubro de 2003. Dispõe sobre o estatuto do idoso e dá outras providências. Disponível em:

http:<//www6.senado.gov.br/legislacao/ListaPublicacoes .action?id=237486>. Acesso em: 23 maio 2005.

BRITO, R. N.; ROESLER, H.; HAUPENTHAL, A.; SOUZA, P. V. Análise comparativa da marcha humana em solo à subaquática em dois níveis de imersão: joelho e quadril. Revista Brasileira de Fisioterapia, São Carlos, v. 8, p. 7-12, 2004.

BUNTERNGCHIT, Y.; LOCKHART, T.; WOLDSTAD, J. C.; SMITH, J. L. Age related effects of transitional floor surfaces and obstruction of view on gait characteristics related to slips and falls. International Journal of Industrial Ergonomics, v. 25, p. 223-232, 2000. 
BURDEN, A. M.; TREW, M.; BALTZOPOULOS, V. Normalisation of gait EMGs: a reexamination. Journal of Electromyography and Kinesiology, v. 13, p. 519-532, 2003.

BUTTS, N. K.; TUCKER, M.; GREENING, C. Physiologic responses to maximal treadmill and deep water running in men and women. American Journal of Sports Medicine, Baltimore, v. 19, p. 612-614, 1991.

CAPOZZO, A. Gait analysis methodology. Human Movement Science, Amsterdam, v. 3, p. 27-50, 1984.

CHUNG, S. H.; GIULIANI, C. A. Whithin- and between-session consistency for electromyographic temporal patterns of walking in non-disabled older adults. Gait \& Posture, Amsterdam, v. 6, p. 110-118, 1997.

CLARYS, J. P.; CABRI, J. Electromyography and the study of sports movements: a review. Journal of Sports Science, v. 11, p. 379-448, 1993.

CRAIK, R. Changes in locomotion in the aging adult. In: WOOLLACOTT, M. H.; SHUMWAY-COOK, A. (Eds.). Development of posture and gait across the life span. Columbia: University of South Carolina, 1990, p. 176-201.

DE LUCA, C. J. The use of surface electromyography in biomechanics. Journal of Applied Biomechanics, Champaign, v. 13, p. 135-163, 1997.

DEGANI, A. M. O andar hemiplégico em ambiente aquático. 2000. Dissertação (Mestrado) - Instituto de Biociências, Universidade Estadual Paulista, Rio Claro.

DEGANI, A. M.; BARELA, J. A. Parâmetros espaço-temporais e angulares do andar de indivíduos idosos em ambiente aquático. In: CONGRESSO BRASILEIRO DE BIOMECÂNICA, 9., 2001. Gramado. Anais... Gramado: UFRS, 2001. p. 152-157. 
DUBO, H. I.; PEAT, M.; WINTER, D. A.; QUANBURY, A. O.; HOBSON, D. A.; STEINKE, T.; REIMER, G. Electromyographic temporal analysis of gait: normal human locomotion. Archives of Physical Medicine and Rehabilitation, Philadelphia, v. 57, p. 415-420, 1976.

ERVILHA, U. F.; DUARTE, M.; AMADIO, A. C. Cinemática da articulação do joelho e atividade eletromiográfica de músculos do membro inferior durante a marcha em ambiente aquático e terrestre. Revista Brasileira de Biomecânica, São Paulo, v. 3, p. 21-26, 2002.

FERRANDEZ, A. M.; PAILHOUS, J.; DURUP, M. Slowness in elderly gait. Experimental Aging Research, Bristol, v. 16, p. 79-89, 1990.

FERRANDEZ, A.-M.; DURUP, M.; FARIOLI, F. Slowness, variability, and modulations of gait in healthy elderly. In: FERRANDEZ, A.-M.; TEASDALE, N. (Eds.). Changes in sensory motor behavior in aging. New York: Elsevier, 1996, p. 53-88.

FRANK, J. S.; PATLA, A. E. Balance and mobility challenges in older adults: implications for preserving community mobility. American Journal of Preventive Medicine, Amsterdam, v. 25, p. 157-163, 2003.

FRANKENBURG, W. K.; DODDS, J.; ARCHER, P.; SHAPIRO, H.; BRENSNICK, B. The Denver II: A major revision and restandardization of the Denver Development Screening Test. Pediatrics, Elk Grove Village, v. 89, p. 91-97, 1992.

FRERIKS, B.; HERMENS, H. J. SENIAM 9: European recommendations for surface electromyography. The Netherlands: Roessingh Research and Development b.v., 1999. CD-ROM.

GAGE, J. R. Gait analysis in cerebral palsy. London: Mac Keith Press, 1991. 
GEHM, F.; BECKER, R. A.; MARTINEZ, F. G.; LOSS, J. F. Análise cinemática da marcha humana em ambiente aquático. Parte $\mathrm{I}$ : terra $X$ água. In: CONGRESSO BRASILEIRO DE BIOMECÂNICA, 10., 2003. Ouro Preto. Anais... Ouro Preto: UFMG, 2003. p. 107-110.

GLEIN, G. W.; NICHOLAS, J. A. Metabolic costs and heart rate responses to treadmill walking in water at different depths and temperatures. The American Journal of Sports Medicine, Thousand Oaks, v. 17, p. 248-252, 1989.

HAMILL, J.; KNUTZEN, K. M. Bases biomecânicas do movimento humano. São Paulo: Manole, 1999.

HARRISON, R. A.; HILLMAN, M.; BUSTRODE, S. Loading of the lower limb when walking partially immersed: implications for clinical practice. Physiotherapy, London, v. 78, p. 164-166, 1992.

HEYNEMAN, C. A.; PREMO, D. E. A 'water walkers' exercise program for the elderly. Public Health Reports, v. 107, p. 213-217, 1992.

HIMANN, J. E.; CUNNINGHAM, D. A.; RECHNITZER, P. A.; PATERSON, D. H. Agerelated changes in speed of walking. Medicine Science of Sports and Exercise, Hagerstown, v. 20, p. 161-166, 1988.

HINKLE, D. E.; WIERSMA, W.; JURS, S. G. Applied statistics for the behavioral sciences. 3rd. Boston: Houghton Mifflin, 1994.

INMAN, V. T.; RALSTON, H. J.; TODD, F. Human locomotion. In: ROSE, J.; GAMBLE, J. G. (Eds.). Human walking. 2. ed. Baltimore: Williams \& Wilkins, 1994, p. 1-22.

KERRIGAN, D. C.; TODD, M. K.; DELLA CROCE, U.; LIPSITZ, L. A.; COLLINS, J. J. Biomechanical gait alterations independent of speed in the healthy elderly: evidence 
for specific limiting impairments. Archives of Physical Medicine and Rehabilitation, Philadelphia, v. 79, p. 317-322, 1998.

KERRIGAN, D. C.; LEE, L. W.; COLLINS, J. J.; RILEY, P. O.; LIPSITZ, L. A. Reduced hip extension during walking: healthy elderly and fallers versus young adults. Archives of Physical Medicine and Rehabilitation, Philadelphia, v. 82, p. 26-30, 2001.

KERRIGAN, D. C.; LEE, L. W.; NIETO, T. J.; MARKMAN, J. D.; COLLINS, J. J.; RILEY, P. O. Kinetic alterations independent of walking speed in elderly fallers. Archives of Physical Medicine and Rehabilitation, Philadelphia, v. 81, p. 730-735, 2000.

KIRTLEY, C.; WHITTLE, M. W.; JEFFERSON, R. J. Influence of walking speed on gait parameters. Journal of Biomedical Engineering, v. 7, p. 282-288, 1985.

KREIGHBAUM, E.; BARTHELS, K. M. Biomechanics: a qualitative approach for studying human movement. 4. ed. Boston: Allyn and Bacon, 1996.

KWON, Y.-O. Object plane deformation due to refraction in two-dimensional underwater motion analysis. Journal of Applied Biomechanics, Champaign, v. 15, p. 396-403, 1999.

LAJOIE, Y.; TEASDALE, N.; BARD, C.; FLEURY, M. Upright standing and gait: are there changes in attentional requirements related to normal aging? Experimental Aging Research, Bristol, v. 22, p. 185-198, 1996.

LARISH, D. D.; MARTIN, P. E.; MUNGIOLE, M. Characteristic patterns of gait in the health old. In: JOSEPH, J. A. (Eds.). Central determinants of age-related declines in motor function. New York: The New York Academy of Sciences, 1988, p. 18-32. 
LARSSON, L.; GRIMBY, G.; KARLSSON, J. Muscle strength and speed of movement in relation to age and muscle morphology. Journal of Applied Physiology, Washington, v. 46, p. 451-456, 1979.

MARTIN, M.; MARSH, A. P. Step length and frequency effects on ground reaction forces during walking. Journal of Biomechanics, New York, v. 25, p. 1237-1239, 1992.

MCMURRAY, R. G.; FIESELMAN, C. C.; AVERY, K. E. Exercise hemodynamics in water and on land in patients with coronary artery disease. Journal of Cardiopulmonary Rehabilitation, Philadelphia, v. 8, p. 68-75, 1988.

MILLS, P. M.; BARRETT, R. S. Swing phase mechanics of healthy young and elderly men. Human Movement Science, Amsterdam, v. 20, p. 427-446, 2001.

MIYOSHI, T.; SATOH, T.; NAKAZAWA, K.; KOMEDA, T.; YANO, H. Selective activation of human soleus and medial gastrocnemius muscles during walking in water. Journal of Gravitational Physiology, El Cerrito, v. 7, p. P107-108, 2000.

MIYOSHI, T.; SHIROTA, T.; YAMAMOTO, S.; NAKAZAWA, K.; AKAI, M. Effect of the walking speed to the lower limb joint angular displacements, joint moments and ground reaction forces during walking in water. Disability and Rehabilitation, London, v. 26, p. 724-732, 2004.

NAKAZAWA, K.; YANO, H.; MYASHITA, M. Ground reaction forces during walking in water. Medicine and Sports Science, v. 39, p. 28-34, 1994.

NIGG, B. M.; HERZOG, W. Biomechanics of the musculo-skeletal system. 2. ed. Chichester: John Wiley \& Sons, 2002.

NIGG, B. M.; FISHER, V.; RONSKY, J. L. Gait characteristics as a function of age and gender. Gait \& Posture, Amsterdam, v. 2, p. 213-220, 1994. 
NILSSON, J.; THORSTENSSON, A. Ground reaction forces at different speeds of human walking and running. Acta Physiologica Scandinavica, Stockholm, v. 136, p. 217-227, 1989.

PERRY, J. Gait analysis: normal and pathological function. Throfare: SLACK, 1992.

PRINCE, F.; CORRIVEAU, H.; HÉBERT, R.; WINTER, D. A. Gait in elderly. Gait \& Posture, Amsterdam, v. 5, p. 128-135, 1997.

RAINOLDI, A.; CESCON, C.; BOTTIN, A.; CASALE, R.; CARUSO, I. Surface EMG alterations induced by underwater recording. Journal of Electromyography and Kinesiology, Oxford, v. 14, p. 325-331, 2004.

RILEY, P. O.; DELLA CROCE, U.; KERRIGAN, D. C. Effect of age on lower extremity joint moment contributions to gait speed. Gait \& Posture, Amsterdam, v. 14, p. 264270, 2001a.

. Propulsive adaptation to changing gait speed. Journal of Biomechanics, New York, v. 34, p. 197-202, $2001 b$.

RISCH, W. D.; KOUBENEC, H. J.; BECKMANN, U.; LANGE, S.; GAUER, O. H. The effect of graded immersion on heart volume, central venous pressure, pulmonary blood distribution, and heart rate in man. Pflügers Archiv: European journal of physiology, Berlin, v. 374, p. 115-118, 1978.

ROBERTSON, D. G. E.; CALDWELL, G. E.; HAMILL, J.; KAMEN, G.; WHITTLESEY, S. N. Research methods in biomechanics. Champaing: Human Kinetics, 2004.

ROSE, J.; GAMBLE, J. G. Human walking. 2. ed. Baltimore: Williams \& Wilkins, 1994. 
SCHULZ, R.; SALTHOUSE, T. Adult development and aging: miths and emerging realities. 3. ed. New Jersey: Prentice Hall, 1999.

SHELDAHL, L. M. Special ergometric techniques and weight reduction. Medicine Science of Sports and Exercise, Hagerstown, v. 18, p. 25-30, 1986.

SIMMONS, V.; HANSEN, P. D. Effectiveness of water exercise on postural mobility in the well elderly: an experimental study on balance enhancement. Journal of Gerontology, Washington, DC, v. 51A, p. M233-M238, 1996.

SKINNER, A. T.; THOMSON, A. M. Duffield: exercícios na água. 3. ed. São Paulo: Manole, 1985.

SODERBERG, G. L. Gait and gait retraining. In: BASMAJIAN, J. V.; WOLF, S. L. (Eds.). Therapeutic exercise. Baltimore: Williams\&Wilkins, 1990, p.

SPIRDUSO, W. W. Physical dimensions of aging. Champaign: Human Kinetics, 1995.

SUTHERLAND, D. H. The development of mature gait. Gait \& Posture, Amsterdam, v. 6, p. 163-170, 1997.

SUTHERLAND, D. H.; KAUFMAN, K. R.; MOITOZA, J. R. Kinematics of normal human walking. In: ROSE; J.; GAMBLE, J. G. (Eds.). Human walking. $2^{\text {nd }}$. Baltimore: Williams \& Wilkins, 1994, p. 23-44.

TIPLER, P. A. Física para cientistas e engenheiros. 4. ed. Rio de Janeiro: LTC, 2000.

VAUGHAN, C. L.; DAVIS, B. L.; O'CONNOR, J. C. Dynamics of human gait. 2. ed. Cape Town: Kiboho Publishers, 1999. CD-ROM. 
WADELL, K.; SUNDELIN, G.; HENRIKSSON-LARSEN, K.; LUNDGREN, R. High intensity physical group training in water--an effective training modality for patients with COPD. Respiratory Medicine, v. 98, p. 428-438, 2004.

WALKER, J. M.; SUE, D.; MILES-ELKOUSY, N.; FORD, G.; TREVELYAN, H. Active mobility of the extremities in older subjects. Physical Therapy, Alexandria, v. 64, p. 919-923, 1984.

WHITE, M. Water exercise: 78 safe and effective exercises for fitness and therapy. Champaign: Human Kinetics, 1995.

WHITE, S. G.; MCNAIR, P. J. Abdominal and erector spinae muscle activity during gait: the use of cluster analysis to identify patterns of activity. Clinical Biomechanics, Oxford, v. 17, p. 177-184, 2002.

WHITTLE, M. W. Clinical gait analysis: a review. Human Movement Science, Amsterdam, v. 15, p. 369-387, 1996a.

. Gait analysis: an introduction. 2. ed. Oxford: Butterworth Heinemann, 1996b.

WIECZOREK, S. A. Equilíbrio em adultos e idosos: relação entre o tempo de movimento e acurácia durante movimentos voluntários na postura em pé. 2003. Dissertação (Mestrado) - Escola de Educação Física e Esporte, Universidade de São Paulo, São Paulo.

WINTER, D. A. Biomechanical motor patterns in normal walking. Journal of Motor Behavior, Washington, v. 15, p. 302-330, 1983.

Biomechanics and motor control of human movement. 2. ed. New York: John Wiley \& Sons., 1990. 
. The biomechanics and motor control of human gait: normal, elderly, and pathological. 2. ed. Waterloo: University of Waterloo Press, 1991.

WINTER, D. A.; YACK, H. J. EMG profiles during normal human walking: stride-tostride and inter-subject variability. Electroencephalography and Clinical Neurophysiology, Amsterdam, v. 67, p. 402-411, 1987.

WINTER, D. A.; PATLA, A. E.; FRANK, J. S.; WALT, S. E. Biomechanical walking pattern changes in the fit and healthy elderly. Physical Therapy, Alexandria, v. 70, p. 340-347, 1990.

YAMAMOTO, S.; NAKAZAWA, K.; YANO, H. Lower limb kinematic during walking in water. In: ISB CONGRESS, 1995. Jyvaskyla. Books of Abstracts... Jyvaskyla: University of Jyvaskyla, 1995. p. 1012-1013.

YANG, J. F.; WINTER, D. A. Electromyographic amplitude normalization methods: improving their sensitivity as diagnostic tools in gait analysis. Archives of Physical Medicine and Rehabilitation, v. 65, p. 517-521, 1984.

- Surface EMG profiles during different walking cadences in humans. Electroencephalography and Clinical Neurophysiology, v. 60, p. 485-491, 1985.

YANO, H.; NAKAZAWA, K.; YAMAMOTO, S. Activation patterns of human ankle muscles during walking in water. In: ISB CONGRESS, 1995. Jyvaskyla. Books of Abstracts... Jyvaskyla: University of Jyvaskyla, 1995. p. 1018-1019. 
ANEXO I - Anamnese.

\section{DADOS CADASTRAIS}

Nome:

Data de nascimento:

Endereço:

Cidade:

CEP:

Telefone:

Telefone (recado):

Moro com pessoas.

Nome do médico: Telefone:

ANAMNESE CLÍNICA

\begin{tabular}{|l|l|l|l|}
\hline Problemas de Saúde & Sim & Não & Observações \\
\hline Pressão arterial alta & & & \\
\hline Pressão arterial baixa & & & \\
\hline Problema cardíaco & & & \\
\hline \multicolumn{1}{|c|}{ Marca-passo } & & & \\
\hline Colesterol alto & & & \\
\hline Triglicérides alto & & & \\
\hline Tireóide & & & \\
\hline Diabetes & & & \\
\hline Osteoporose & & & \\
\hline Artrite & & & \\
\hline Artrose & & & \\
\hline Tendinite & & & \\
\hline Problema muscular & & & \\
\hline Desvio na cervical & & & \\
\hline Torácica & & & \\
\hline Lombar & & & \\
\hline Deficiência auditiva & & & \\
\hline Aparelho auditivo & & & \\
\hline Deficiencia visual & & & \\
\hline
\end{tabular}


ANEXO I - Anamnese (cont.).

\begin{tabular}{|c|l|l|l|}
\hline Doença Neurológica & & & \\
\hline Crises convulsivas & & & \\
\hline Deficiência física & & & \\
\hline Órtese & & & \\
\hline Prótese & & & \\
\hline Labirintite & & & \\
\hline Outros & & & \\
\hline
\end{tabular}

\begin{tabular}{|l|l|l|l|}
\hline Sintomas & Sim & Não & Observações \\
\hline Dores de cabeça & & & \\
\hline TONTURAS & & & \\
\hline Vertigens & & & \\
\hline Nistagmo & & & \\
\hline Dor muscular & & & \\
\hline Fraqueza muscular & & & \\
\hline Fraqueza generalizada & & & \\
\hline Enrijecimento articular & & & \\
\hline Dor na coluna cervical & & & \\
\hline Torácica & & & \\
\hline \multicolumn{1}{|c|}{ Lombar } & & & \\
\hline Outros & & \\
\hline
\end{tabular}

\section{Medicamentos}

Usa medicamentos regularmente: ( ) Sim ( )Não

\begin{tabular}{|l|l|l|l|l|}
\hline Tipos & Sim & Não & Posologia & Observações \\
\hline Anti-depressivo & & & & \\
\hline Diurético & & & & \\
\hline Hormônio & & & & \\
\hline Calmante & & & & \\
\hline
\end{tabular}


ANEXO I - Anamnese (cont.).

\begin{tabular}{|l|l|l|l|l|}
\hline Analgésico & & & & \\
\hline Estimulante & & & & \\
\hline Anti-inflamatório & & & & \\
\hline Outros & & & & \\
\hline
\end{tabular}

Hábitos Comuns

\begin{tabular}{|l|l|l|l|l|}
\hline Hábito & Sim & Não & Tipo & Quanto \\
\hline Tabagismo & & & & \\
\hline Bebida alcoólica & & & & \\
\hline Calçado mais utilizado & & & & \\
\hline Outros & & & & \\
\hline
\end{tabular}

História de Quedas

\begin{tabular}{|l|l|l|l|l|}
\hline Característica & Sim & Não & Freqüência & Como \\
\hline $\begin{array}{l}\text { Dificuldade para realizar } \\
\text { movimentos rápidos }\end{array}$ & & & & \\
\hline $\begin{array}{l}\text { Dificuldade de equilibrar- } \\
\text { se }\end{array}$ & & & & \\
\hline Perde equilíbrio facilmente & & & & \\
\hline Tropeça facilmente & & & & \\
\hline $\begin{array}{l}\text { Sente alguma coisa } \\
\text { quando se levanta } \\
\text { rapidamente }\end{array}$ & & & & \\
\hline $\begin{array}{l}\text { Dificuldade para sentir a } \\
\text { forma, textura, } \\
\text { temperatura de objetos } \\
\text { (pés) }\end{array}$ & & & & \\
\hline Sofre quedas & & & & \\
\hline $\begin{array}{l}\text { Sente tontura durante a } \\
\text { queda }\end{array}$ & & & & \\
\hline $\begin{array}{l}\text { Quando ocorreu a queda } \\
\text { mais recente }\end{array}$ & & & & \\
\hline Sofreu fraturas & & & \\
\hline Outras lesões & & & \\
\hline
\end{tabular}


ANEXO I - Anamnese (cont.).

Fez cirurgia

Outros

\section{QUESTÕES ADICIONAIS}

Pratica atividade(s) aquática(s)? Qual(is)?

Freqüência? Há quanto tempo pratica a(s) atividade(s) acima?

Outras atividades físicas? Quais?

Há quanto tempo? Freqüência? 
ANEXO II - Informações sobre o programa de educação física para idosos da Escola de Educação Física e Esporte, Universidade de São Paulo.

\begin{tabular}{|c|c|}
\hline $\begin{array}{l}\text { Docente } \\
\text { Responsável: }\end{array}$ & Profa. Dra. Suely dos Santos \\
\hline Objetivo: & $\begin{array}{l}\text { Visa melhorar e manter em nível ótimo as capacidades físicas, } \\
\text { motoras e funcionais dos idosos }\end{array}$ \\
\hline Público alvo: & Comunidade em geral com mais de 60 anos \\
\hline Horário: & $\begin{array}{l}3^{a} \text { e } 5^{a} \text { das } 08: 40 h s \text { ou } 10: 00 h s \\
4^{a} \text { e } 6^{a} \text { das } 08: 40 h s \text { ou } 10: 00 h s\end{array}$ \\
\hline $\begin{array}{l}\text { Corpo } \\
\text { docente: }\end{array}$ & Professora Rosana Aparecida Andreotti \\
\hline Programa: & $\begin{array}{l}\text { Conhecer e conscientizar-se de seu corpo, das suas capacidades } \\
\text { funcionais, das suas habilidades motoras e das suas limitações; } \\
\text { desenvolver capacidades físicas e motoras como força, } \\
\text { flexibilidade, capacidade aeróbia, agilidade, equilíbrio, tempo de } \\
\text { reação e de movimento, para aumentar a aptidão física geral/total } \\
\text { e por decorrência da capacidade funcional; descobrir o prazer de } \\
\text { movimentar-se e de dominar o próprio corpo em diferentes } \\
\text { situações motoras e em situações desafio; transferir para o } \\
\text { cotidiano as habilidades motoras aprendidas e os novos domínios } \\
\text { adquiridos. }\end{array}$ \\
\hline
\end{tabular}


ANEXO III - Carta do Comitê de Ética.

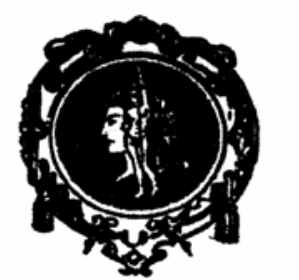

\section{UNIVERSIDADE DE SÃO PAULO ESCOLA dE EdUCAÇÃo FÍSICA E ESPORTE}

Of.CEP/04102/EEFE/19092002

Ref.: Parecer $\underline{\text { CEP n }}{ }^{\circ} 016$

Pelo presente, informo que o Comitê de Ética em Pesquisa da EEFE-USP aprovou, quanto aos aspectos éticos em pesquisa, em reunião de 17/09/02, de acordo com os requisitos da Resolução CNS/196/96, o projeto de pesquisa intitulado "Análise do andar de idosos em ambientes aquático e terrestre", sob a responsabilidade de Marcos Duarte.

Atenciosamente,

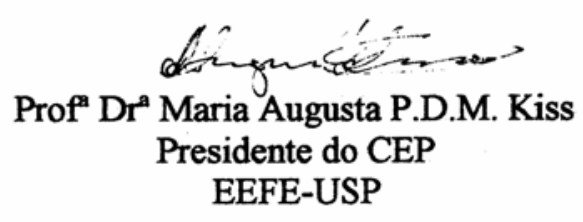

Ao

Ilmo. Sr.

Prof. Dr. Marcos Duarte 
ANEXO IV - Termo de consentimento.

Projeto Análise do Andar de Adultos e Idosos nos Ambientes Terrestre e Aquático

Eu, declaro que tenho anos de idade e

concordo em participar das pesquisas conduzidas pela Profa. Ms. Ana Maria Forti Barela e Prof. Dr. Marcos Duarte na Escola de Educação Física e Esporte, Universidade de São Paulo.

\section{Objetivo do Estudo:}

O objetivo deste estudo é analisar como o andar é executado dentro e fora da água.

\section{Explicação do procedimento:}

Durante o experimento, irei locomover-me andando primeiramente fora da água e posteriormente dentro de uma piscina. Pequenas marcas serão afixadas com fita adesiva na minha pele para registrar os deslocamentos das minhas pernas e pés e a atividade dos meus músculos. Estas marcas não serão conectadas a nenhum cabo elétrico.

\section{Duração do experimento:}

Cada experimento terá a duração de aproximadamente uma hora e será realizado em apenas um dia.

\section{Benefícios:}

Irei ajudar no entendimento da locomoção de idosos tanto dentro como fora da água e estou ciente de que este estudo poderá trazer benefícios para diversas populações que enfrentam problemas de locomoção. Porém, não terei nenhum benefício direto.

\section{Desconforto e risco:}

Fui informado de que o experimento será não-invasivo e que não envolve qualquer risco à minha saúde física e mental, além dos riscos encontrados nas atividades normais da vida diária.

\section{Liberdade de participação:}

A minha participação neste estudo é voluntária, tenho direito de interrompê-la a qualquer momento e minha identidade não será revelada. Eu tenho direito de fazer qualquer pergunta nos intervalos do experimento. Os pesquisadores me explicaram todos os riscos envolvidos, a necessidade da pesquisa e se prontificaram a responder todas as questões sobre o experimento. Eu aceitei participar neste estudo de livre e espontânea vontade.

Entendo que é meu direito manter uma cópia deste consentimento.

Nome por extenso

$\overline{R G}$

Data

\section{Assinatura do voluntário}

Telefone para contato

Para questões associadas com este estudo, por favor, entrar em contato com Profa. Ms. Ana Maria Forti Barela e/ou Prof. Dr. Marcos Duarte (coordenador do Laboratório de Biofísica).

Rua Prof. Mello Moraes, 65 - Cidade Universitária CEP: 05508-030 Fone/Fax: (11) 3812-6123 
ANEXO V - Resultados dos testes post hoc de Tukey da interação entre grupos (adultos e idosos) e ambientes (ambiente terrestre (AT) e ambiente aquático (AA)) de acordo com as variáveis analisadas.

Duração da passada:

\begin{tabular}{|c|c|c|c|c|c|c|}
\hline Grupo & Ambiente & Média & $\begin{array}{c}\{1\} \\
0,95\end{array}$ & $\begin{array}{c}\{2\} \\
2,40\end{array}$ & $\begin{array}{c}\{3\} \\
0,99\end{array}$ & $\begin{array}{c}\{4\} \\
2,02\end{array}$ \\
\hline Adultos & AT $\{1\}$ & & - & $28,80^{*}$ & 0,79 & . \\
\hline Adultos & $A A\{2\}$ & & $28,80^{*}$ & - & - & $7,55^{*}$ \\
\hline Idosos & AT $\{3\}$ & & 0,79 & - & - & $20,46^{*}$ \\
\hline Idosos & $A A\{4\}$ & & - & $7,55^{*}$ & $20,46^{*}$ & $\begin{array}{l}- \\
-\end{array}$ \\
\hline
\end{tabular}

Velocidade da passada:

\begin{tabular}{|c|c|c|c|c|c|c|}
\hline Grupo & Ambiente & Média & $\begin{array}{c}\{1\} \\
1,39\end{array}$ & $\begin{array}{c}\{2\} \\
0,50\end{array}$ & $\begin{array}{c}\{3\} \\
1,20\end{array}$ & $\begin{array}{c}\{4\} \\
0,49\end{array}$ \\
\hline Adultos & AT $\{1\}$ & & - & $24,28^{*}$ & $5,18^{*}$ & - \\
\hline Adultos & $A A\{2\}$ & & $24,28^{*}$ & - & - & 0,27 \\
\hline Idosos & AT $\{3\}$ & & $5,18^{*}$ & - & - & $-19,37^{*}$ \\
\hline Idosos & $\mathrm{AA}\{4\}$ & & - & 0,27 & $19,37^{*}$ & - \\
\hline
\end{tabular}

\section{Cadência da passada:}

\begin{tabular}{|c|c|c|c|c|c|c|}
\hline Grupo & Ambiente & Média & $\begin{array}{c}\{1\} \\
2,11\end{array}$ & $\begin{array}{c}\{2\} \\
0,84\end{array}$ & $\begin{array}{c}\{3\} \\
2,04\end{array}$ & $\begin{array}{c}\{4\} \\
1,04\end{array}$ \\
\hline Adultos & AT $\{1\}$ & & - & $42,52^{*}$ & 2,34 & - \\
\hline Adultos & $\mathrm{AA}\{2\}$ & & $42,52^{*}$ & - & - & $6,70^{*}$ \\
\hline Idosos & AT $\{3\}$ & & 2,34 & 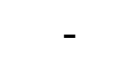 & - & $33,48^{*}$ \\
\hline Idosos & $A A\{4\}$ & & - & $6,70^{*}$ & $33,48^{*}$ & - \\
\hline
\end{tabular}


ANEXO V - Resultados dos testes post hoc de Tukey da interação entre grupos (adultos e idosos) e ambientes (ambiente terrestre (AT) e ambiente aquático (AA)) de acordo com as variáveis analisadas (cont.).

Posição articular do joelho na fase de contato inicial:

\begin{tabular}{|c|c|c|c|c|c|c|}
\hline Grupo & Ambiente & Média & $\begin{array}{c}\{1\} \\
6,98\end{array}$ & $\begin{array}{c}\{2\} \\
8,13\end{array}$ & $\begin{array}{c}\{3\} \\
4,36\end{array}$ & $\begin{array}{c}\{4\} \\
16,02\end{array}$ \\
\hline Adultos & AT $\{1\}$ & & - & 0,81 & 1,84 & - \\
\hline Adultos & $\mathrm{AA}\{2\}$ & & 0,81 & - & - & $5,55^{*}$ \\
\hline Idosos & AT $\{3\}$ & & 1,84 & - & - & 8,20 * \\
\hline Idosos & $\mathrm{AA}\{4\}$ & & - & $5,55^{*}$ & $8,20^{*}$ & - \\
\hline
\end{tabular}

Posição articular do joelho na fase de balanço inicial:

\begin{tabular}{|c|c|c|c|c|c|c|}
\hline Grupo & Ambiente & Média & $\begin{array}{c}\{1\} \\
42,35\end{array}$ & $\begin{array}{c}\{2\} \\
35,29\end{array}$ & $\begin{array}{c}\{3\} \\
40,83\end{array}$ & $\begin{array}{c}\{4\} \\
42,49\end{array}$ \\
\hline Adultos & AT $\{1\}$ & & - & $4,36^{*}$ & 0,94 & - \\
\hline Adultos & $\mathrm{AA}\{2\}$ & & $4,36^{*}$ & - & - & $4,45^{*}$ \\
\hline Idosos & AT $\{3\}$ & & 0,94 & - & - & 1,03 \\
\hline Idosos & $\mathrm{AA}\{4\}$ & & - & $4,45^{*}$ & 1,03 & - \\
\hline
\end{tabular}

Posição articular do quadril na fase de balanço inicial:

\begin{tabular}{|c|c|c|c|c|c|c|}
\hline Grupo & Ambiente & Média & $\begin{array}{c}\{1\} \\
-0,96\end{array}$ & $\begin{array}{c}\{2\} \\
1,94\end{array}$ & $\begin{array}{c}\{3\} \\
-1,55\end{array}$ & $\begin{array}{c}\{4\} \\
8,20\end{array}$ \\
\hline Adultos & AT $\{1\}$ & & - & 2,15 & 0,44 & - \\
\hline Adultos & $\mathrm{AA}\{2\}$ & & 2,15 & - & - & $4,65^{\star}$ \\
\hline Idosos & AT $\{3\}$ & & 0,44 & - & - & $7,24^{*}$ \\
\hline Idosos & $\mathrm{AA}\{4\}$ & & - & $4,65^{*}$ & $7,24^{*}$ & $\begin{array}{ll}- \\
-\end{array}$ \\
\hline
\end{tabular}


ANEXO V - Resultados dos testes post hoc de Tukey da interação entre grupos (adultos e idosos) e ambientes (ambiente terrestre (AT) e ambiente aquático (AA)) de acordo com as variáveis analisadas (cont.).

Impulso horizontal:

\begin{tabular}{|c|c|c|c|c|c|c|}
\hline Grupo & Ambiente & Média & $\begin{array}{c}\{1\} \\
0,00\end{array}$ & $\begin{array}{c}\{2\} \\
0,20\end{array}$ & $\begin{array}{c}\{3\} \\
0,00\end{array}$ & $\begin{array}{c}\{4\} \\
0,15\end{array}$ \\
\hline Adultos & AT $\{1\}$ & & - & $16,91^{*}$ & 0,02 & - \\
\hline Adultos & $\mathrm{AA}\{2\}$ & & $16,91^{*}$ & - & - & $12,70^{*}$ \\
\hline Idosos & AT $\{3\}$ & & 0,02 & - & - & $4,23^{*}$ \\
\hline Idosos & $\mathrm{AA}\{4\}$ & & - & $12,70^{*}$ & $4,23^{*}$ & - \\
\hline
\end{tabular}

Magnitude da atividade EMG do músculo tensor da fáscia látea durante o período de apoio:

\begin{tabular}{|c|c|c|c|c|c|c|}
\hline Grupo & Ambiente & Média & $\begin{array}{c}\{1\} \\
-0,99\end{array}$ & $\begin{array}{c}\{2\} \\
-1,31\end{array}$ & $\begin{array}{c}\{3\} \\
-0,97\end{array}$ & $\begin{array}{c}\{4\} \\
-0,94\end{array}$ \\
\hline Adultos & AT $\{1\}$ & & - & $5,10^{*}$ & 0,40 & - \\
\hline Adultos & $\mathrm{AA}\{2\}$ & & $5,10^{*}$ & - & - & $5,93^{*}$ \\
\hline Idosos & AT $\{3\}$ & & 0,40 & - & - & 0,43 \\
\hline Idosos & $A A\{4\}$ & & - & $5,93^{*}$ & 0,43 & - \\
\hline
\end{tabular}

Magnitude da atividade EMG do músculo tibial anterior durante o período de apoio:

\begin{tabular}{|c|c|c|c|c|c|c|}
\hline Grupo & Ambiente & Média & $\begin{array}{c}\{1\} \\
-0,34\end{array}$ & $\begin{array}{c}\{2\} \\
-0,71\end{array}$ & $\begin{array}{c}\{3\} \\
-0,42\end{array}$ & $\begin{array}{c}\{4\} \\
-0,53\end{array}$ \\
\hline Adultos & AT $\{1\}$ & & - & $8,52^{*}$ & 1,81 & - \\
\hline Adultos & $A A\{2\}$ & & $8,52^{*}$ & - & - & $4,16^{*}$ \\
\hline Idosos & AT $\{3\}$ & & 1,81 & - & - & 2,27 \\
\hline Idosos & $\mathrm{AA}\{4\}$ & & - & $4,16^{*}$ & 2,27 & - \\
\hline
\end{tabular}


ANEXO V - Resultados dos testes post hoc de Tukey da interação entre grupos (adultos e idosos) e ambientes (ambiente terrestre (AT) e ambiente aquático (AA)) de acordo com as variáveis analisadas (cont.).

Magnitude da atividade EMG do músculo tibial anterior durante o período de balanço:

\begin{tabular}{|c|c|c|c|c|c|c|}
\hline Grupo & Ambiente & Média & $\begin{array}{c}\{1\} \\
-0,42\end{array}$ & $\begin{array}{c}\{2\} \\
-0,69\end{array}$ & $\begin{array}{c}\{3\} \\
-0,49\end{array}$ & $\begin{array}{c}\{4\} \\
-0,56\end{array}$ \\
\hline Adultos & AT $\{1\}$ & & - & $9,13^{*}$ & 2,37 & 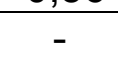 \\
\hline Adultos & $\mathrm{AA}\{2\}$ & & $9,13^{*}$ & - & - & $4,10^{*}$ \\
\hline Idosos & AT $\{3\}$ & & 2,37 & - & - & 2,41 \\
\hline Idosos & $A A\{4\}$ & & - & $4,10^{*}$ & 2,41 & - \\
\hline
\end{tabular}

Magnitude da atividade EMG do músculo gastrocnêmio medial durante o período de balanço:

\begin{tabular}{|c|c|c|c|c|c|c|}
\hline Grupo & Ambiente & Média & $\begin{array}{c}\{1\} \\
-1,09\end{array}$ & $\begin{array}{c}\{2\} \\
-1,43 \\
\end{array}$ & $\begin{array}{c}\{3\} \\
-1,17\end{array}$ & $\begin{array}{c}\{4\} \\
-0,98\end{array}$ \\
\hline Adultos & AT $\{1\}$ & & - & 3,56 & 0,84 & 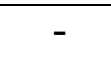 \\
\hline Adultos & $\mathrm{AA}\{2\}$ & & 3,56 & - & - & $4,62^{*}$ \\
\hline Idosos & AT $\{3\}$ & & 0,84 & - & - & 1,94 \\
\hline Idosos & $\mathrm{AA}\{4\}$ & & - & $4,62^{*}$ & 1,94 & - \\
\hline
\end{tabular}

Coeficiente de variação do ângulo do tornozelo:

\begin{tabular}{|c|c|c|c|c|c|c|}
\hline Grupo & Ambiente & Média & $\begin{array}{c}\{1\} \\
22,73\end{array}$ & $\begin{array}{c}\{2\} \\
49,57\end{array}$ & $\begin{array}{c}\{3\} \\
16,11\end{array}$ & $\begin{array}{c}\{4\} \\
74,78\end{array}$ \\
\hline Adultos & AT $\{1\}$ & & - & $6,98^{*}$ & 1,72 & - \\
\hline Adultos & $\mathrm{AA}\{2\}$ & & $6,98^{*}$ & - & - & $6,56^{*}$ \\
\hline Idosos & AT $\{3\}$ & & 1,72 & - & - & $15,26^{*}$ \\
\hline Idosos & $\mathrm{AA}\{4\}$ & & - & $6,56^{*}$ & $15,26^{*}$ & - \\
\hline
\end{tabular}


ANEXO V - Resultados dos testes post hoc de Tukey da interação entre grupos (adultos e idosos) e ambientes (ambiente terrestre (AT) e ambiente aquático (AA)) de acordo com as variáveis analisadas (cont.).

Coeficiente de variação da atividade EMG do músculo eretor espinhal:

\begin{tabular}{|c|c|c|c|c|c|c|}
\hline Grupo & Ambiente & Média & $\begin{array}{c}\{1\} \\
29,51\end{array}$ & $\begin{array}{c}\{2\} \\
34,84\end{array}$ & $\begin{array}{c}\{3\} \\
33,73\end{array}$ & $\begin{array}{c}\{4\} \\
28,97\end{array}$ \\
\hline Adultos & AT $\{1\}$ & & - & 2,76 & 2,08 & - \\
\hline Adultos & $\mathrm{AA}\{2\}$ & & 2,76 & - & - & 2,88 \\
\hline Idosos & AT $\{3\}$ & & 2,08 & - & - & 2,21 \\
\hline Idosos & $\mathrm{AA}\{4\}$ & & - & 2,88 & 2,21 & - \\
\hline
\end{tabular}


APÊNDICE 1 - Valores médios das variáveis comprimento $(\mathrm{m})$, duração $(\mathrm{s})$, velocidade $(\mathrm{m} / \mathrm{s})$ e cadência (passadas/s) da passada e duração do período de apoio (PA) (\%) nos ambientes terrestre (AT) e aquático (AA) para cada participante dos dois grupos (adultos e idosos).

\begin{tabular}{|c|c|c|c|c|c|c|c|c|c|c|}
\hline \multirow[b]{2}{*}{ Adultos } & \multicolumn{5}{|c|}{ AT } & \multicolumn{5}{|c|}{ AA } \\
\hline & Comp. & Duração & Vel. & Cadência & Dur. PA & Comp. & Duração & Vel. & Cadência & Dur. PA \\
\hline 1 & 1,15 & 0,93 & 1,24 & 2,16 & 62,61 & 0,97 & 2,61 & 0,37 & 0,78 & 63,22 \\
\hline 2 & 1,37 & 0,96 & 1,43 & 2,07 & 61,52 & 1,15 & 2,17 & 0,53 & 0,92 & 59,52 \\
\hline 3 & 1,60 & 1,02 & 1,57 & 1,96 & 60,08 & 1,09 & 2,21 & 0,49 & 0,91 & 61,75 \\
\hline 4 & 1,36 & 0,83 & 1,63 & 2,40 & 59,34 & 1,21 & 2,22 & 0,55 & 0,91 & 61,39 \\
\hline 5 & 1,35 & 0,95 & 1,42 & 2,10 & 61,94 & 1,22 & 2,67 & 0,46 & 0,75 & 60,16 \\
\hline 6 & 1,20 & 0,98 & 1,22 & 2,04 & 60,84 & 1,51 & 2,52 & 0,60 & 0,79 & 56,41 \\
\hline 7 & 1,28 & 1,03 & 1,24 & 1,95 & 64,56 & 1,11 & 2,47 & 0,45 & 0,81 & 58,51 \\
\hline 8 & 1,27 & 0,93 & 1,37 & 2,15 & 62,99 & 1,08 & 2,28 & 0,48 & 0,88 & 61,40 \\
\hline 9 & 1,19 & 0,86 & 1,38 & 2,33 & 60,23 & 1,23 & 2,07 & 0,59 & 0,97 & 58,62 \\
\hline 10 & 1,44 & 1,02 & 1,42 & 1,97 & 65,23 & 1,32 & 2,83 & 0,48 & 0,73 & 62,98 \\
\hline MEDIA & 1,32 & 0,95 & 1,39 & 2,11 & 61,93 & 1,19 & 2,41 & 0,50 & 0,84 & 60,39 \\
\hline $\begin{array}{l}\text { D.P. } \\
\text { Idosos }\end{array}$ & 0,13 & 0,07 & 0,14 & 0,15 & 1,94 & 0,15 & 0,25 & 0,07 & 0,08 & 2,16 \\
\hline 1 & 1,12 & 1,15 & 0,97 & 1,74 & 62,95 & 1,17 & 2,39 & 0,49 & 0,84 & 64,01 \\
\hline 2 & 1,12 & 1,04 & 1,08 & 1,92 & 62,92 & 0,90 & 2,27 & 0,40 & 0,89 & 65,22 \\
\hline 3 & 1,16 & 1,06 & 1,12 & 1,92 & 63,56 & 1,11 & 2,08 & 0,54 & 0,97 & 63,30 \\
\hline 4 & 1,29 & 0,94 & 1,38 & 2,13 & 62,93 & 1,09 & 2,13 & 0,51 & 0,94 & 62,50 \\
\hline 5 & 1,12 & 0,85 & 1,32 & 2,35 & 61,75 & 0,79 & 1,54 & 0,52 & 1,34 & 57,16 \\
\hline 6 & 1,29 & 0,94 & 1,37 & 2,12 & 63,00 & 0,91 & 2,31 & 0,40 & 0,90 & 59,30 \\
\hline 7 & 1,07 & 0,88 & 1,22 & 2,27 & 63,10 & 0,78 & 1,64 & 0,51 & 1,30 & 66,86 \\
\hline 8 & 1,05 & 1,03 & 1,02 & 1,95 & 66,93 & 0,89 & 1,88 & 0,49 & 1,11 & 67,18 \\
\hline 9 & 1,21 & 1,09 & 1,10 & 1,83 & 64,50 & 1,20 & 2,07 & 0,60 & 1,00 & 60,66 \\
\hline 10 & 1,29 & 0,91 & 1,42 & 2,20 & 61,91 & 0,85 & 1,88 & 0,46 & 1,09 & 67,37 \\
\hline MEDIA & 1,17 & 0,99 & 1,20 & 2,04 & 63,35 & 0,97 & 2,02 & 0,49 & 1,04 & 63,36 \\
\hline D.P. & 0,09 & 0,10 & 0,16 & 0,20 & 1,47 & 0,16 & 0,28 & 0,06 & 0,17 & 3,49 \\
\hline
\end{tabular}


APÊNDICE 2 - Valores médios do coeficiente de variação (\%) dos ângulos articulares do tornozelo, joelho e quadril durante os o ciclo do andar nos ambientes terrestre (AT) e aquático (AA) para cada participante dos dois grupos (adultos e idosos).

\begin{tabular}{|c|c|c|c|c|c|c|}
\hline & & AT & & & AA & \\
\hline Adultos & Tornozelo & Joelho & Quadril & Tornozelo & Joelho & Quadril \\
\hline 1 & 19.59 & 16.15 & 21.01 & 50.13 & 27.76 & 23.31 \\
\hline 2 & 27.18 & 9.76 & 25.95 & 71.15 & 17.36 & 17.35 \\
\hline 3 & 17.03 & 7.72 & 15.52 & 42.66 & 11.51 & 16.02 \\
\hline 4 & 29.12 & 15.22 & 13.74 & 56.47 & 40.95 & 30.50 \\
\hline 5 & 13.01 & 7.38 & 14.91 & 49.64 & 20.24 & 33.58 \\
\hline 6 & 24.09 & 10.43 & 32.28 & 59.42 & 19.21 & 27.05 \\
\hline 7 & 15.74 & 10.10 & 24.68 & 42.01 & 15.50 & 20.35 \\
\hline 8 & 28.56 & 18.07 & 29.88 & 35.87 & 14.21 & 18.46 \\
\hline 9 & 33.22 & 10.30 & 18.37 & 34.91 & 11.78 & 16.29 \\
\hline 10 & 19.71 & 15.34 & 40.70 & 53.39 & 28.66 & 54.71 \\
\hline MEDIA & 22.72 & 12.05 & 23.71 & 49.57 & 20.72 & 25.76 \\
\hline $\begin{array}{c}\text { D.P. } \\
\text { Idosos }\end{array}$ & 6.68 & 3.79 & 8.73 & 11.22 & 9.25 & 11.87 \\
\hline 1 & 18.35 & 11.40 & 40.23 & 76.53 & 19.46 & 21.89 \\
\hline 2 & 15.85 & 17.95 & 28.33 & 56.33 & 19.27 & 21.71 \\
\hline 3 & 13.44 & 11.29 & 22.77 & 71.96 & 20.77 & 24.48 \\
\hline 4 & 26.79 & 13.69 & 16.38 & 96.98 & 21.55 & 31.52 \\
\hline 5 & 15.50 & 7.20 & 21.59 & 102.74 & 32.40 & 29.62 \\
\hline 6 & 10.68 & 6.76 & 17.70 & 101.07 & 24.54 & 27.92 \\
\hline 7 & 8.78 & 7.76 & 25.06 & 55.69 & 13.48 & 25.27 \\
\hline 8 & 20.14 & 14.31 & 23.71 & 80.51 & 22.91 & 26.92 \\
\hline 9 & 12.84 & 10.49 & 20.66 & 35.34 & 15.91 & 14.08 \\
\hline 10 & 18.74 & 12.16 & 15.37 & 70.60 & 25.38 & 17.09 \\
\hline MEDIA & 16.11 & 11.30 & 23.18 & 74.78 & 21.57 & 24.05 \\
\hline D.P. & 5.20 & 3.50 & 7.21 & 21.83 & 5.27 & 5.47 \\
\hline
\end{tabular}


APÊNDICE 3 - Valores médios do coeficiente de variação (\%) das componentes da força de reação do solo vertical (Fz) e horizontal ânteroposterior (Fy A-P) nos ambientes terrestre (AT) e aquático (AA) para cada participante dos dois grupos (adultos e idosos).

\begin{tabular}{crrrr}
\hline \multicolumn{3}{c}{ AT } & \multicolumn{2}{c}{ AA } \\
\hline Adultos & \multicolumn{1}{c}{ Fz } & Fy A-P & \multicolumn{1}{c}{ Fz } & Fy A-P \\
\hline 1 & 7.29 & 21.73 & 15.15 & 33.12 \\
2 & 4.80 & 13.46 & 18.33 & 37.18 \\
3 & 6.69 & 14.17 & 11.73 & 23.27 \\
4 & 12.45 & 26.42 & 14.10 & 22.00 \\
5 & 5.69 & 14.09 & 20.27 & 27.90 \\
6 & 7.60 & 13.56 & 12.41 & 23.09 \\
7 & 6.22 & 17.59 & 8.84 & 23.83 \\
8 & 14.07 & 23.35 & 11.44 & 23.58 \\
9 & 6.78 & 14.49 & 16.59 & 27.76 \\
10 & 4.30 & 9.79 & 15.30 & 25.08 \\
MEDIA & $\mathbf{7 . 5 9}$ & $\mathbf{1 6 . 8 7}$ & $\mathbf{1 4 . 4 2}$ & $\mathbf{2 6 . 6 8}$ \\
D.P. & $\mathbf{3 . 1 8}$ & $\mathbf{5 . 2 8}$ & $\mathbf{3 . 4 5}$ & $\mathbf{4 . 9 6}$ \\
Idosos & & & & \\
1 & 6.06 & 20.29 & 15.06 & 38.07 \\
2 & 8.51 & 23.25 & 14.21 & 26.58 \\
3 & 8.63 & 10.96 & 15.16 & 30.32 \\
4 & 7.99 & 16.80 & 13.71 & 24.24 \\
5 & 6.95 & 18.00 & 30.53 & 40.56 \\
6 & 5.10 & 16.22 & 14.81 & 29.29 \\
7 & 4.89 & 12.82 & 13.55 & 22.49 \\
8 & 7.62 & 25.34 & 19.29 & 40.48 \\
9 & 5.56 & 12.05 & 22.54 & 28.55 \\
10 & 8.73 & 19.26 & 8.86 & 34.48 \\
MEDIA & $\mathbf{7 . 0 0}$ & $\mathbf{1 7 . 5 0}$ & $\mathbf{1 6 . 7 7}$ & $\mathbf{3 1 . 5 1}$ \\
D.P. & $\mathbf{1 . 5 0}$ & $\mathbf{4 . 7 4}$ & $\mathbf{6 . 0 3}$ & $\mathbf{6 . 5 6}$ \\
\hline & & & &
\end{tabular}


APÊNDICE 4 - Valores médios do coeficiente de variação (\%) dos músculos gastrocnêmio medial (GM), tibial anterior (TA), cabeça curta do bíceps femoral (BFCC), vasto lateral (VL), cabeça longa do bíceps femoral (BFCL), tensor da fáscia látea (TFL), eretor espinhal (EE) e reto do abdome (RA) durante o ciclo do andar nos ambientes terrestre (AT) e aquático (AA) para cada participante dos dois grupos (adultos e idosos).

\begin{tabular}{|c|c|c|c|c|c|c|c|c|}
\hline \multirow[b]{2}{*}{ Adultos } & \multicolumn{8}{|c|}{ AT } \\
\hline & GM & TA & BFCC & VL & BFCL & TFL & EE & RA \\
\hline 1 & 23.11 & 36.38 & 24.49 & 28.33 & 29.76 & 17.74 & 36.84 & - \\
\hline 2 & 20.68 & 26.81 & 31.74 & 19.24 & 31.02 & 13.89 & 25.64 & 31.62 \\
\hline 3 & 18.05 & 42.95 & 23.67 & 35.32 & 43.43 & 25.46 & 22.16 & - \\
\hline 4 & 34.86 & 29.82 & 33.96 & 24.29 & 43.89 & 25.58 & 33.12 & 41.36 \\
\hline 5 & 20.68 & 14.88 & 24.65 & 23.25 & 20.30 & 19.37 & 24.77 & 26.50 \\
\hline 6 & 28.12 & 29.96 & 50.46 & 26.45 & 46.07 & 49.30 & 31.36 & 38.59 \\
\hline 7 & 24.74 & 24.85 & 28.10 & 27.51 & 34.45 & 46.52 & 33.80 & 0.00 \\
\hline 8 & 28.26 & 36.01 & 27.68 & 34.10 & 53.82 & 28.10 & 29.81 & 42.89 \\
\hline 9 & 22.76 & 28.19 & 23.68 & 28.76 & 30.66 & 28.65 & 32.19 & 31.61 \\
\hline 10 & 17.84 & 24.36 & 28.16 & 28.98 & 31.38 & 17.92 & 25.38 & 33.63 \\
\hline MEDIA & 23.91 & 29.42 & 29.66 & 27.62 & 36.48 & 27.25 & 29.51 & 30.77 \\
\hline $\begin{array}{l}\text { D.P. } \\
\text { Idosos }\end{array}$ & 5.28 & 7.76 & 8.08 & 4.79 & 9.98 & 11.95 & 4.76 & 13.60 \\
\hline 1 & 46.35 & 33.92 & 34.23 & 42.26 & 24.17 & 17.22 & 27.42 & - \\
\hline 2 & 35.62 & 45.46 & 40.47 & 26.19 & 40.22 & 16.56 & 28.70 & \\
\hline 3 & 31.80 & 24.99 & 27.68 & 25.22 & 31.18 & 28.95 & 31.20 & 0.00 \\
\hline 4 & 29.19 & 36.05 & 41.95 & 29.81 & 57.26 & 31.47 & 33.63 & 0.00 \\
\hline 5 & 20.78 & 29.47 & 24.20 & 22.05 & 30.83 & 33.96 & & 24.54 \\
\hline 6 & 38.89 & 32.15 & 37.28 & 30.72 & 45.14 & 34.01 & 32.36 & 0.00 \\
\hline 7 & 26.07 & 29.29 & 24.72 & 25.79 & 25.86 & 15.72 & 33.18 & - \\
\hline 8 & 28.21 & 30.44 & 20.52 & 28.35 & 26.36 & 29.74 & 28.00 & 0.00 \\
\hline 9 & 28.50 & 52.97 & 34.70 & 30.10 & 61.93 & 23.15 & 42.15 & 0.00 \\
\hline 10 & 27.62 & 31.55 & 24.17 & 32.80 & 50.22 & 27.42 & 46.86 & 22.90 \\
\hline MEDIA & 31.30 & 34.63 & 30.99 & 29.33 & 39.32 & 25.82 & 33.73 & 6.78 \\
\hline D.P. & 7.28 & 8.42 & 7.65 & 5.53 & 13.76 & 7.16 & 6.61 & 11.58 \\
\hline
\end{tabular}


APÊNDICE 4 - Valores médios do coeficiente de variação (\%) dos músculos gastrocnêmio medial (GM), tibial anterior (TA), cabeça curta do bíceps femoral (BFCC), vasto lateral (VL), cabeça longa do bíceps femoral (BFCL), tensor da fáscia látea (TFL), eretor espinhal (EE) e reto do abdome (RA) durante o ciclo do andar nos ambientes terrestre (AT) e aquático (AA) para cada participante dos dois grupos (adultos e idosos) (cont.).

\begin{tabular}{|c|c|c|c|c|c|c|c|c|}
\hline \multirow[b]{2}{*}{ Adultos } & \multicolumn{8}{|c|}{ AA } \\
\hline & GM & TA & BFCC & VL & BFCL & TFL & EE & RA \\
\hline 1 & 67.79 & 36.74 & 29.65 & 23.70 & 27.31 & 13.57 & 29.95 & - \\
\hline 2 & 64.56 & 35.37 & 46.13 & 33.59 & 34.46 & 27.54 & 30.80 & . \\
\hline 3 & 46.14 & 40.77 & 30.94 & 41.25 & 34.62 & 33.97 & 31.16 & - \\
\hline 4 & 34.90 & 57.79 & 34.22 & 61.88 & 56.86 & 89.80 & 25.72 & 41.90 \\
\hline 5 & 47.89 & 32.47 & 45.78 & 17.73 & 34.20 & 50.62 & 34.43 & \\
\hline 6 & 63.68 & 41.31 & 39.69 & 31.64 & 38.59 & 73.42 & 31.97 & 0.00 \\
\hline 7 & 39.05 & 34.55 & 29.76 & 33.42 & 38.19 & 55.93 & 36.64 & . \\
\hline 8 & 64.82 & 25.93 & 39.70 & 41.90 & 57.24 & 70.04 & 42.99 & - \\
\hline 9 & 51.44 & 31.74 & 39.46 & 30.78 & 34.63 & 89.12 & 34.84 & - \\
\hline 10 & 29.76 & 45.71 & 31.19 & 44.58 & 33.43 & 44.97 & 49.90 & 37.66 \\
\hline MEDIA & 51.00 & 38.24 & 36.65 & 36.05 & 38.95 & 54.90 & 34.84 & 26.52 \\
\hline $\begin{array}{l}\text { D.P. } \\
\text { Idosos }\end{array}$ & 13.76 & 8.85 & 6.36 & 12.24 & 10.01 & 25.77 & 7.01 & 23.06 \\
\hline 1 & 81.54 & 61.34 & 30.38 & 58.29 & 49.96 & 17.22 & 28.60 & - \\
\hline 2 & 54.97 & 49.27 & 45.62 & - & 39.50 & 16.56 & 33.90 & - \\
\hline 3 & 66.18 & 40.73 & 39.84 & 27.18 & 30.74 & 28.95 & 33.82 & - \\
\hline 4 & 94.53 & 29.30 & 47.56 & 51.76 & 69.93 & 31.47 & - & 0.00 \\
\hline 5 & 79.98 & 46.49 & 48.07 & 25.65 & 38.41 & 33.96 & - & - \\
\hline 6 & 34.22 & 55.49 & 34.59 & 55.73 & 42.85 & 34.01 & 18.76 & - \\
\hline 7 & 92.19 & 47.56 & 29.44 & 21.47 & 23.58 & 15.72 & 27.19 & - \\
\hline 8 & 60.63 & - & 35.73 & 48.69 & 41.96 & 29.74 & 24.70 & 0.00 \\
\hline 9 & 46.17 & 43.00 & 38.82 & 37.00 & 47.40 & 23.15 & 31.37 & . \\
\hline 10 & 55.38 & 40.70 & 25.08 & 35.57 & 33.84 & 27.42 & 33.45 & 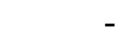 \\
\hline MEDIA & 66.58 & 45.99 & 37.51 & 40.15 & 41.82 & 25.82 & 28.97 & 0.00 \\
\hline D.P. & 20.00 & 9.24 & 7.94 & 13.86 & 12.58 & 7.16 & 5.34 & 0.00 \\
\hline
\end{tabular}


APÊNDICE 5 - Valores médios da amplitude de movimento articular (graus) do tornozelo, joelho e quadril durante os períodos de apoio e balanço e durante o ciclo completo nos ambientes terrestre (AT) e aquático (AA) para cada participante dos dois grupos (adultos e idosos).

\begin{tabular}{|c|c|c|c|c|c|c|c|c|c|}
\hline \multirow[b]{3}{*}{ Adultos } & \multicolumn{9}{|c|}{ AT } \\
\hline & \multicolumn{3}{|c|}{ Tornozelo } & \multicolumn{3}{|c|}{ Joelho } & \multicolumn{3}{|c|}{ Quadril } \\
\hline & Apoio & Balanço & Ciclo & Apoio & Balanço & Ciclo & Apoio & Balanço & Ciclo \\
\hline 1 & 29,28 & 21,37 & 31,06 & 39,22 & 56,22 & 56,22 & 22,07 & 16,56 & 23,48 \\
\hline 2 & 33,98 & 27,72 & 35,99 & 38,95 & 66,39 & 66,39 & 19,05 & 25,27 & 28,49 \\
\hline 3 & 31,89 & 28,02 & 33,22 & 38,24 & 64,37 & 64,40 & 26,24 & 17,87 & 26,24 \\
\hline 4 & 26,17 & 26,88 & 32,88 & 25,06 & 63,80 & 64,06 & 41,17 & 31,76 & 41,17 \\
\hline 5 & 38,12 & 33,93 & 38,59 & 37,15 & 65,24 & 65,24 & 23,32 & 23,18 & 26,95 \\
\hline 6 & 23,30 & 24,92 & 25,53 & 31,41 & 56,46 & 56,49 & 18,92 & 13,43 & 19,20 \\
\hline 7 & 31,82 & 26,99 & 35,64 & 38,80 & 60,97 & 60,97 & 23,88 & 20,27 & 27,10 \\
\hline 8 & 30,12 & 22,88 & 33,31 & 41,87 & 63,06 & 65,36 & 34,79 & 22,28 & 35,29 \\
\hline 9 & 27,91 & 35,53 & 35,53 & 36,27 & 52,00 & 53,25 & 24,61 & 20,85 & 26,23 \\
\hline 10 & 27,38 & 18,59 & 27,40 & 51,69 & 56,38 & 62,13 & 36,07 & 21,97 & 39,06 \\
\hline MEDIA & 30,00 & 26,68 & 32,91 & 37,87 & 60,49 & 61,45 & 27,01 & 21,34 & 29,32 \\
\hline $\begin{array}{c}\text { D.P. } \\
\text { Idosos }\end{array}$ & 4,22 & 5,22 & 4,01 & 6,83 & 4,87 & 4,59 & 7,64 & 5,03 & 6,97 \\
\hline 1 & 17,64 & 14,25 & 19,41 & 30,82 & 55,05 & 56,12 & 20,97 & 15,84 & 23,52 \\
\hline 2 & 24,84 & 24,78 & 26,04 & 40,88 & 66,53 & 66,65 & 32,78 & 32,24 & 39,07 \\
\hline 3 & 27,54 & 26,09 & 34,50 & 35,44 & 67,41 & 67,61 & 33,89 & 30,20 & 36,49 \\
\hline 4 & 22,49 & 22,27 & 29,59 & 31,18 & 59,09 & 60,52 & 33,79 & 25,01 & 33,79 \\
\hline 5 & 26,12 & 21,20 & 26,47 & 37,39 & 63,82 & 63,82 & 25,71 & 24,19 & 31,34 \\
\hline 6 & 22,35 & 16,70 & 22,43 & 36,32 & 58,75 & 58,75 & 25,26 & 18,35 & 26,63 \\
\hline 7 & 21,43 & 12,38 & 21,68 & 28,90 & 49,11 & 49,17 & 26,45 & 24,94 & 29,72 \\
\hline 8 & 29,46 & 25,80 & 30,52 & 42,52 & 60,69 & 61,63 & 30,55 & 23,02 & 33,31 \\
\hline 9 & 27,18 & 20,02 & 29,14 & 37,92 & 55,53 & 55,53 & 21,72 & 13,68 & 22,02 \\
\hline 10 & 22,10 & 15,11 & 22,55 & 40,78 & 58,96 & 58,96 & 24,02 & 19,76 & 25,62 \\
\hline MEDIA & 24,12 & 19,86 & 26,23 & 36,21 & 59,50 & 59,88 & 27,51 & 22,72 & 30,15 \\
\hline D.P. & 3,55 & 5,01 & 4,74 & 4,66 & 5,54 & 5,52 & 4,89 & 5,92 & 5,65 \\
\hline
\end{tabular}


APÊNDICE 5 - Valores médios da amplitude de movimento articular (graus) do tornozelo, joelho e quadril durante os períodos de apoio e balanço e durante o ciclo completo nos ambientes terrestre (AT) e aquático (AA) para cada participante dos dois grupos (adultos e idosos) (cont.).

\begin{tabular}{|c|c|c|c|c|c|c|c|c|c|}
\hline \multirow[b]{3}{*}{ Adultos } & \multicolumn{9}{|c|}{ AA } \\
\hline & \multicolumn{3}{|c|}{ Tornozelo } & \multicolumn{3}{|c|}{ Joelho } & \multicolumn{3}{|c|}{ Quadril } \\
\hline & Apoio & Balanço & Ciclo & Apoio & Balanço & Ciclo & Apoio & Balanço & Ciclo \\
\hline 1 & 22,99 & 18,12 & 24,87 & 31,58 & 47,24 & 54,96 & 20,49 & 21,61 & 30,21 \\
\hline 2 & 23,04 & 16,91 & 23,04 & 34,40 & 49,63 & 60,35 & 25,35 & 23,52 & 29,22 \\
\hline 3 & 33,08 & 31,44 & 36,70 & 35,12 & 40,25 & 57,33 & 22,25 & 18,12 & 26,68 \\
\hline 4 & 32,58 & 22,94 & 33,15 & 36,38 & 45,88 & 45,94 & 26,13 & 20,99 & 31,11 \\
\hline 5 & 55,03 & 48,47 & 57,75 & 34,68 & 67,25 & 67,25 & 24,46 & 23,85 & 30,64 \\
\hline 6 & 28,59 & 33,94 & 34,38 & 22,57 & 58,20 & 58,98 & 20,64 & 19,87 & 23,18 \\
\hline 7 & 17,96 & 19,31 & 19,80 & 22,88 & 43,80 & 45,11 & 20,75 & 20,95 & 25,66 \\
\hline 8 & 16,56 & 15,92 & 19,10 & 28,69 & 35,74 & 48,18 & 31,39 & 20,56 & 31,86 \\
\hline 9 & 38,32 & 37,19 & 40,64 & 32,08 & 61,72 & 71,59 & 25,71 & 28,01 & 35,13 \\
\hline 10 & 33,40 & 24,11 & 33,43 & 34,56 & 53,21 & 54,62 & 27,58 & 21,87 & 32,36 \\
\hline MEDIA & 30,16 & 26,84 & 32,29 & 31,29 & 50,29 & 56,43 & 24,48 & 21,94 & 29,61 \\
\hline $\begin{array}{l}\text { D.P. } \\
\text { Idosos }\end{array}$ & 11,30 & 10,64 & 11,62 & 5,02 & 9,85 & 8,70 & 3,53 & 2,70 & 3,53 \\
\hline 1 & 20,12 & 24,77 & 26,08 & 26,51 & 45,30 & 52,28 & 21,13 & 21,42 & 28,49 \\
\hline 2 & 19,74 & 23,47 & 27,33 & 40,43 & 46,63 & 56,41 & 29,89 & 24,11 & 36,51 \\
\hline 3 & 26,62 & 26,60 & 32,59 & 37,90 & 40,44 & 52,87 & 33,84 & 25,04 & 37,33 \\
\hline 4 & 20,95 & 16,65 & 23,04 & 44,61 & 29,37 & 83 & 31,23 & 16,27 & 31,78 \\
\hline 5 & 16,06 & 15 , & 21,41 & 40,19 & 45,45 & 50,80 & 20,53 & 11,86 & 26,98 \\
\hline 6 & 17,81 & 14,25 & 21,39 & 34,87 & 54,72 & 61,45 & 20,26 & 19,77 & 31,65 \\
\hline 7 & 25,96 & 14,92 & 26,73 & 35,68 & 38,79 & 48,70 & 26,30 & 22,17 & 34,45 \\
\hline 8 & 23,94 & 22,95 & 27,09 & 41,80 & 46,27 & 58,73 & 26,03 & 20,63 & 29,49 \\
\hline 9 & 33,02 & 27,36 & 33,57 & 33,08 & 36,90 & 53,90 & 28,71 & 23,08 & 33,19 \\
\hline 10 & 13,69 & 16,60 & 19,42 & 36,34 & 31,20 & 40,58 & 21,51 & 14,81 & 24,53 \\
\hline MEDIA & 21,79 & 20,27 & 25,87 & 37,14 & 41,51 & 52,65 & 25,94 & 19,92 & 31,44 \\
\hline D.P. & 5,71 & 5,23 & 4,70 & 5,12 & 7,72 & 5,76 & 4,92 & 4,29 & 4,12 \\
\hline
\end{tabular}


APÊNDICE 6 - Valores médios dos ângulos articulares (graus) do tornozelo, joelho e quadril nas fases de contato inicial (Cl) e balanço inicial (BI) nos ambientes terrestre (AT) e aquático (AA) para cada participante dos dois grupos (adultos e idosos).

\begin{tabular}{|c|c|c|c|c|c|c|c|c|c|c|c|c|}
\hline \multirow[b]{3}{*}{ Adultos } & \multicolumn{6}{|c|}{ AT } & \multicolumn{6}{|c|}{ AA } \\
\hline & \multicolumn{2}{|c|}{ Tornozelo } & \multicolumn{2}{|c|}{ Joelho } & \multicolumn{2}{|c|}{ Quadril } & \multicolumn{2}{|c|}{ Tornozelo } & \multicolumn{2}{|c|}{ Joelho } & \multicolumn{2}{|c|}{ Quadril } \\
\hline & $\mathrm{Cl}$ & BI & $\mathrm{Cl}$ & $\mathrm{BI}$ & $\mathrm{Cl}$ & BI & $\mathrm{Cl}$ & BI & $\mathrm{Cl}$ & BI & $\mathrm{Cl}$ & $\mathrm{BI}$ \\
\hline 1 & 10,63 & $-5,00$ & 10,11 & 49,35 & 16,23 & 1,07 & $-2,75$ & $-13,21$ & 7,39 & 38,62 & 18,57 & 6,61 \\
\hline 2 & $-0,13$ & $-20,29$ & 6,81 & 47,32 & 13,01 & $-2,40$ & $-4,66$ & $-12,69$ & 11,64 & 39,53 & 23,63 & 4,45 \\
\hline 3 & 4,42 & $-16,12$ & 9,68 & 42,87 & 19,54 & 0,75 & 3,96 & $-20,56$ & 22,68 & 43,90 & 14,63 & 1,29 \\
\hline 4 & $-6,10$ & $-22,08$ & $-0,89$ & 25,79 & 27,92 & $-5,42$ & $-14,70$ & $-22,10$ & $-2,04$ & 34,59 & 18,52 & 3,31 \\
\hline 5 & 7,56 & $-18,32$ & 5,98 & 44,09 & 18,90 & $-0,17$ & $-4,97$ & $-43,76$ & 0,20 & 35,98 & 18,77 & 2,21 \\
\hline 6 & 5,70 & $-14,97$ & 3,40 & 31,77 & 7,62 & $-5,83$ & $-1,68$ & $-21,26$ & $-0,44$ & 22,46 & 12,18 & $-4,62$ \\
\hline 7 & 6,41 & $-12,83$ & 12,29 & 51,82 & 18,25 & 2,00 & $-2,48$ & $-9,99$ & 8,31 & 32,08 & 18,98 & 3,39 \\
\hline 8 & 8,25 & $-8,78$ & 15,19 & 48,54 & 23,38 & 0,35 & 2,44 & $-2,97$ & 21,45 & 36,83 & 22,86 & 1,23 \\
\hline 9 & 3,69 & $-21,76$ & 6,00 & 36,85 & 22,23 & 2,80 & $-0,55$ & $-26,28$ & 10,65 & 35,88 & 24,23 & 6,32 \\
\hline 10 & $-2,00$ & $-13,34$ & 1,27 & 45,15 & 14,85 & $-2,76$ & $-2,95$ & $-17,00$ & 1,51 & 33,01 & 12,15 & $-4,76$ \\
\hline MEDIA & 3,84 & $-15,35$ & 6,98 & 42,36 & 18,19 & $-0,96$ & $-2,83$ & $-18,98$ & 8,13 & 35,29 & 18,45 & 1,94 \\
\hline $\begin{array}{l}\text { D.P. } \\
\text { Idosos }\end{array}$ & 5,15 & 5,59 & 4,97 & 8,36 & 5,71 & 3,00 & 5,05 & 11,05 & 8,77 & 5,65 & 4,39 & 3,95 \\
\hline 1 & 4,81 & $-1,20$ & 4,84 & 37,13 & 16,17 & 5,06 & $-3,27$ & $-8,45$ & 11,99 & 36,49 & 21,32 & 8,36 \\
\hline 2 & 4,35 & $-7,36$ & 1,65 & 42,55 & 15,45 & $-9,65$ & $-2,02$ & $-5,05$ & 16,63 & 47,70 & 27,11 & 10,60 \\
\hline 3 & 3,98 & $-9,97$ & 0,56 & 35,42 & 13,92 & $-13,90$ & $-1,08$ & $-14,93$ & 15,58 & 41,41 & 25,60 & 4,34 \\
\hline 4 & 3,43 & $-10,70$ & 0,09 & 28,65 & 20,56 & $-6,36$ & $-3,54$ & $-10,34$ & 22,43 & 45,22 & 17,07 & 1,60 \\
\hline 5 & 8,82 & $-3,30$ & 6,72 & 45,24 & 14,14 & $-3,97$ & $-2,16$ & 0,17 & 9,81 & 40,67 & 20,99 & 19,18 \\
\hline 6 & 8,67 & $-1,00$ & 5,75 & 42,99 & 22,85 & 5,82 & $-3,92$ & $-5,64$ & 9,65 & 41,73 & 19,14 & 9,47 \\
\hline 7 & 5,16 & 3,54 & 13,57 & 42,61 & 25,75 & 4,27 & $-1,52$ & $-6,87$ & 21,87 & 43,62 & 26,02 & 7,62 \\
\hline 8 & 7,12 & $-9,59$ & 4,03 & 47,16 & 16,06 & $-3,87$ & $-0,40$ & $-11,02$ & 17,29 & 47,78 & 20,91 & 5,81 \\
\hline 9 & 4,54 & $-9,43$ & 3,33 & 41,76 & 19,20 & 6,34 & 10,30 & $-11,35$ & 24,60 & 40,46 & 26,56 & 8,82 \\
\hline 10 & 2,04 & $-5,38$ & 3,11 & 44,80 & 18,01 & 0,76 & $-8,33$ & $-9,78$ & 10,38 & 39,87 & 16,57 & 6,20 \\
\hline MEDIA & 5,29 & $-5,44$ & 4,36 & 40,83 & 18,21 & $-1,55$ & $-1,59$ & $-8,33$ & 16,02 & 42,50 & 22,13 & 8,20 \\
\hline D.P. & 2,23 & 4,81 & 3,88 & 5,56 & 3,89 & 7,09 & 4,73 & 4,20 & 5,56 & 3,59 & 3,95 & 4,68 \\
\hline
\end{tabular}


APÊNDICE 7 - Valores médios do peso corporal (PC), primeiro pico (Pico 1) e segundo pico (Pico 2) da componente vertical da força de reação do solo normalizados pelo PC (PC aparente para o ambiente aquático), força de impacto (PC/s) e impulso horizontal (PC.s) nos ambientes terrestre (AT), e aquático (AA) para cada participante dos dois grupos (adultos e idosos).

\begin{tabular}{|c|c|c|c|c|c|c|c|c|c|c|c|}
\hline \multirow[b]{2}{*}{ Adultos } & \multicolumn{6}{|c|}{ AT } & \multicolumn{5}{|c|}{ AA } \\
\hline & $P C$ & Pico 1 & Pico 2 & Impacto & Impulso & PCA & Red. PCA & Pico 1 & Pico 2 & Impacto & Impulso \\
\hline 1 & 535.90 & 1.15 & 1.13 & 9.49 & -0.0014 & 195.95 & -63.44 & 0.97 & 0.90 & 3.51 & 0.15 \\
\hline 2 & 525.64 & 1.13 & 1.10 & 9.28 & 0.0025 & 189.19 & -64.01 & 1.08 & 1.03 & 5.22 & 0.20 \\
\hline 3 & 669.23 & 1.22 & 1.32 & 9.91 & 0.0062 & 252.16 & -62.32 & 0.99 & 0.98 & 6.71 & 0.19 \\
\hline 4 & 535.90 & 1.51 & 1.06 & 14.31 & 0.0029 & 210.81 & -60.66 & 1.02 & 1.08 & 3.67 & 0.24 \\
\hline 5 & 436.92 & 1.24 & 1.20 & 9.08 & 0.0035 & 159.59 & -63.47 & 0.92 & 0.95 & 2.88 & 0.25 \\
\hline 6 & 664.10 & 1.32 & 1.12 & 10.67 & -0.0068 & 234.19 & -64.74 & 1.09 & 1.07 & 8.02 & 0.25 \\
\hline 7 & 667.18 & 1.11 & 1.05 & 7.26 & 0.0035 & 244.86 & -63.30 & 0.98 & 0.92 & 5.75 & 0.08 \\
\hline 8 & 484.62 & 1.40 & 1.28 & 11.63 & 0.0003 & 195.68 & -59.62 & 1.02 & 0.93 & 5.79 & 0.17 \\
\hline 9 & 474.36 & 1.23 & 1.22 & 11.06 & 0.0008 & 160.95 & -66.07 & 0.99 & 1.05 & 7.40 & 0.25 \\
\hline 10 & 564.10 & 1.38 & 1.49 & 9.78 & -0.0120 & 202.70 & -64.07 & 1.21 & 1.21 & 5.14 & 0.26 \\
\hline MÉDIA & 555.80 & 1.27 & 1.20 & 10.25 & -0.0001 & 204.61 & -63.17 & 1.03 & 1.01 & 5.41 & 0.20 \\
\hline $\begin{array}{c}\text { D.P. } \\
\text { Idosos }\end{array}$ & 84.72 & 0.13 & 0.14 & 1.87 & 0.0055 & 31.84 & 1.89 & 0.08 & 0.10 & 1.70 & 0.06 \\
\hline 1 & 674.36 & 1.07 & 1.07 & 8.01 & -0.0032 & 262.16 & -61.12 & 0.96 & 0.98 & 4.02 & 0.18 \\
\hline 2 & 524.36 & 1.09 & 1.16 & 6.54 & -0.0016 & 197.30 & -62.37 & 1.03 & 0.97 & 1.29 & 0.15 \\
\hline 3 & 700.77 & 1.08 & 1.10 & 6.33 & 0.0014 & 244.59 & -65.10 & 0.99 & 1.08 & 3.77 & 0.10 \\
\hline 4 & 602.31 & 1.19 & 1.27 & 9.14 & -0.0027 & 222.97 & -62.98 & 0.92 & 0.96 & 4.64 & 0.20 \\
\hline 5 & 446.15 & 1.27 & 1.07 & 8.67 & 0.0025 & 155.41 & -65.17 & 0.91 & 1.08 & 2.55 & 0.15 \\
\hline 6 & 488.46 & 1.15 & 1.16 & 9.38 & 0.0004 & 179.86 & -63.18 & 0.97 & 0.95 & 6.64 & 0.14 \\
\hline 7 & 528.97 & 1.06 & 1.12 & 8.76 & -0.0017 & 236.22 & -55.34 & 1.02 & 1.01 & 1.75 & 0.12 \\
\hline 8 & 492.56 & 0.95 & 1.11 & 5.10 & -0.0001 & 173.78 & -64.72 & 1.00 & 1.05 & 3.62 & 0.08 \\
\hline 9 & 781.03 & 1.13 & 1.08 & 7.44 & 0.0026 & 275.81 & -64.69 & 0.88 & 1.04 & 3.32 & 0.22 \\
\hline 10 & 531.28 & 1.26 & 1.07 & 11.21 & 0.0000 & 213.24 & -59.86 & 0.94 & 0.94 & 5.49 & 0.12 \\
\hline MÉDIA & 577.03 & 1.12 & 1.12 & 8.06 & -0.0003 & 216.13 & -62.45 & 0.96 & 1.01 & 3.71 & 0.14 \\
\hline D.P. & 108.69 & 0.10 & 0.06 & 1.77 & 0.0020 & 39.58 & 3.06 & 0.05 & 0.05 & 1.63 & 0.04 \\
\hline
\end{tabular}


APÊNDICE 8 - Valores médios da magnitude da atividade eletromiográfica normalizados pela CVMI dos músculos gastrocnêmio medial (GM), tibial anterior (TA), cabeça curta do bíceps femoral (BFCC), vasto lateral (VL), cabeça longa do bíceps femoral (BFCL), tensor da fáscia látea (TFL), eretor espinhal (EE) e reto do abdome (RA) durante os períodos de apoio e balanço nos ambientes terrestre (AT), e aquático (AA) para cada participante dos dois grupos (adultos e idosos).

\begin{tabular}{ccrrrrrrrr}
\hline & \multicolumn{10}{c}{ AT } \\
\cline { 2 - 9 } & \multicolumn{2}{c}{ GM } & \multicolumn{9}{c}{ TA } & \multicolumn{2}{c}{ BFCC } & \multicolumn{3}{c}{ VL } \\
\hline Adultos & Apoio & Balanço & Apoio & Balanço & Apoio & Balanço & Apoio & Balanço \\
\hline 1 & 0,92 & 0,06 & 0,72 & 0,49 & 0,33 & 0,24 & 0,13 & 0,08 \\
2 & 0,74 & 0,12 & 0,35 & 0,35 & 0,14 & 0,09 & 0,19 & 0,13 \\
3 & 0,93 & 0,10 & 0,33 & 0,26 & 0,16 & 0,17 & 0,18 & 0,10 \\
4 & 0,80 & 0,58 & 0,37 & 0,35 & 0,33 & 0,24 & 0,07 & 0,04 \\
5 & 1,00 & 0,08 & 0,95 & 0,76 & 0,09 & 0,08 & 0,09 & 0,04 \\
6 & 0,32 & 0,06 & 0,35 & 0,38 & 0,12 & 0,11 & 0,12 & 0,09 \\
7 & 0,43 & 0,01 & 0,28 & 0,24 & 0,21 & 0,13 & 0,11 & 0,06 \\
8 & 1,16 & 0,11 & 0,72 & 0,48 & 0,25 & 0,15 & 0,28 & 0,15 \\
9 & 0,87 & 0,08 & 0,67 & 0,59 & 0,37 & 0,23 & 0,13 & 0,09 \\
10 & 0,49 & 0,07 & 0,30 & 0,22 & 0,23 & 0,20 & 0,50 & 0,32 \\
MEDIA & $\mathbf{0 , 7 7}$ & $\mathbf{0 , 1 3}$ & $\mathbf{0 , 5 1}$ & $\mathbf{0 , 4 1}$ & $\mathbf{0 , 2 2}$ & $\mathbf{0 , 1 6}$ & $\mathbf{0 , 1 8}$ & $\mathbf{0 , 1 1}$ \\
D.P. & $\mathbf{0 , 2 7}$ & $\mathbf{0 , 1 6}$ & $\mathbf{0 , 2 4}$ & $\mathbf{0 , 1 7}$ & $\mathbf{0 , 1 0}$ & $\mathbf{0 , 0 6}$ & $\mathbf{0 , 1 3}$ & $\mathbf{0 , 0 8}$ \\
Idosos & $\mathbf{A p o i o}$ & Balanç0 & & & & & & \\
1 & 0,43 & 0,02 & 0,20 & 0,18 & 0,41 & 0,21 & 0,36 & 0,30 \\
2 & 0,44 & 0,03 & 0,25 & 0,21 & 0,13 & 0,08 & 0,23 & 0,13 \\
3 & 1,30 & 0,21 & 0,55 & 0,34 & 0,52 & 0,35 & 0,41 & 0,21 \\
4 & 0,67 & 0,02 & 0,52 & 0,47 & 0,31 & 0,17 & 0,47 & 0,27 \\
5 & 0,72 & 0,20 & 0,61 & 0,55 & 0,09 & 0,08 & 0,94 & 0,58 \\
6 & 0,70 & 0,62 & 0,36 & 0,32 & 0,27 & 0,24 & 0,23 & 0,13 \\
7 & 1,25 & 0,09 & 0,49 & 0,43 & 0,19 & 0,18 & 0,48 & 0,38 \\
8 & 1,17 & 0,25 & 0,77 & 0,62 & 0,30 & 0,29 & 0,34 & 0,13 \\
9 & 0,54 & 0,02 & 0,51 & 0,45 & 0,08 & 0,10 & 0,32 & 0,23 \\
10 & 0,47 & 0,05 & 0,21 & 0,20 & 0,16 & 0,14 & 0,34 & 0,24 \\
MEDIA & $\mathbf{0 , 7 7}$ & $\mathbf{0 , 1 5}$ & $\mathbf{0 , 4 5}$ & $\mathbf{0 , 3 8}$ & $\mathbf{0 , 2 5}$ & $\mathbf{0 , 1 9}$ & $\mathbf{0 , 4 1}$ & $\mathbf{0 , 2 6}$ \\
D.P. & $\mathbf{0 , 3 4}$ & $\mathbf{0 , 1 9}$ & $\mathbf{0 , 1 9}$ & $\mathbf{0 , 1 5}$ & $\mathbf{0 , 1 4}$ & $\mathbf{0 , 0 9}$ & $\mathbf{0 , 2 0}$ & $\mathbf{0 , 1 4}$ \\
\hline
\end{tabular}


APÊNDICE 8 - Valores médios da magnitude da atividade eletromiográfica normalizados pela CVMI dos músculos gastrocnêmio medial (GM), tibial anterior (TA), cabeça curta do bíceps femoral (BFCC), vasto lateral (VL), cabeça longa do bíceps femoral (BFCL), tensor da fáscia látea (TFL), eretor espinhal (EE) e reto do abdome (RA) durante os períodos de apoio e balanço nos ambientes terrestre (AT), e aquático (AA) para cada participante dos dois grupos (adultos e idosos) (cont.).

\begin{tabular}{ccrrrrrrrr}
\hline & \multicolumn{1}{c}{ AT } \\
\cline { 2 - 9 } & \multicolumn{2}{c}{ BFCL } & \multicolumn{9}{c}{ TFL } & \multicolumn{3}{c}{ EE } & \multicolumn{2}{c}{ RA } \\
\hline Adultos & Apoio & Balanço & Apoio & Balanço & Apoio & Balanço & Apoio & Balanço \\
\hline 1 & 0,20 & 0,15 & 0,09 & 0,04 & 0,21 & 0,12 & - & - \\
2 & 0,16 & 0,25 & 0,17 & 0,16 & 0,07 & 0,03 & 0,12 & 0,11 \\
3 & 0,11 & 0,10 & 0,09 & 0,04 & 0,81 & 0,52 & - & - \\
4 & 0,10 & 0,09 & 0,52 & 0,34 & 0,58 & 0,38 & 0,02 & 0,02 \\
5 & 0,23 & 0,13 & 0,10 & 0,02 & 0,49 & 0,27 & 0,12 & 0,10 \\
6 & 0,14 & 0,12 & 0,03 & 0,02 & 0,14 & 0,04 & 0,02 & 0,02 \\
7 & 0,22 & 0,20 & 0,05 & 0,05 & 0,20 & 0,07 & 0,03 & 0,02 \\
8 & 0,26 & 0,15 & 0,12 & 0,05 & 0,28 & 0,08 & 0,02 & 0,05 \\
9 & 0,17 & 0,13 & 0,08 & 0,05 & 0,23 & 0,11 & 0,07 & 0,07 \\
10 & 0,15 & 0,19 & 0,12 & 0,07 & 0,17 & 0,03 & 0,06 & 0,06 \\
MEDIA & $\mathbf{0 , 1 7}$ & $\mathbf{0 , 1 5}$ & $\mathbf{0 , 1 4}$ & $\mathbf{0 , 0 9}$ & $\mathbf{0 , 3 2}$ & $\mathbf{0 , 1 6}$ & $\mathbf{0 , 0 6}$ & $\mathbf{0 , 0 5}$ \\
D.P. & $\mathbf{0 , 0 5}$ & $\mathbf{0 , 0 5}$ & $\mathbf{0 , 1 4}$ & $\mathbf{0 , 1 0}$ & $\mathbf{0 , 2 3}$ & $\mathbf{0 , 1 7}$ & $\mathbf{0 , 0 4}$ & $\mathbf{0 , 0 4}$ \\
Idosos & & & & & & & & \\
1 & 0,05 & 0,05 & 0,04 & 0,02 & 0,17 & 0,04 & - & - \\
2 & 0,13 & 0,08 & 0,06 & 0,03 & 0,24 & 0,08 & - & - \\
3 & 0,20 & 0,18 & 0,06 & 0,05 & 0,19 & 0,10 & 0,10 & 0,08 \\
4 & 0,29 & 0,32 & 0,32 & 0,17 & 0,61 & 0,48 & 0,09 & 0,04 \\
5 & 0,26 & 0,25 & 0,16 & 0,12 & - & - & 0,22 & 0,11 \\
6 & 0,24 & 0,27 & 0,05 & 0,05 & 0,13 & 0,04 & 0,01 & 0,02 \\
7 & 0,16 & 0,10 & 0,08 & 0,06 & 0,20 & 0,06 & - & - \\
8 & 0,47 & 0,40 & 0,50 & 0,31 & 0,36 & 0,16 & 0,47 & 0,27 \\
9 & 0,18 & 0,17 & 0,37 & 0,24 & 0,14 & 0,06 & 0,05 & 0,03 \\
10 & 0,12 & 0,10 & 0,04 & 0,03 & 0,22 & 0,15 & 0,02 & 0,02 \\
MEDIA & $\mathbf{0 , 2 1}$ & $\mathbf{0 , 1 9}$ & $\mathbf{0 , 1 7}$ & $\mathbf{0 , 1 1}$ & $\mathbf{0 , 2 5}$ & $\mathbf{0 , 1 3}$ & $\mathbf{0 , 1 4}$ & $\mathbf{0 , 0 8}$ \\
D.P. & $\mathbf{0 , 1 1}$ & $\mathbf{0 , 1 1}$ & $\mathbf{0 , 1 7}$ & $\mathbf{0 , 1 0}$ & $\mathbf{0 , 1 5}$ & $\mathbf{0 , 1 4}$ & $\mathbf{0 , 1 6}$ & $\mathbf{0 , 0 9}$ \\
\hline & & & & & & & &
\end{tabular}


APÊNDICE 8 - Valores médios da magnitude da atividade eletromiográfica normalizados pela CVMI dos músculos gastrocnêmio medial (GM), tibial anterior (TA), cabeça curta do bíceps femoral (BFCC), vasto lateral (VL), cabeça longa do bíceps femoral (BFCL), tensor da fáscia látea (TFL), eretor espinhal (EE) e reto do abdome (RA) durante os períodos de apoio e balanço nos ambientes terrestre (AT), e aquático (AA) para cada participante dos dois grupos (adultos e idosos) (cont.).

\begin{tabular}{crrrrrrrrr}
\hline & \multicolumn{10}{c}{ AA } \\
\cline { 2 - 9 } & \multicolumn{2}{c}{ GM } & \multicolumn{9}{c}{ TA } & \multicolumn{2}{c}{ BFCC } & \multicolumn{3}{c}{ VL } \\
\hline Adultos & Apoio & Balanço & Apoio & Balanço & Apoio & Balanço & Apoio & Balanço \\
\hline 1 & 0,56 & 0,05 & 0,14 & 0,24 & 0,17 & 0,07 & 0,02 & 0,01 \\
2 & 0,72 & 0,05 & 0,18 & 0,16 & 0,22 & 0,07 & 0,09 & 0,04 \\
3 & 0,56 & 0,02 & 0,08 & 0,11 & 0,09 & 0,03 & 0,03 & 0,01 \\
4 & 0,66 & 0,23 & 0,21 & 0,18 & 0,26 & 0,09 & 0,04 & 0,14 \\
5 & 0,50 & 0,04 & 0,77 & 0,51 & 0,16 & 0,02 & 0,04 & 0,03 \\
6 & 0,36 & 0,02 & 0,20 & 0,24 & 0,26 & 0,05 & 0,01 & 0,01 \\
7 & 0,26 & 0,01 & 0,10 & 0,11 & 0,04 & 0,02 & 0,03 & 0,02 \\
8 & 0,48 & 0,04 & 0,22 & 0,35 & 0,09 & 0,07 & 0,05 & 0,03 \\
9 & 0,43 & 0,05 & 0,25 & 0,25 & 0,29 & 0,09 & 0,03 & 0,02 \\
10 & 0,07 & 0,03 & 0,20 & 0,15 & 0,11 & 0,04 & 0,16 & 0,13 \\
MEDIA & $\mathbf{0 , 4 6}$ & $\mathbf{0 , 0 5}$ & $\mathbf{0 , 2 4}$ & $\mathbf{0 , 2 3}$ & $\mathbf{0 , 1 7}$ & $\mathbf{0 , 0 6}$ & $\mathbf{0 , 0 5}$ & $\mathbf{0 , 0 4}$ \\
D.P. & $\mathbf{0 , 1 9}$ & $\mathbf{0 , 0 6}$ & $\mathbf{0 , 1 9}$ & $\mathbf{0 , 1 2}$ & $\mathbf{0 , 0 9}$ & $\mathbf{0 , 0 3}$ & $\mathbf{0 , 0 4}$ & $\mathbf{0 , 0 5}$ \\
Idosos & & & & & & & & \\
1 & 0,36 & 0,06 & 0,22 & 0,25 & 0,04 & 0,02 & 0,17 & 0,06 \\
2 & 0,46 & 0,07 & 0,14 & 0,16 & 0,20 & 0,08 & - & - \\
3 & 1,12 & 0,09 & 0,51 & 0,40 & 0,36 & 0,21 & 0,15 & 0,05 \\
4 & 0,64 & 0,02 & 0,65 & 0,42 & 0,25 & 0,13 & 0,38 & 0,19 \\
5 & 0,67 & 0,18 & 0,26 & 0,32 & 0,10 & 0,04 & 0,04 & 0,06 \\
6 & 0,23 & 0,12 & 0,30 & 0,19 & 0,08 & 0,05 & 0,15 & 0,04 \\
7 & 1,24 & 0,37 & 0,46 & 0,50 & 0,26 & 0,22 & 0,24 & 0,16 \\
8 & 1,16 & 0,23 & - & - & 0,66 & 0,45 & 0,36 & 0,57 \\
9 & 0,53 & 0,36 & 0,63 & 0,47 & 0,21 & 0,09 & 0,14 & 0,04 \\
10 & 0,37 & 0,07 & 0,08 & 0,09 & 0,09 & 0,05 & 0,14 & 0,04 \\
MEDIA & $\mathbf{0 , 6 8}$ & $\mathbf{0 , 1 6}$ & $\mathbf{0 , 3 6}$ & $\mathbf{0 , 3 1}$ & $\mathbf{0 , 2 3}$ & $\mathbf{0 , 1 3}$ & $\mathbf{0 , 2 0}$ & $\mathbf{0 , 1 3}$ \\
D.P. & $\mathbf{0 , 3 7}$ & $\mathbf{0 , 1 3}$ & $\mathbf{0 , 2 1}$ & $\mathbf{0 , 1 5}$ & $\mathbf{0 , 1 8}$ & $\mathbf{0 , 1 3}$ & $\mathbf{0 , 1 1}$ & $\mathbf{0 , 1 7}$ \\
\hline
\end{tabular}


APÊNDICE 8 - Valores médios da magnitude da atividade eletromiográfica normalizados pela CVMI dos músculos gastrocnêmio medial (GM), tibial anterior (TA), cabeça curta do bíceps femoral (BFCC), vasto lateral (VL), cabeça longa do bíceps femoral (BFCL), tensor da fáscia látea (TFL), eretor espinhal (EE) e reto do abdome (RA) durante os períodos de apoio e balanço nos ambientes terrestre (AT), e aquático (AA) para cada participante dos dois grupos (adultos e idosos) (cont.).

\begin{tabular}{crrrrrrrrr}
\hline & \multicolumn{10}{c}{ AA } \\
\cline { 2 - 9 } & \multicolumn{1}{c}{ BFCL } & \multicolumn{1}{c}{ TFL } & \multicolumn{2}{c}{ EE } & \multicolumn{2}{c}{ RA } \\
\hline Adultos & Apoio & Balanço & Apoio & Balanço & Apoio & Balanço & Apoio & Balanço \\
\hline 1 & 0,04 & 0,02 & 0,05 & 0,05 & 0,26 & 0,24 & - & - \\
2 & 0,21 & 0,09 & 0,14 & 0,22 & 0,06 & 0,04 & - & - \\
3 & 0,08 & 0,03 & 0,03 & 0,06 & 0,20 & 0,13 & - & - \\
4 & 0,16 & 0,05 & 0,07 & 0,13 & 0,22 & 0,22 & 0,01 & 0,01 \\
5 & 0,33 & 0,06 & 0,05 & 0,10 & 0,07 & 0,04 & - & - \\
6 & 0,32 & 0,07 & 0,03 & 0,06 & 0,20 & 0,18 & 0,03 & 0,02 \\
7 & 0,15 & 0,10 & 0,02 & 0,07 & 0,22 & 0,18 & - & - \\
8 & 0,11 & 0,09 & 0,03 & 0,10 & 0,38 & 0,31 & - & - \\
9 & 0,14 & 0,03 & 0,05 & 0,04 & 0,22 & 0,18 & - & - \\
10 & 0,19 & 0,08 & 0,13 & 0,10 & 0,12 & 0,10 & 0,02 & 0,02 \\
MEDIA & $\mathbf{0 , 1 7}$ & $\mathbf{0 , 0 6}$ & $\mathbf{0 , 0 6}$ & $\mathbf{0 , 0 9}$ & $\mathbf{0 , 1 9}$ & $\mathbf{0 , 1 6}$ & $\mathbf{0 , 0 2}$ & $\mathbf{0 , 0 1}$ \\
D.P. & $\mathbf{0 , 0 9}$ & $\mathbf{0 , 0 3}$ & $\mathbf{0 , 0 4}$ & $\mathbf{0 , 0 5}$ & $\mathbf{0 , 0 9}$ & $\mathbf{0 , 0 9}$ & $\mathbf{0 , 0 1}$ & $\mathbf{0 , 0 1}$ \\
Idosos & & & & & & & & \\
1 & 0,25 & 0,14 & 0,10 & 0,28 & 0,20 & 0,19 & - & - \\
2 & 0,20 & 0,07 & 0,04 & 0,06 & 0,21 & 0,17 & - & - \\
3 & 0,38 & 0,19 & 0,13 & 0,13 & 0,27 & 0,24 & - & - \\
4 & 0,33 & 0,22 & 0,17 & 0,20 & - & - & 0,07 & 0,04 \\
5 & 0,07 & 0,03 & 0,13 & 0,16 & - & - & - & - \\
6 & 0,22 & 0,14 & 0,06 & 0,13 & 0,18 & 0,16 & - & - \\
7 & 0,45 & 0,33 & 0,07 & 0,18 & 0,17 & 0,15 & - & - \\
8 & 0,90 & 0,50 & 0,36 & 0,17 & 0,77 & 0,72 & 0,51 & 0,53 \\
9 & 0,61 & 0,20 & 0,21 & 0,12 & 0,22 & 0,18 & - & - \\
10 & 0,04 & 0,02 & 0,11 & 0,11 & 0,23 & 0,20 & - & - \\
MEDIA & $\mathbf{0 , 3 4}$ & $\mathbf{0 , 1 9}$ & $\mathbf{0 , 1 4}$ & $\mathbf{0 , 1 5}$ & $\mathbf{0 , 2 8}$ & $\mathbf{0 , 2 5}$ & $\mathbf{0 , 2 9}$ & $\mathbf{0 , 2 8}$ \\
D.P. & $\mathbf{0 , 2 6}$ & $\mathbf{0 , 1 4}$ & $\mathbf{0 , 0 9}$ & $\mathbf{0 , 0 6}$ & $\mathbf{0 , 2 0}$ & $\mathbf{0 , 1 9}$ & $\mathbf{0 , 3 2}$ & $\mathbf{0 , 3 5}$ \\
\hline
\end{tabular}


